\title{
Studies on the Synthesis of the Alkaloid (-)-Gilbertine via Indolidene Chemistry
}

Ken S. Feldman* and Tamara S. Folda

Department of Chemistry, The Pennsylvania State University, University Park, Pennsylvania 16802, United States

Supporting Information

Table of Contents

\begin{tabular}{|c|c|c|}
\hline General Methods & S3 & ${ }^{1} \mathrm{H}$ NMR of $\mathbf{2 4 b}$ \\
\hline${ }^{1} \mathrm{H}$ NMR of 17 & S4 & ${ }^{13} \mathrm{C}$ NMR of $\mathbf{2 4 b}$ \\
\hline${ }^{1}$ H NMR of $\mathbf{1 8}$ & S5 & ${ }^{1} \mathrm{H}$ NMR of $\mathbf{2 5 a}$ \\
\hline${ }^{1} \mathrm{H}$ NMR of 19 & S6 & ${ }^{13} \mathrm{C}$ NMR of $\mathbf{2 5 a}$ \\
\hline${ }^{13} \mathrm{C}$ NMR of 19 & S7 & ${ }^{1} \mathrm{H}$ NMR of $\mathbf{2 5 b}$ \\
\hline${ }^{1} \mathrm{H}$ NMR of $\mathbf{2 0}$ & S8 & ${ }^{13} \mathrm{C}$ NMR of $\mathbf{2 5 b}$ \\
\hline${ }^{13} \mathrm{C}$ NMR of $\mathbf{2 0}$ & S9 & ${ }^{1} \mathrm{H}$ NMR of $\mathbf{2 6 a}$ \\
\hline${ }^{1} \mathrm{H}$ NMR of $\mathbf{2 1}$ & $\mathrm{S} 10$ & ${ }^{13} \mathrm{C}$ NMR of $\mathbf{2 6 a}$ \\
\hline${ }^{13} \mathrm{C}$ NMR of 21 & $\mathrm{~S} 11$ & ${ }^{1} \mathrm{H}$ NMR of $\mathbf{2 6 b}$ \\
\hline${ }^{1} \mathrm{H}$ NMR of 15 & $\mathrm{~S} 12$ & ${ }^{13} \mathrm{C}$ NMR of $\mathbf{2 6 b}$ \\
\hline${ }^{13} \mathrm{C}$ NMR of 15 & $\mathrm{~S} 13$ & ${ }^{1} \mathrm{H}$ NMR of $27 \mathbf{a}$ \\
\hline${ }^{1} \mathrm{H}$ NMR of 22 & S14 & ${ }^{13} \mathrm{C}$ NMR of $27 \mathbf{a}$ \\
\hline${ }^{13} \mathrm{C}$ NMR of 22 & S15 & ${ }^{1} \mathrm{H}$ NMR of $\mathbf{2 7 b}$ \\
\hline${ }^{1} \mathrm{H}$ NMR of 23a & S16 & ${ }^{13} \mathrm{C}$ NMR of $\mathbf{2 7 b}$ \\
\hline${ }^{1} \mathrm{H}$ NMR of $\mathbf{2 3 b}$ & S17 & ${ }^{1} \mathrm{H}$ NMR of $\mathbf{2 8 a}$ \\
\hline${ }^{1} \mathrm{H}$ NMR of $\mathbf{2 4 a}$ & S18 & ${ }^{13} \mathrm{C}$ NMR of $\mathbf{2 8 a}$ \\
\hline${ }^{13} \mathrm{C}$ NMR of $24 a$ & S19 & ${ }^{1} \mathrm{H}$ NMR of $\mathbf{2 8 b}$ \\
\hline
\end{tabular}




\begin{tabular}{|c|c|c|}
\hline${ }^{13} \mathrm{C}$ NMR of $\mathbf{2 8 b}$ & S37 & ${ }^{1} \mathrm{H}$ NMR of $\mathbf{4 2}$ \\
\hline${ }^{1} \mathrm{H}$ NMR of $\mathbf{3 0 a}$ & S38 & ${ }^{13} \mathrm{C}$ NMR of 42 \\
\hline${ }^{13} \mathrm{C}$ NMR of $\mathbf{3 0 a}$ & S39 & ${ }^{1} \mathrm{H}$ NMR of $\mathbf{4 0}$ \\
\hline${ }^{1} \mathrm{H}$ NMR of $\mathbf{3 1 a}$ & $\mathrm{S} 40$ & ${ }^{13} \mathrm{C}$ NMR of 40 \\
\hline${ }^{13} \mathrm{C}$ NMR of 31a & S41 & ${ }^{1} \mathrm{H}$ NMR of 44 \\
\hline${ }^{1} \mathrm{H}$ NMR of $\mathbf{3 2 a}$ & S42 & ${ }^{13} \mathrm{C}$ NMR of 44 \\
\hline${ }^{13} \mathrm{C}$ NMR of $\mathbf{3 2 a}$ & S43 & HMBC of 12 \\
\hline${ }^{1} \mathrm{H}$ NMR of $\mathbf{3 0 b}$ & S44 & HSQC of 12 \\
\hline${ }^{13} \mathrm{C}$ NMR of $\mathbf{3 0 b}$ & S45 & COSY of 12 \\
\hline${ }^{1} \mathrm{H}$ NMR of $\mathbf{3 0 c}$ & S46 & NOSEY of $\mathbf{1 2}$ \\
\hline${ }^{13} \mathrm{C}$ NMR of $\mathbf{3 0 c}$ & S47 & HMBC of 9 \\
\hline${ }^{1} \mathrm{H}$ NMR of $\mathbf{3 2 b}$ & S48 & HSQC of 9 \\
\hline${ }^{13} \mathrm{C}$ NMR of $\mathbf{3 2 b}$ & S49 & COSY of 9 \\
\hline${ }^{1} \mathrm{H}$ NMR of 34 & S50 & NOSEY of 9 \\
\hline${ }^{13} \mathrm{C}$ NMR of 34 & S51 & \\
\hline${ }^{1} \mathrm{H}$ NMR of $\mathbf{1 2}$ & S52 & \\
\hline${ }^{13} \mathrm{C}$ NMR of 12 & S53 & \\
\hline${ }^{1} \mathrm{H}$ NMR of 35 & S54 & \\
\hline${ }^{13} \mathrm{C}$ NMR of 35 & S55 & \\
\hline${ }^{1} \mathrm{H}$ NMR of 43 & S56 & \\
\hline${ }^{13} \mathrm{C}$ NMR of 43 & S57 & \\
\hline${ }^{1} \mathrm{H}$ NMR of $\mathbf{1 1}$ & S58 & \\
\hline${ }^{13} \mathrm{C}$ NMR of 11 & S59 & \\
\hline${ }^{1} \mathrm{H}$ NMR of 9 & S60 & \\
\hline${ }^{13} \mathrm{C}$ NMR of 9 & S61 & \\
\hline
\end{tabular}


General Methods. All reagents were used without further purification unless otherwise indicated. All reactions were run in flame-dried Schlenk glassware unless otherwise specified. Photochemical reactions were run in a Rayonet RPR-100 Photochemical Reactor. 
17, ${ }^{1} \mathrm{H}$ NMR

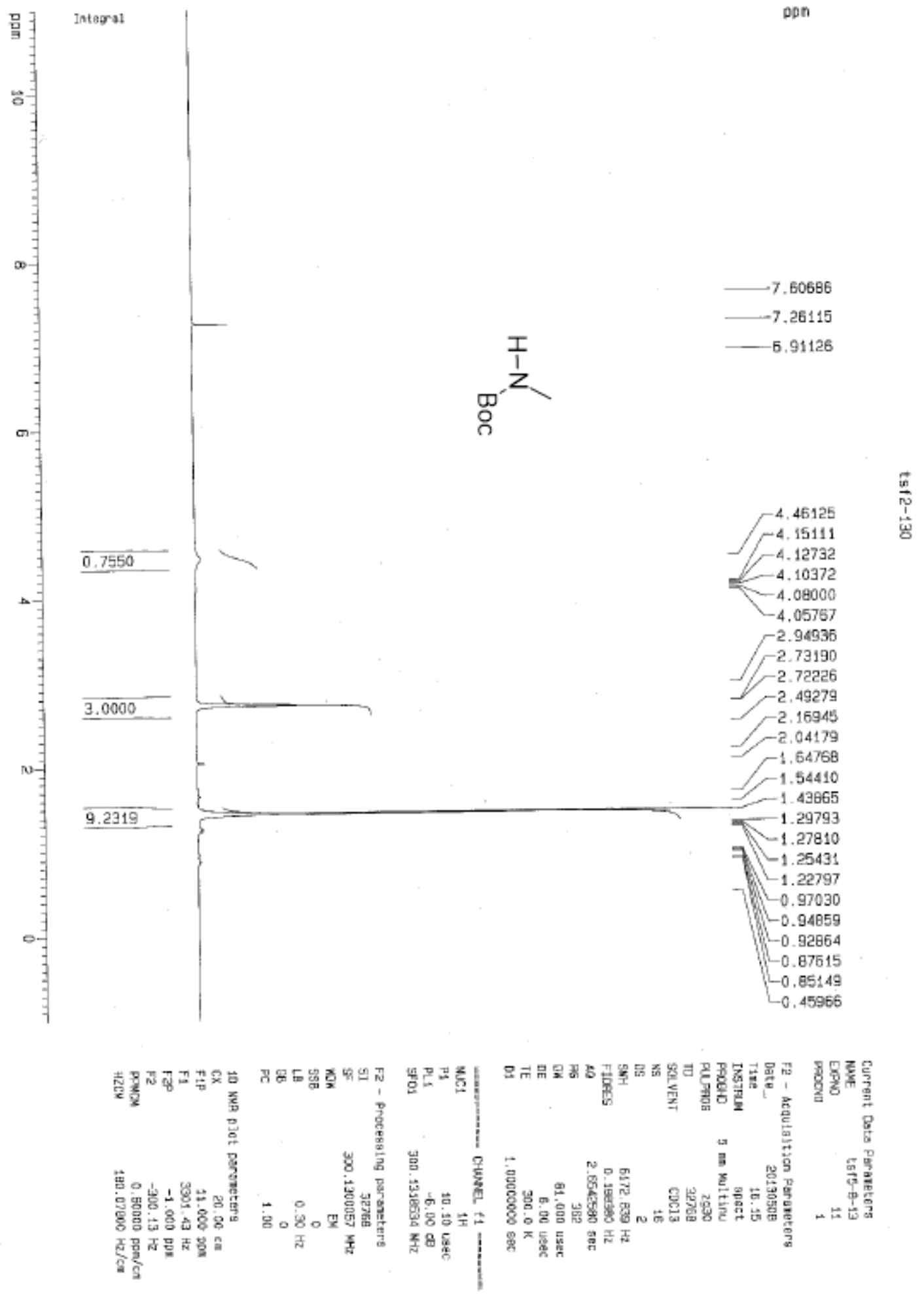




\section{8, ${ }^{1} \mathrm{H}$ NMR}

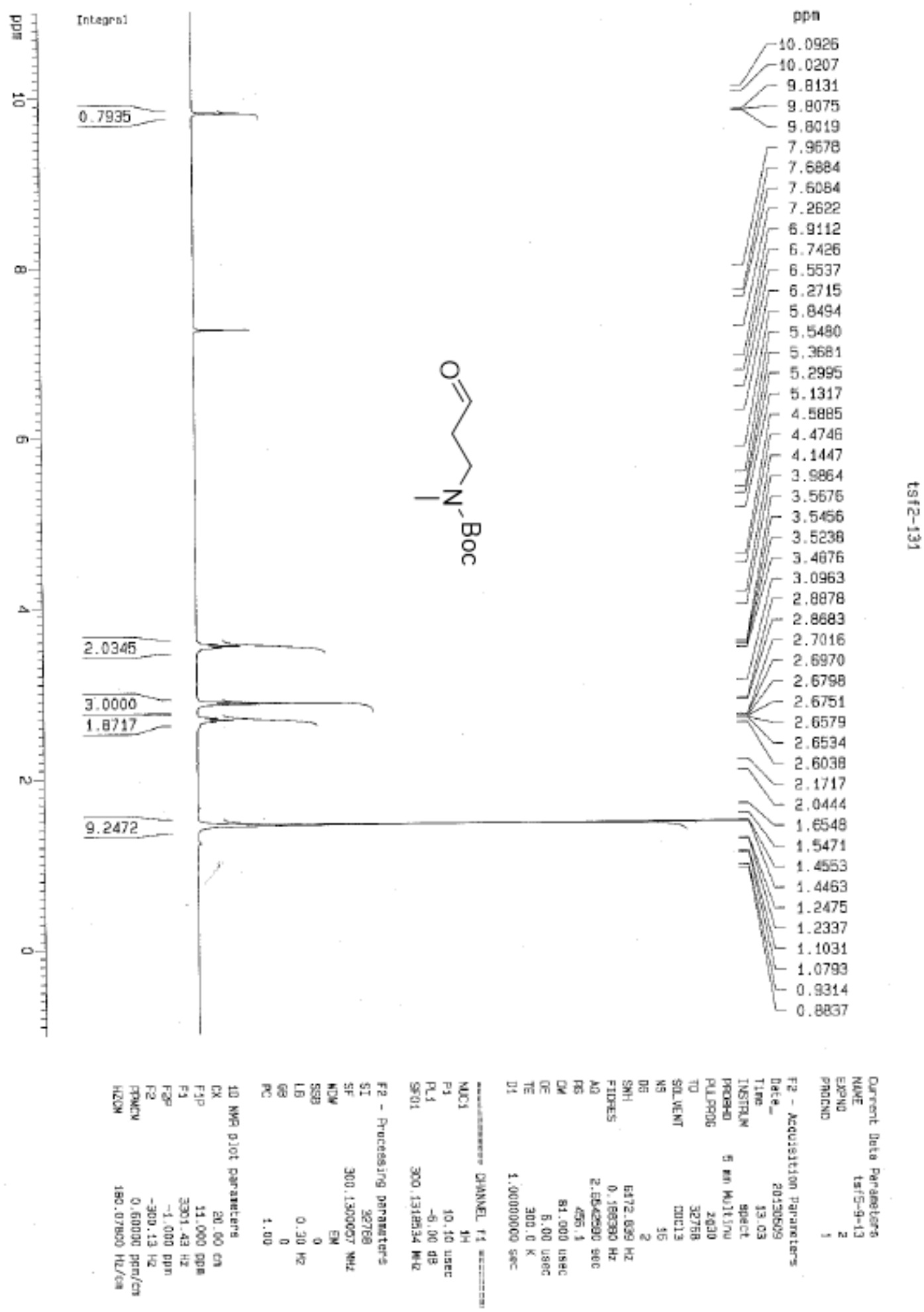


19, ${ }^{1} \mathrm{H}$ NMR

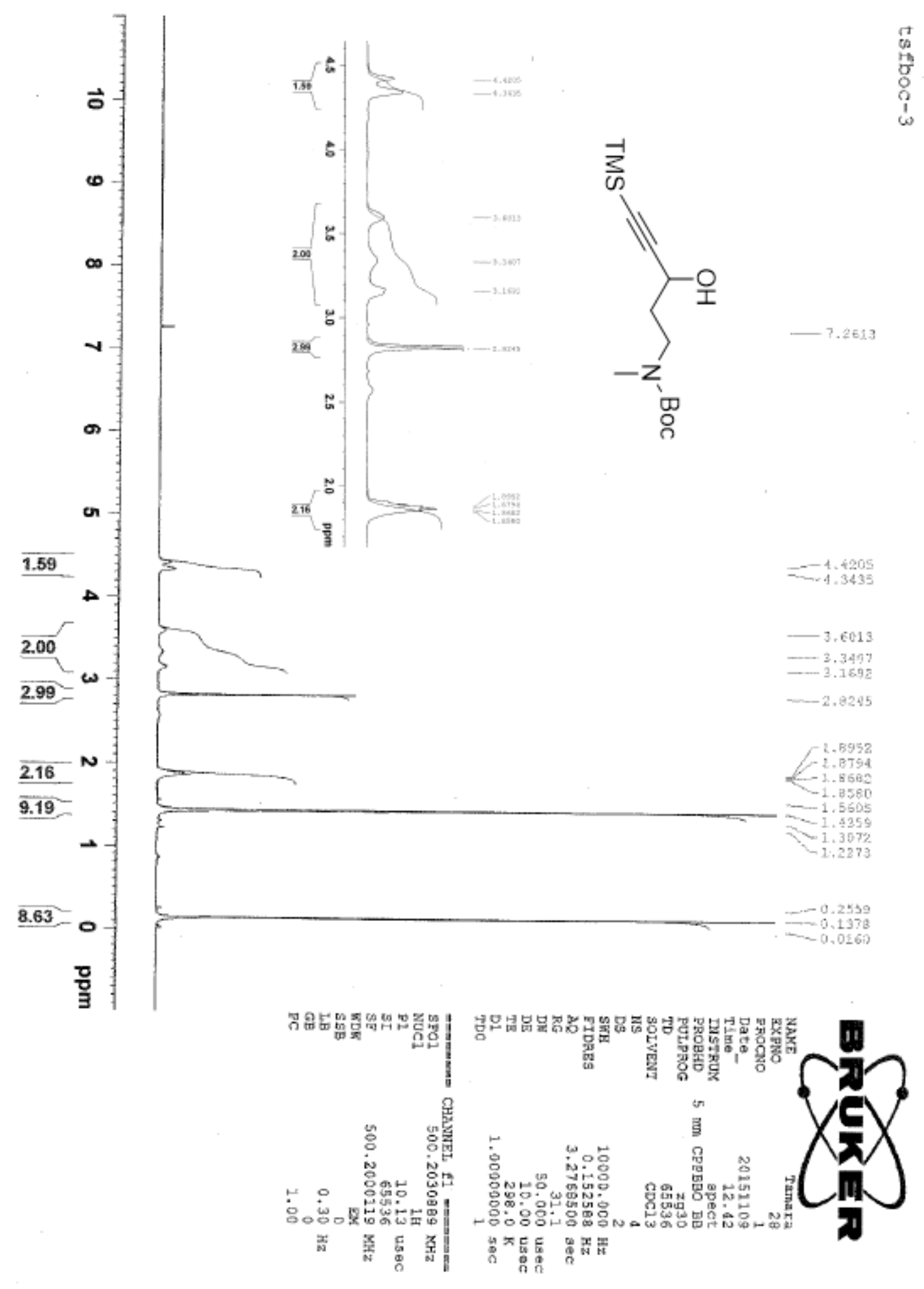


19, ${ }^{13} \mathrm{C} \mathrm{NMR}$

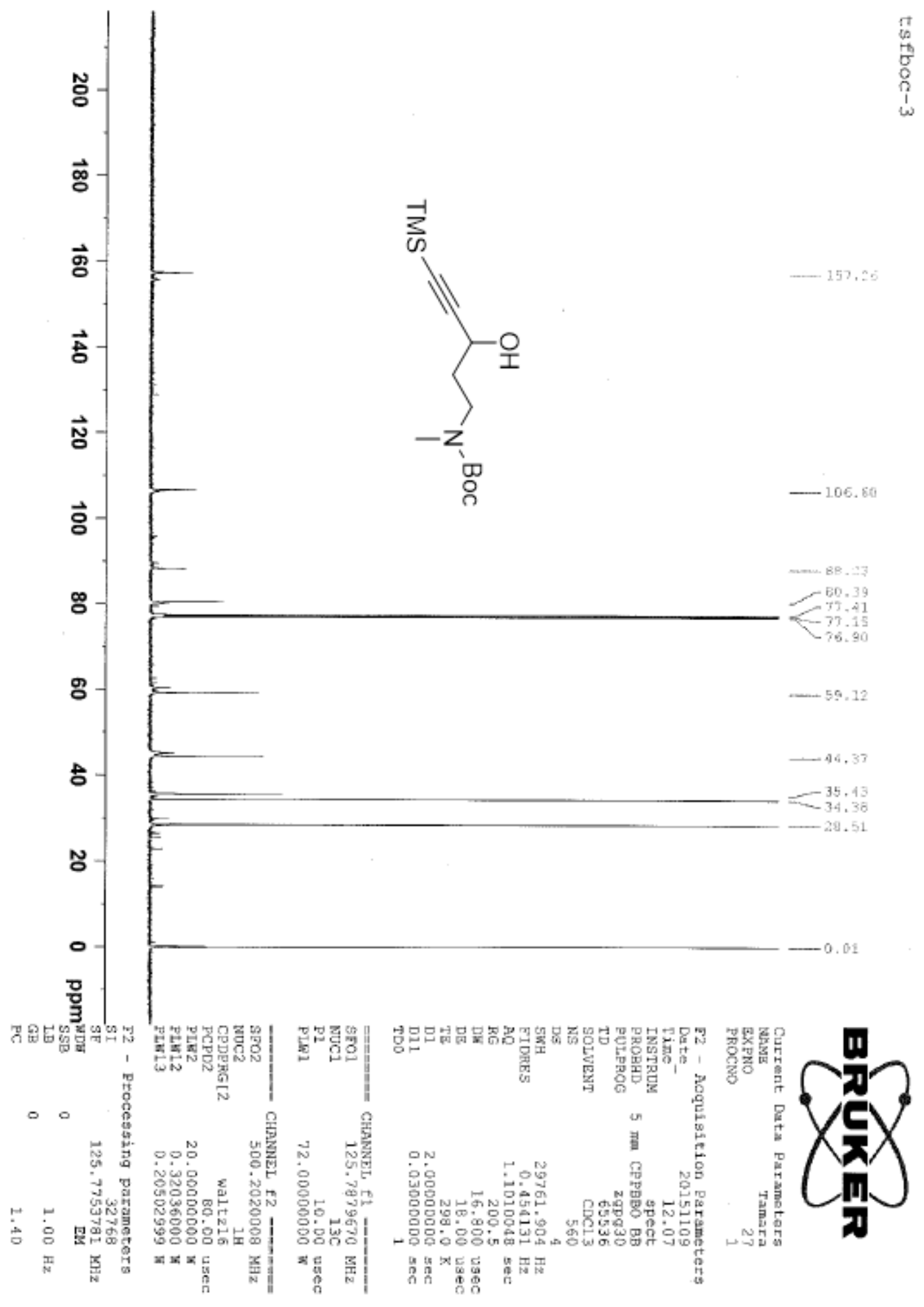




\section{0, ${ }^{1} \mathrm{H}$ NMR}

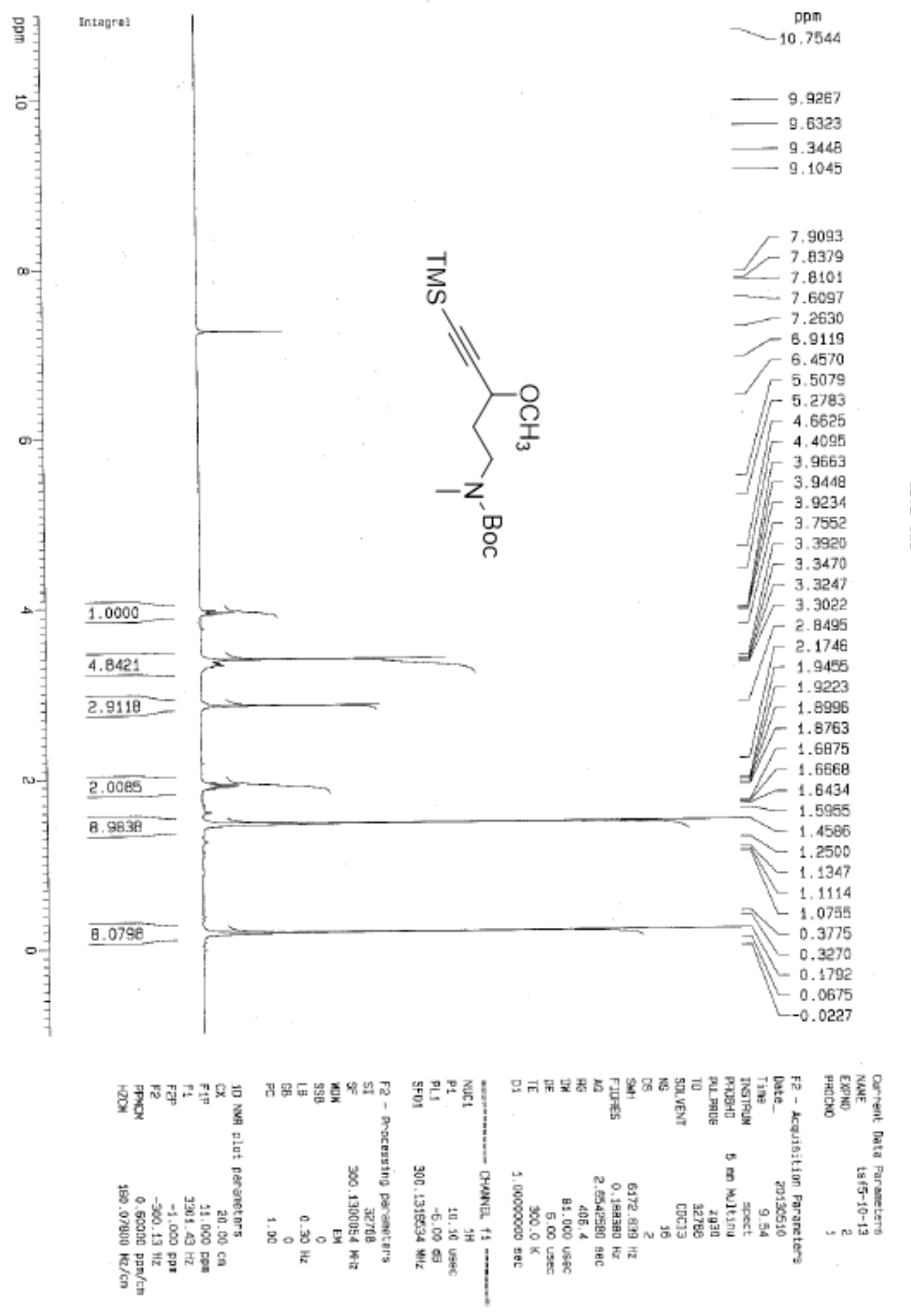




$$
\text { 20, }{ }^{13} \mathrm{C} \text { NMR }
$$

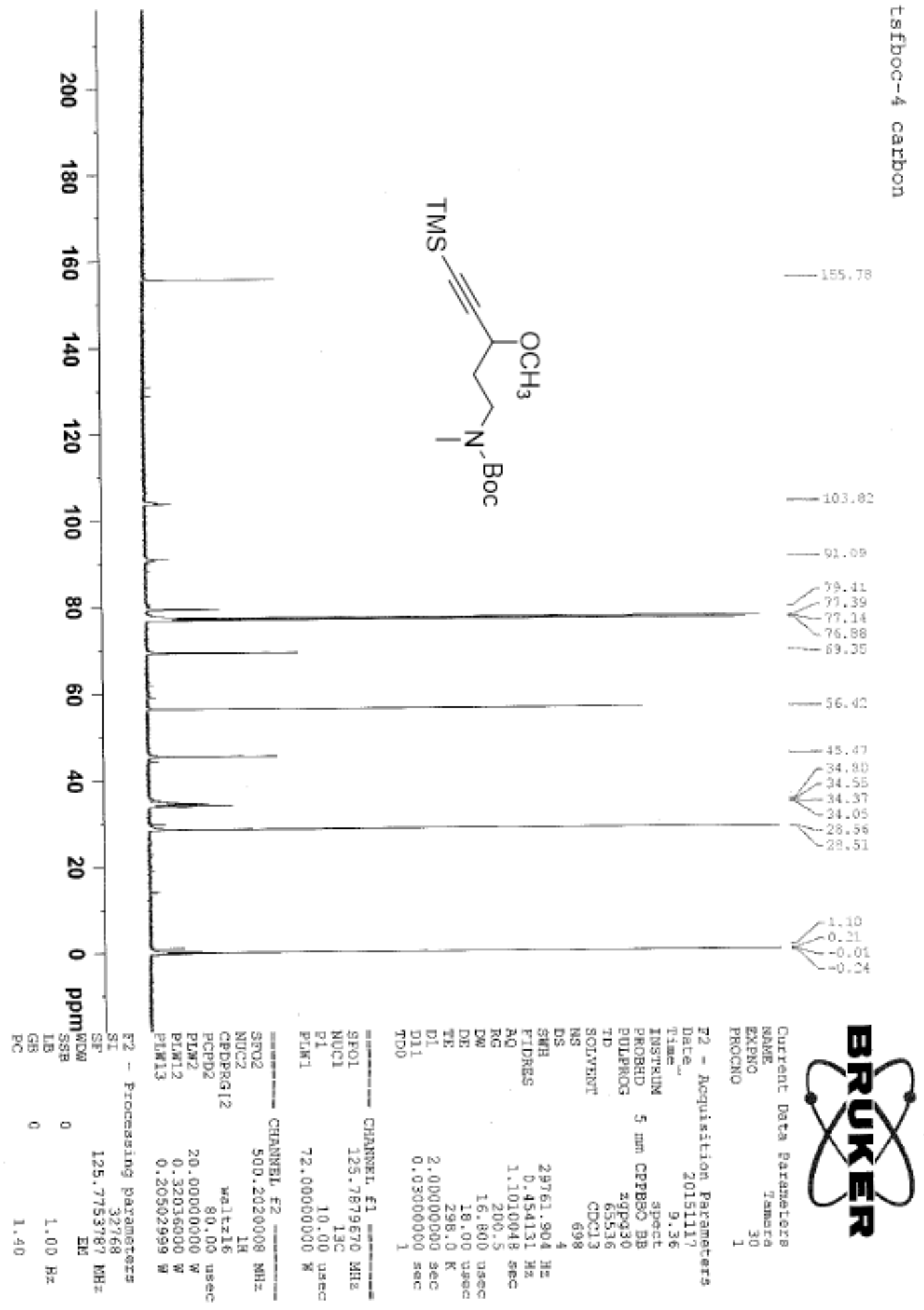


21, ${ }^{1} \mathrm{H}$ NMR

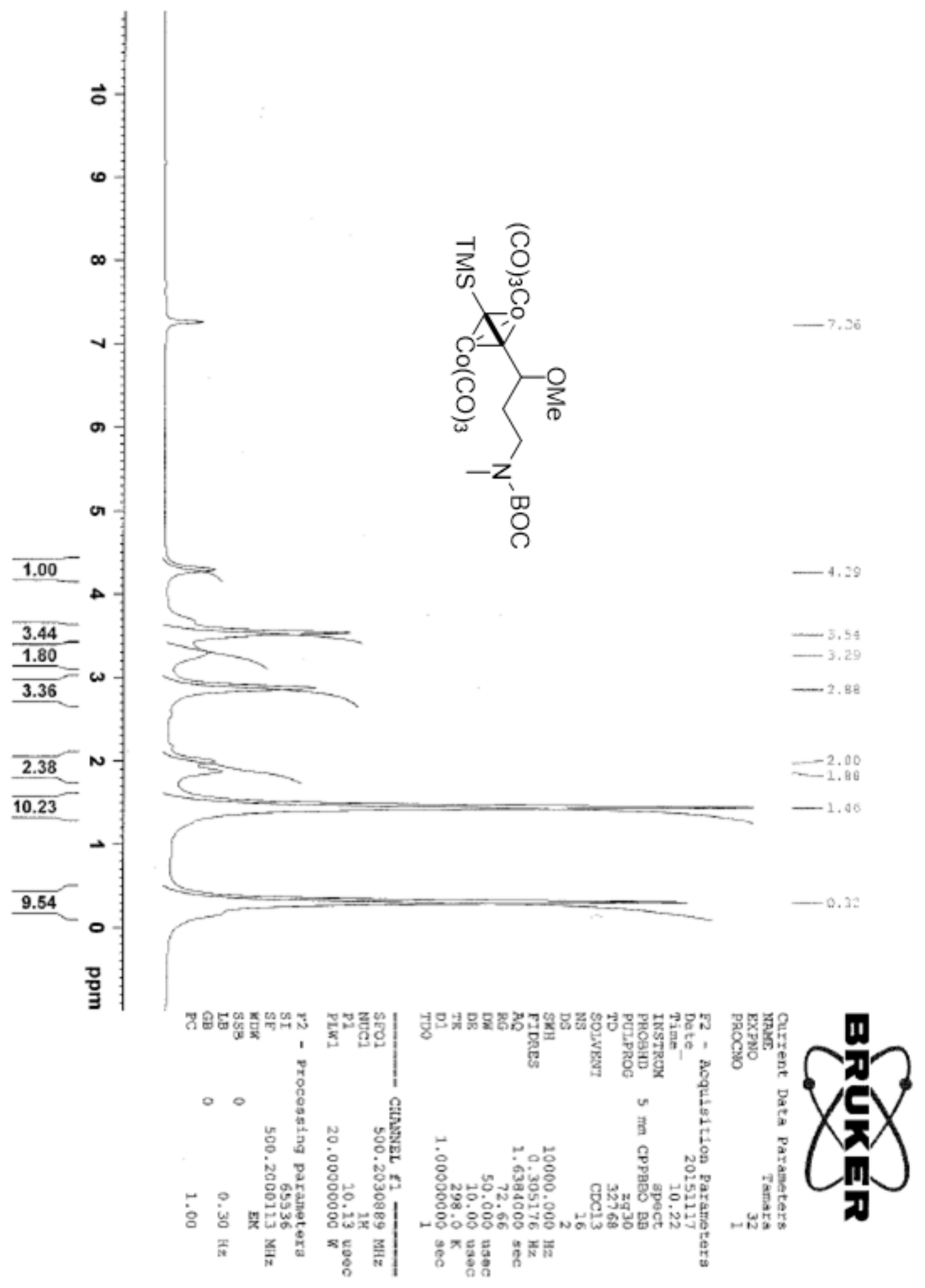


21, ${ }^{13} \mathrm{C}$ NMR

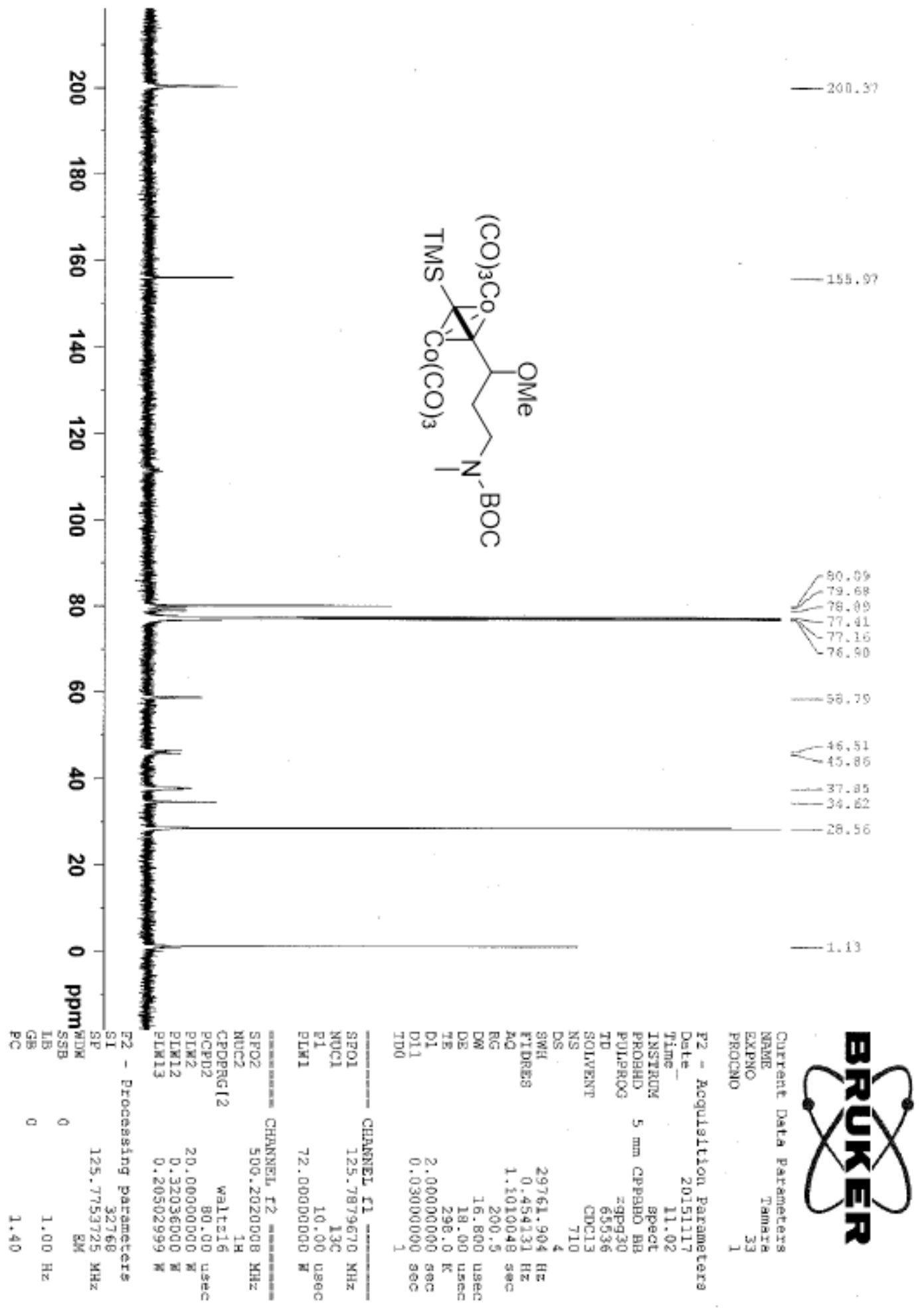


15, ${ }^{1} \mathrm{H}$ NMR

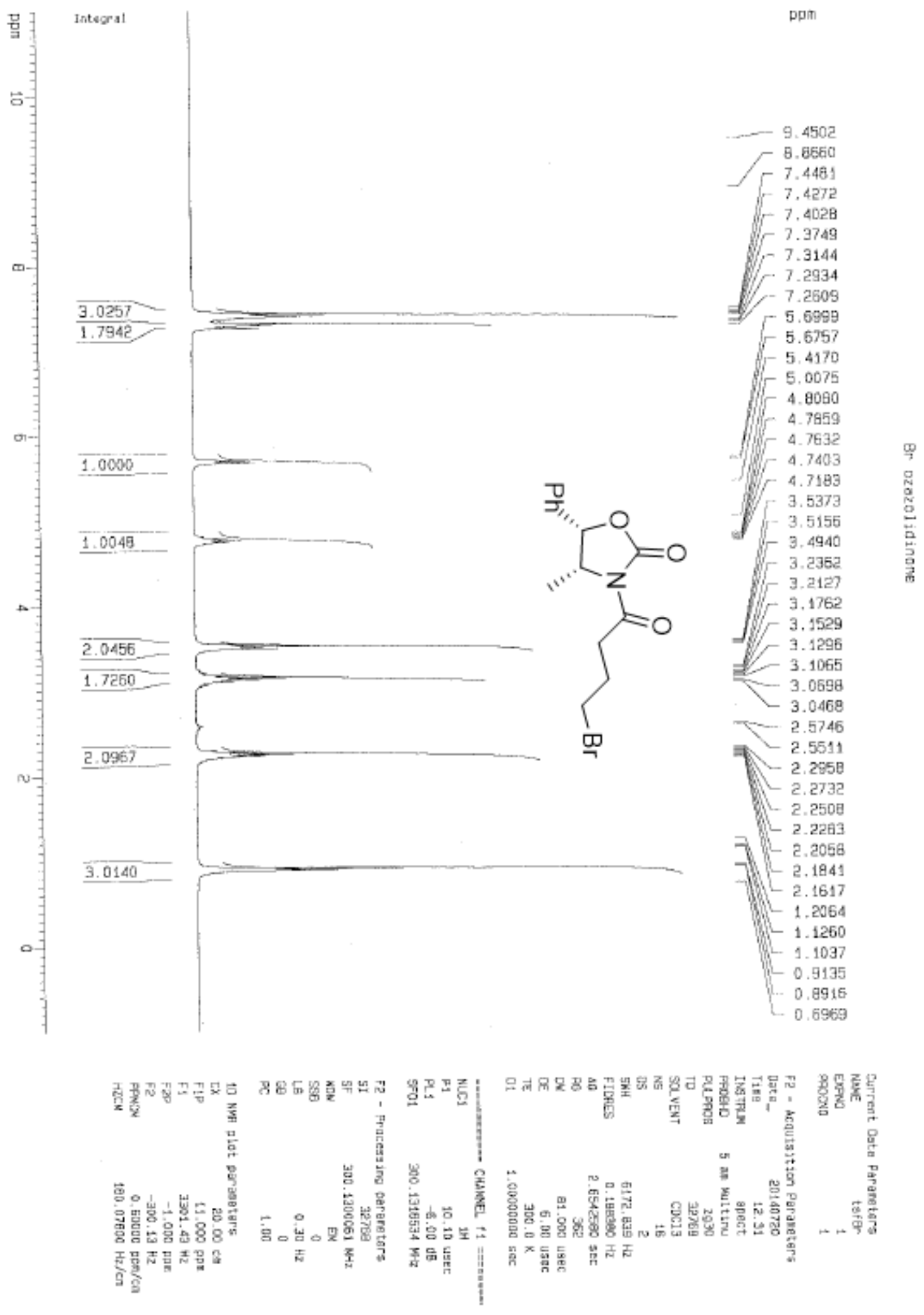




\section{5, ${ }^{13} \mathrm{C}$ NMR}

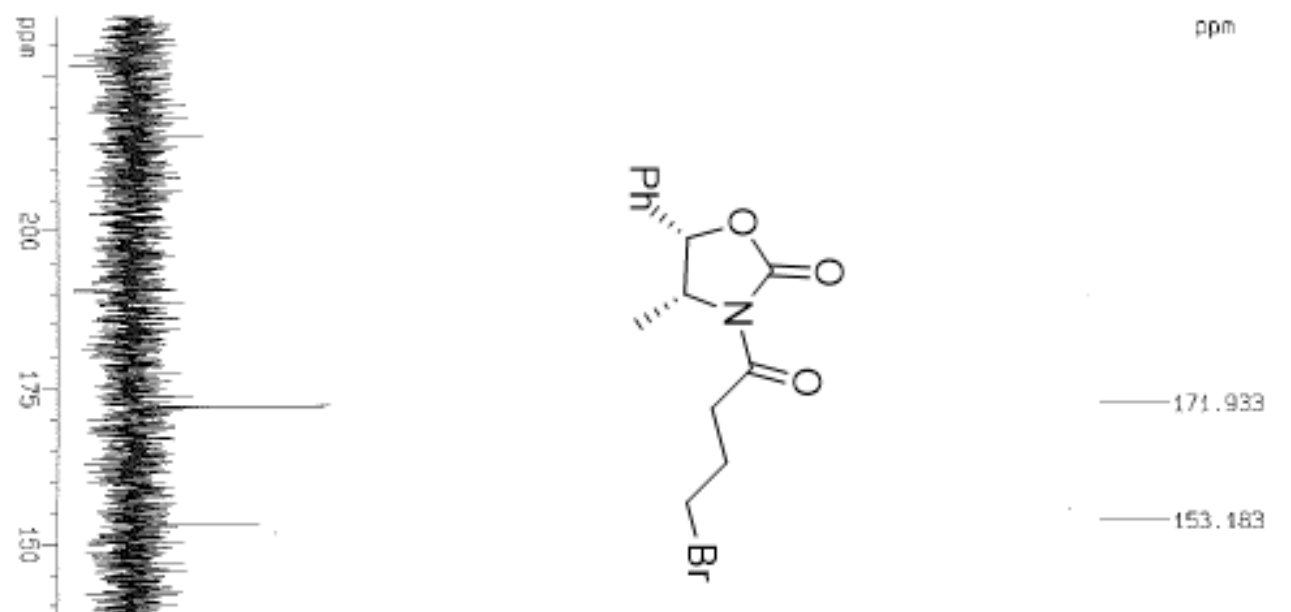

$-133.306$

-128.975
-128.889

ज

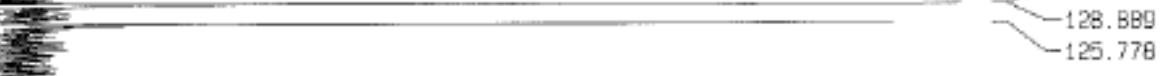

g

흥-

-
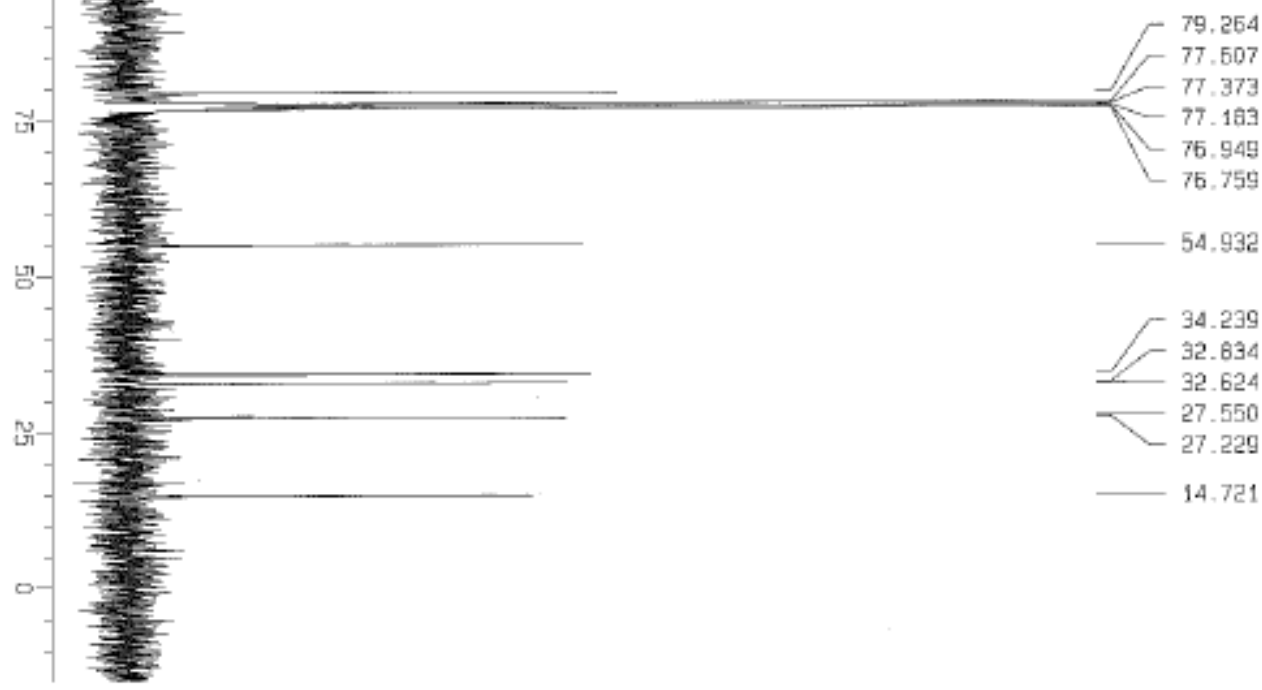

$-54,932$

r 34.239

$-32.634$

32.624

$-27.550$

- 14.721

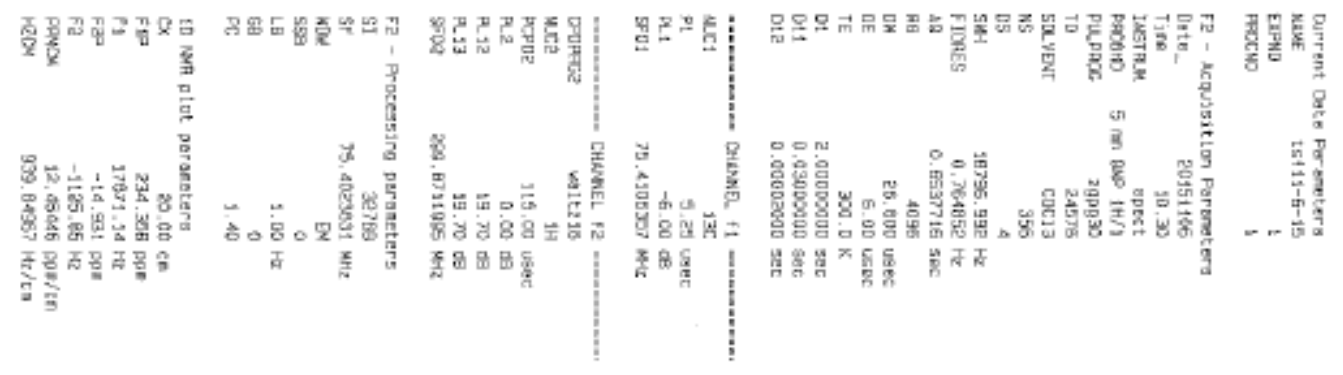


22, ${ }^{1} \mathrm{H}$ NMR

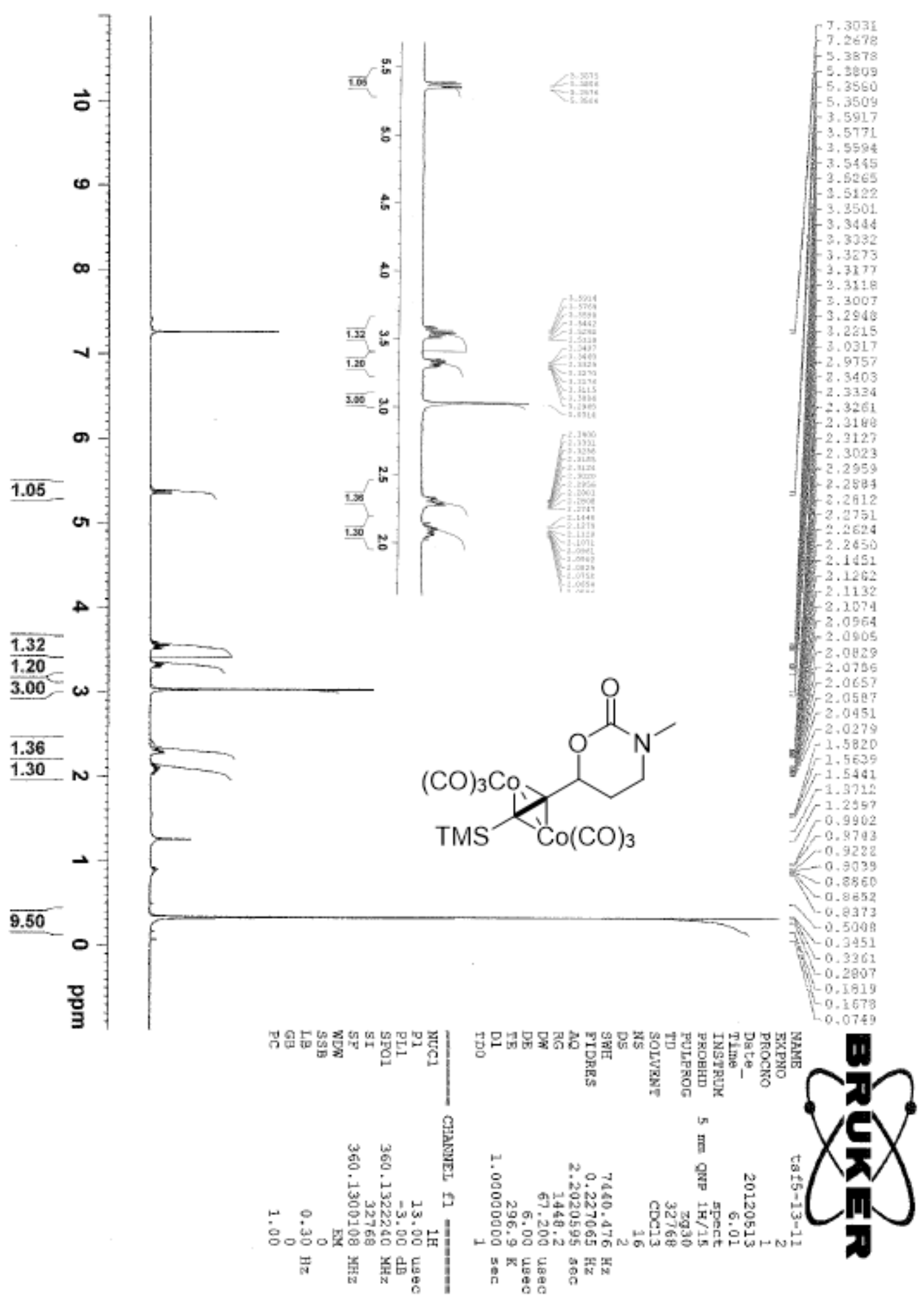


22, ${ }^{13} \mathrm{C}$ NMR

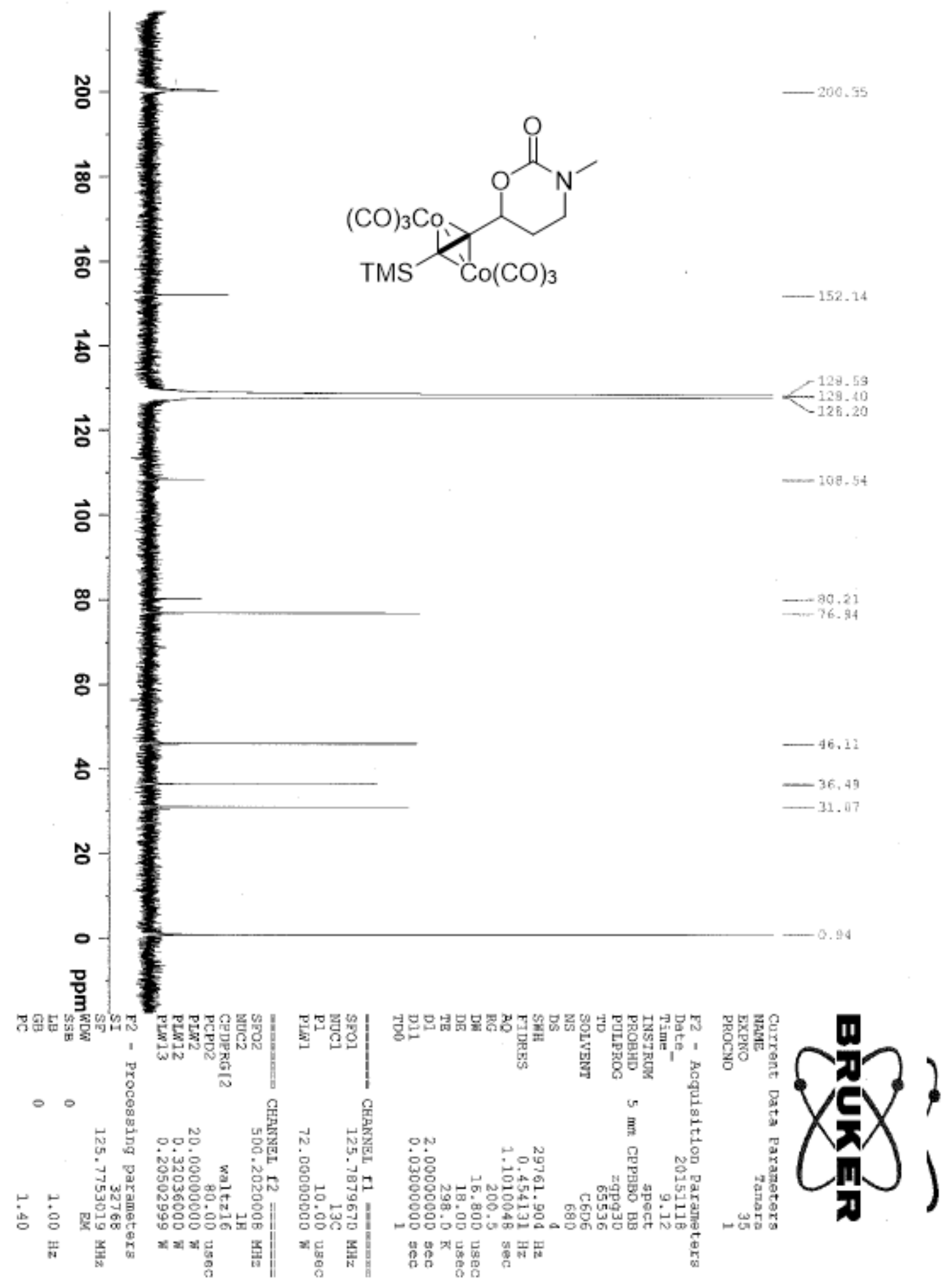




\section{3a, ${ }^{1} \mathrm{H}$ NMR}

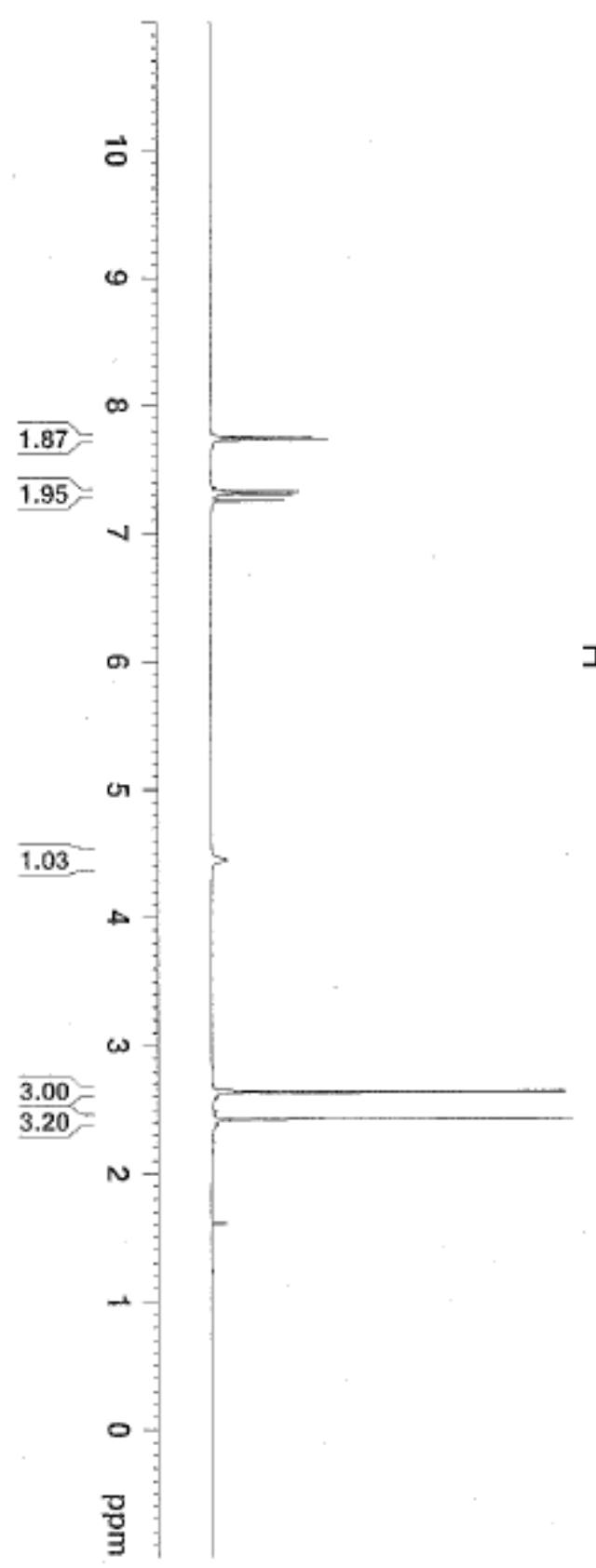

告

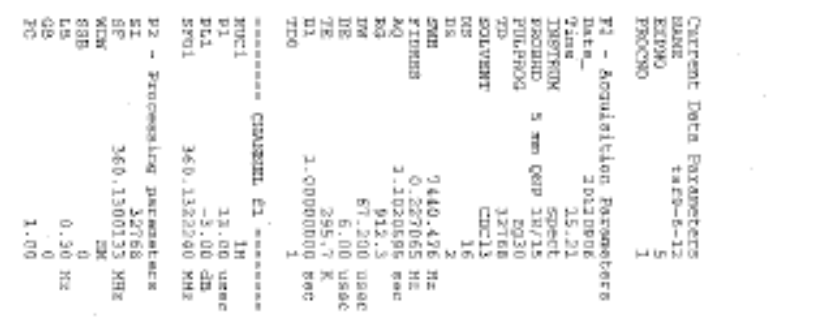


23b, ${ }^{1} \mathrm{H}$ NMR

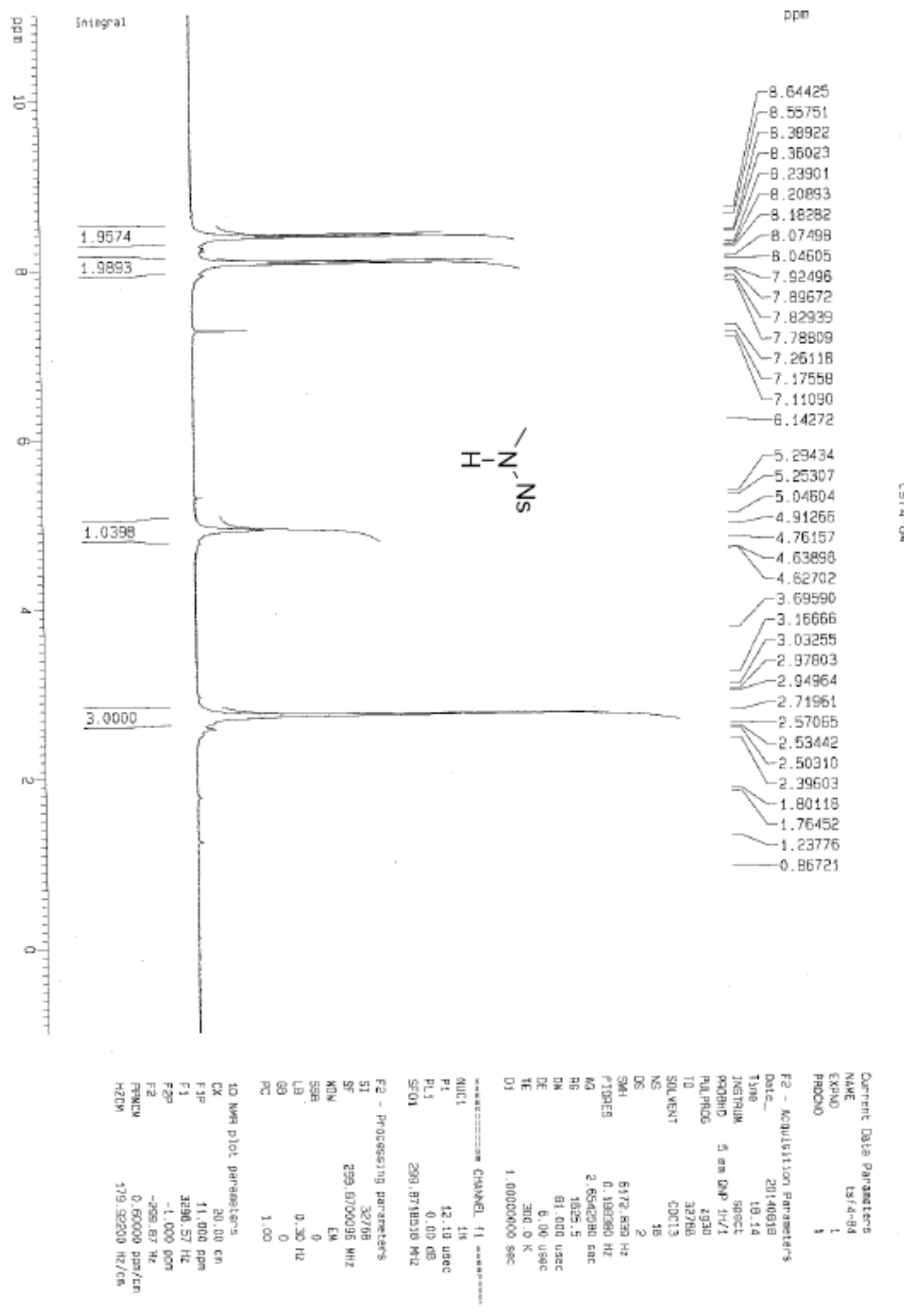


24a, ${ }^{1} \mathrm{H}$ NMR
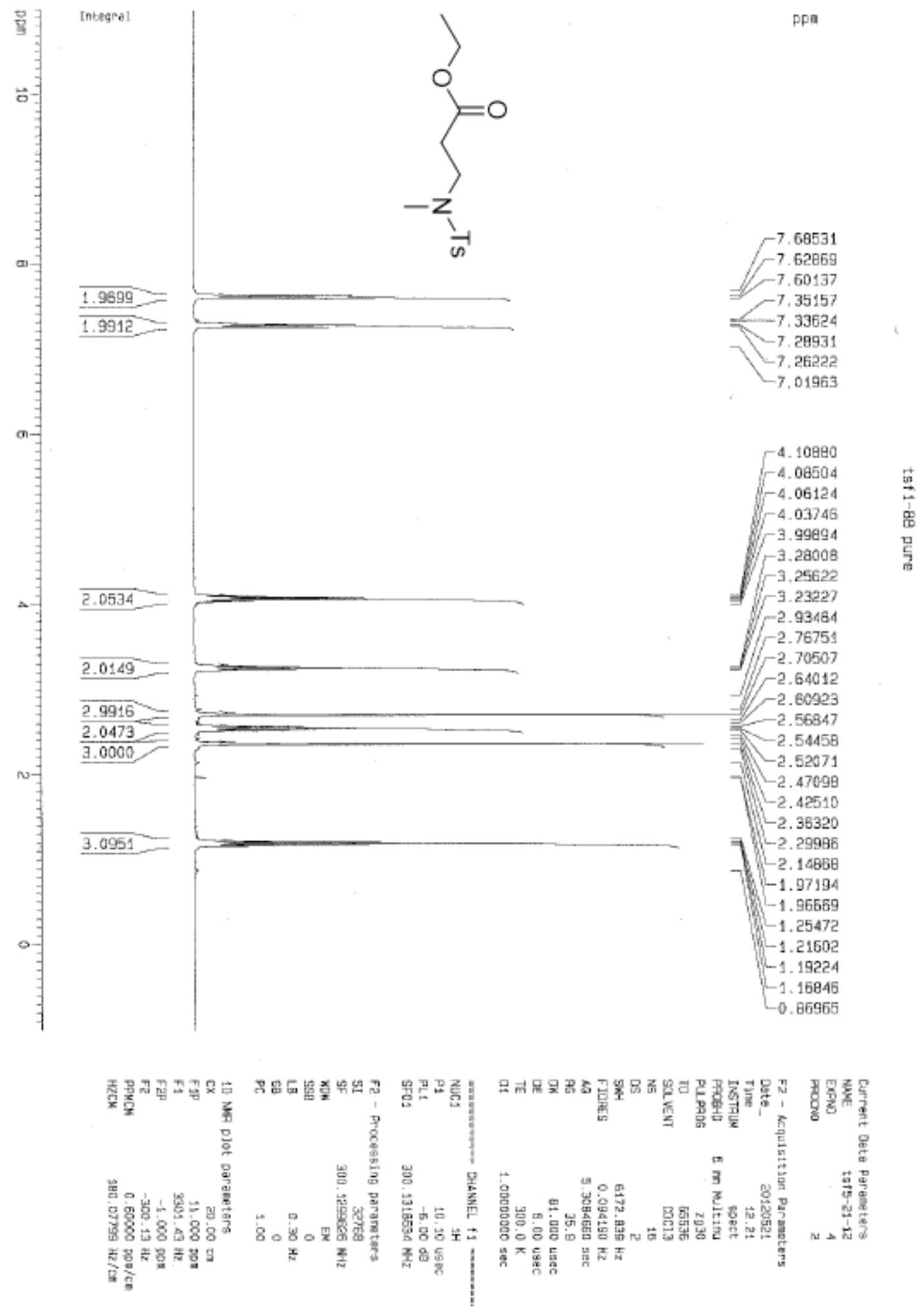
24a, ${ }^{13} \mathrm{C}$ NMR

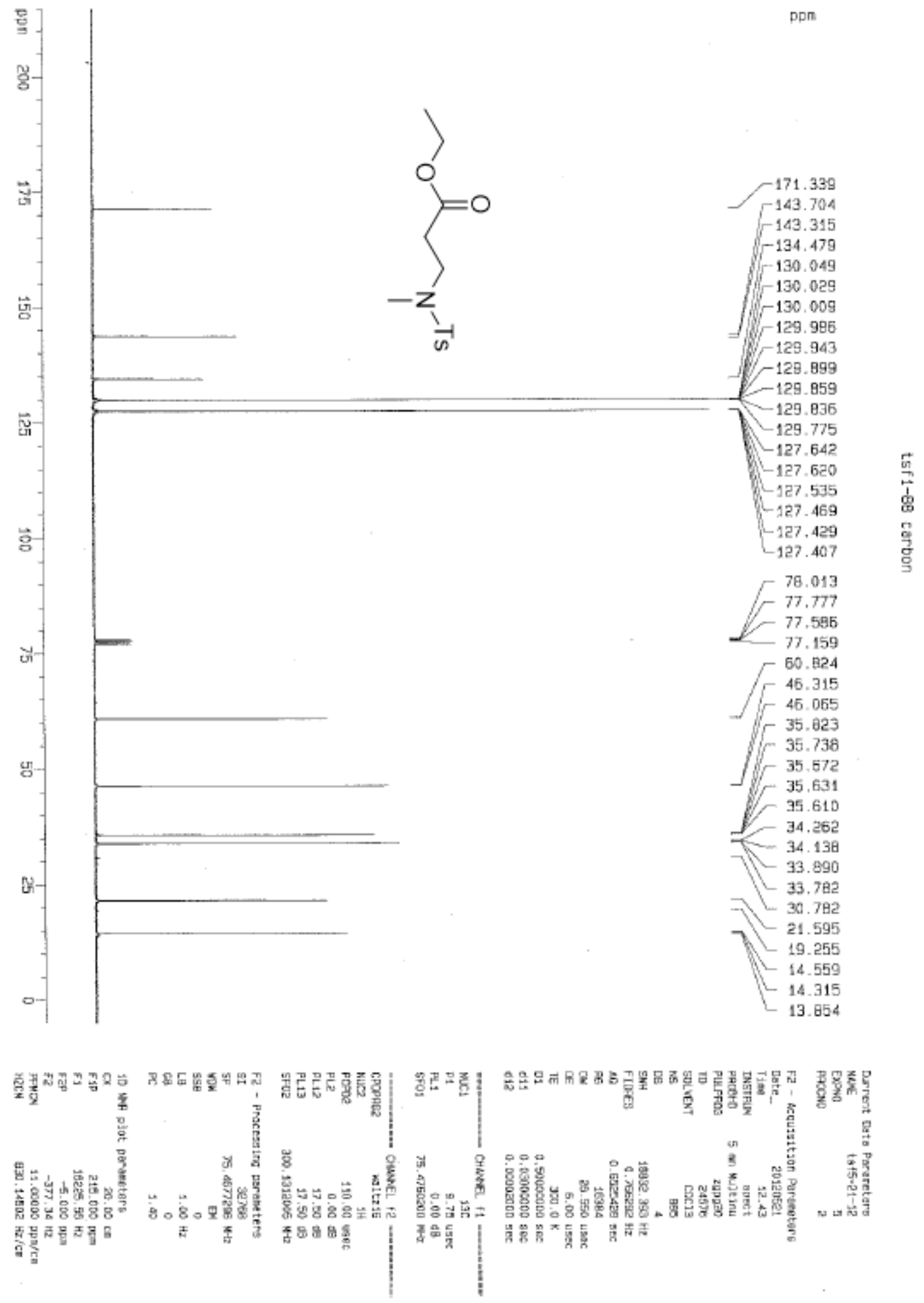


24b, ${ }^{1} \mathrm{H}$ NMR

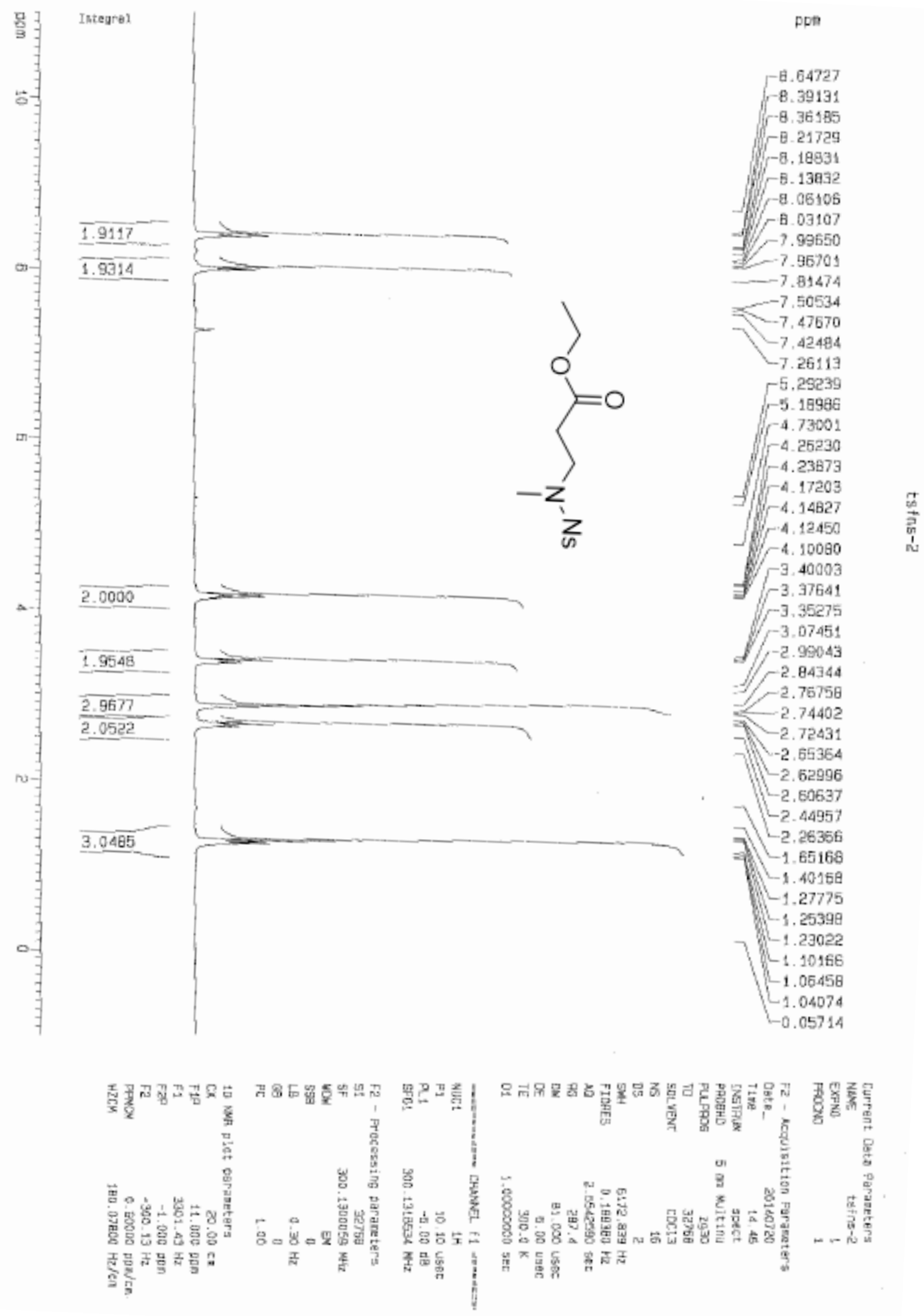


24b, ${ }^{13} \mathrm{C}$ NMR

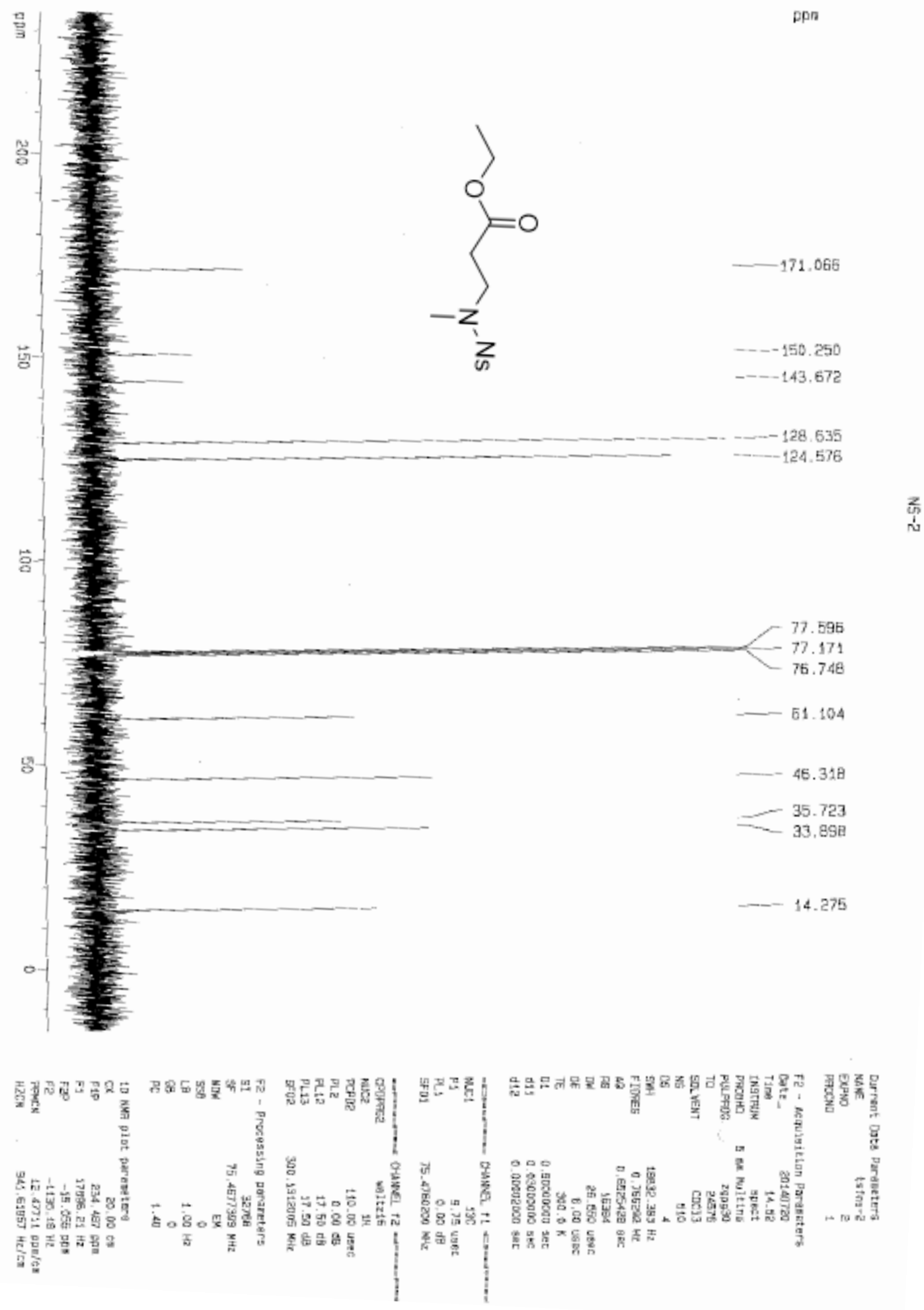


25a, ${ }^{1} \mathrm{H}$ NMR

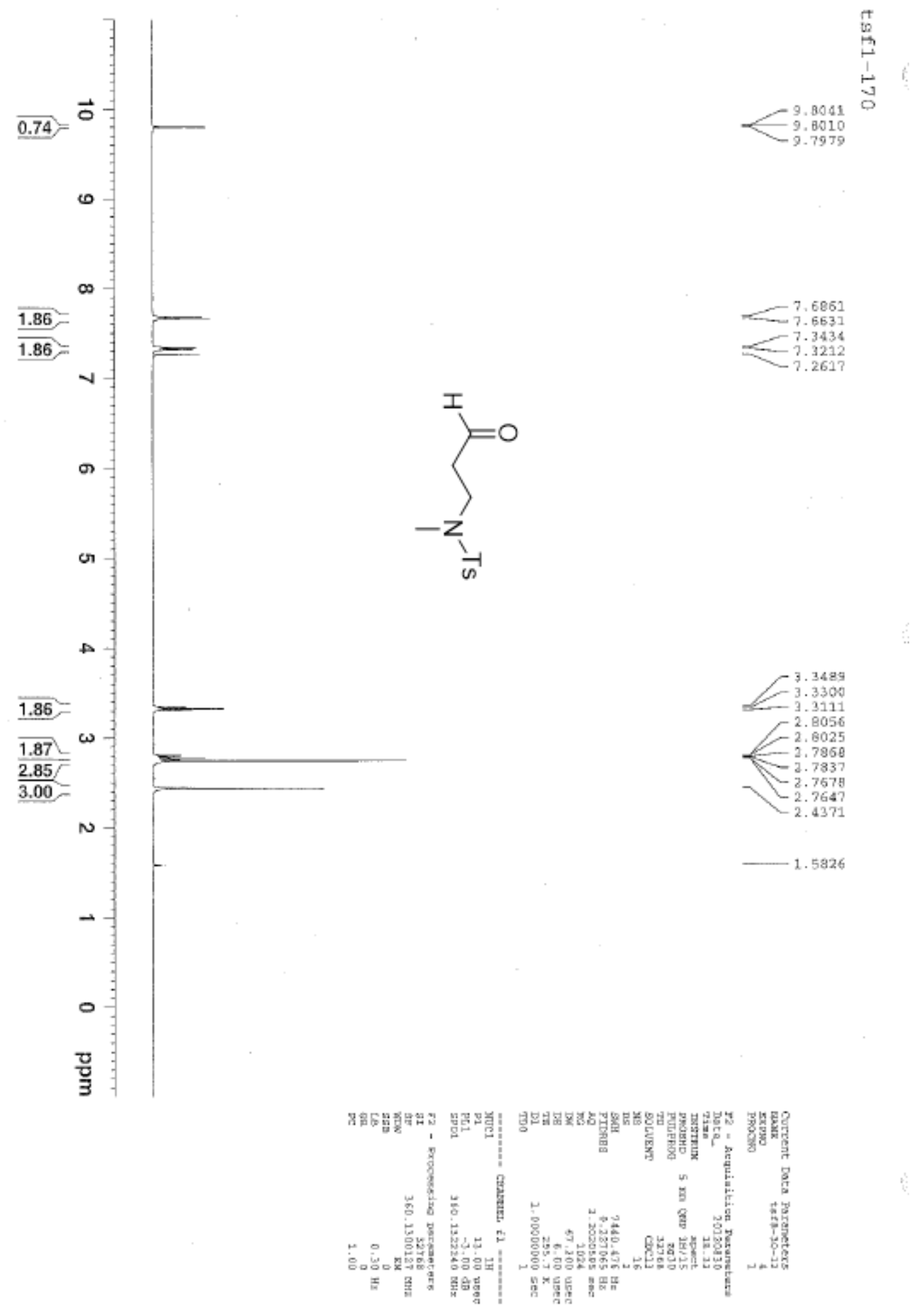


25a, ${ }^{13} \mathrm{C}$ NMR

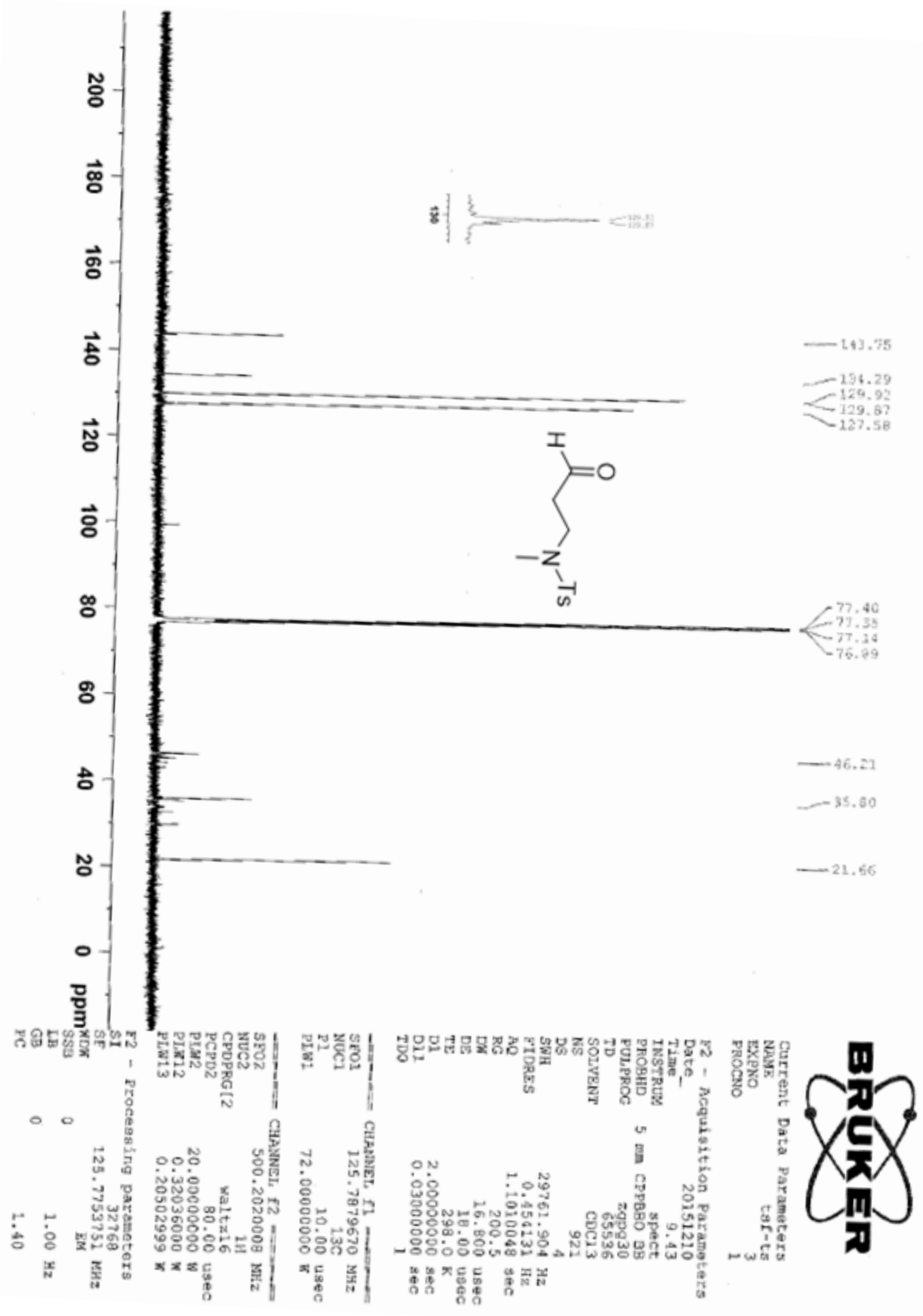


25b, ${ }^{1} \mathrm{H}$ NMR

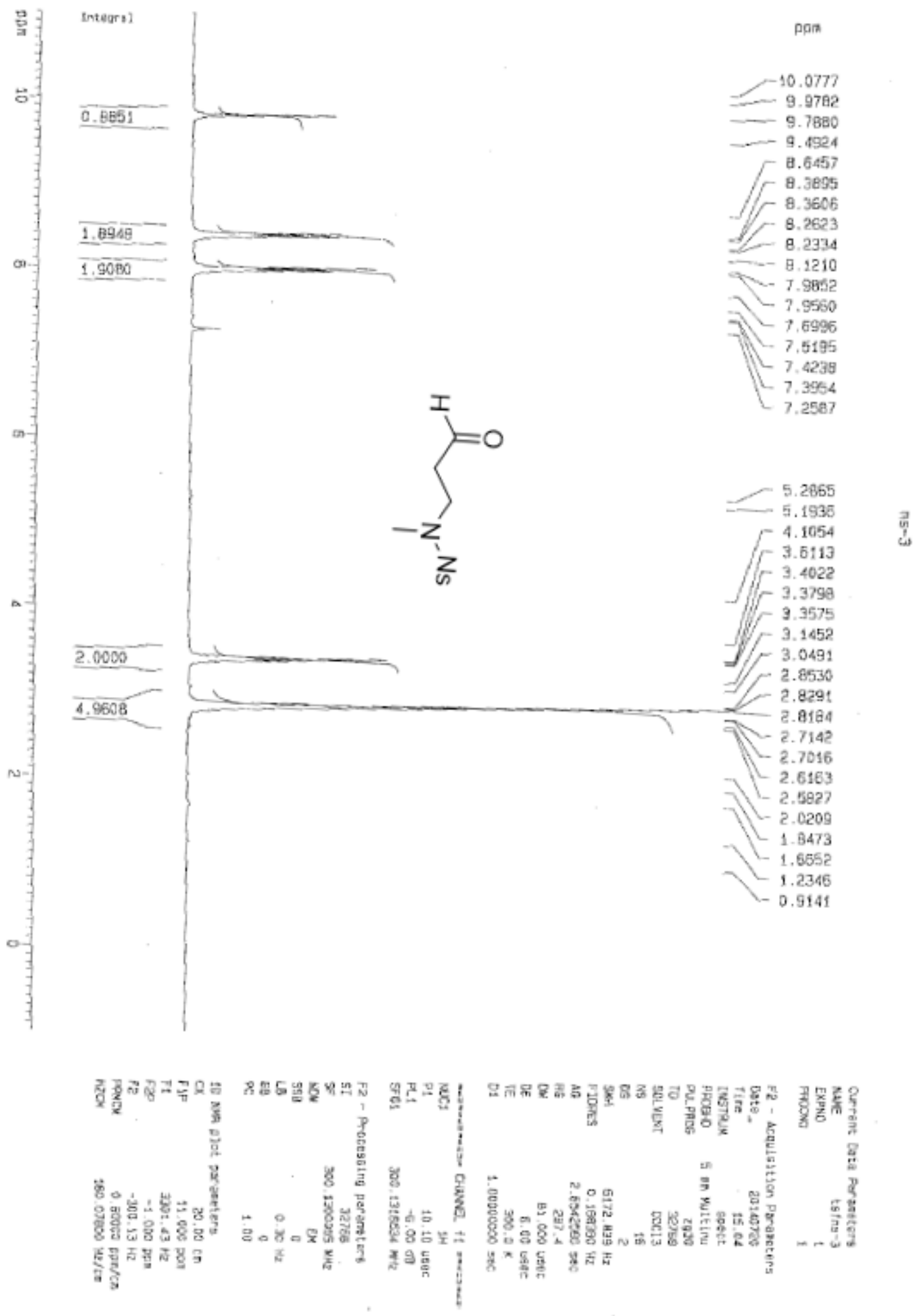


25b, ${ }^{13} \mathrm{C}$ NMR

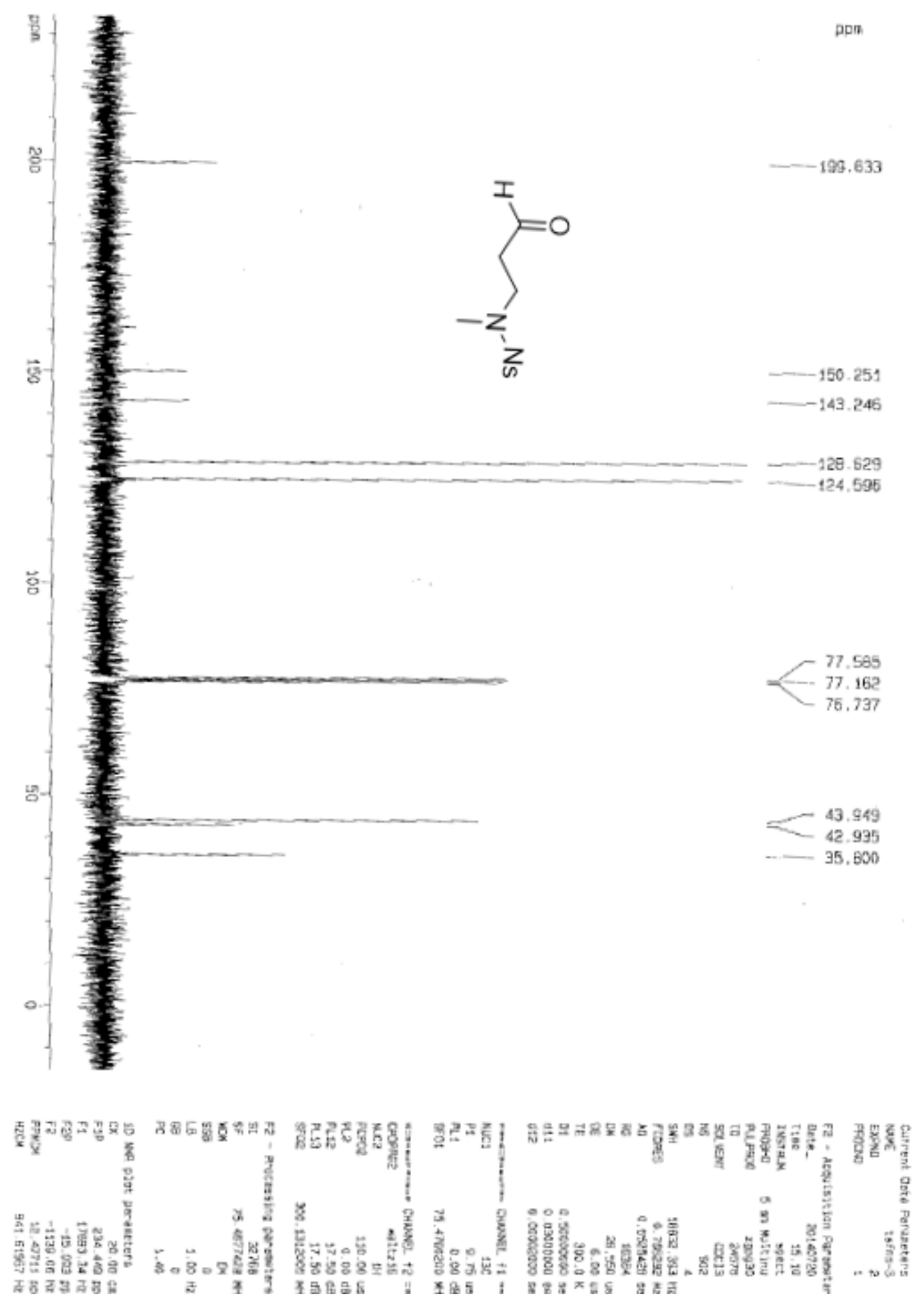




\section{6a, ${ }^{1} \mathrm{H}$ NMR}

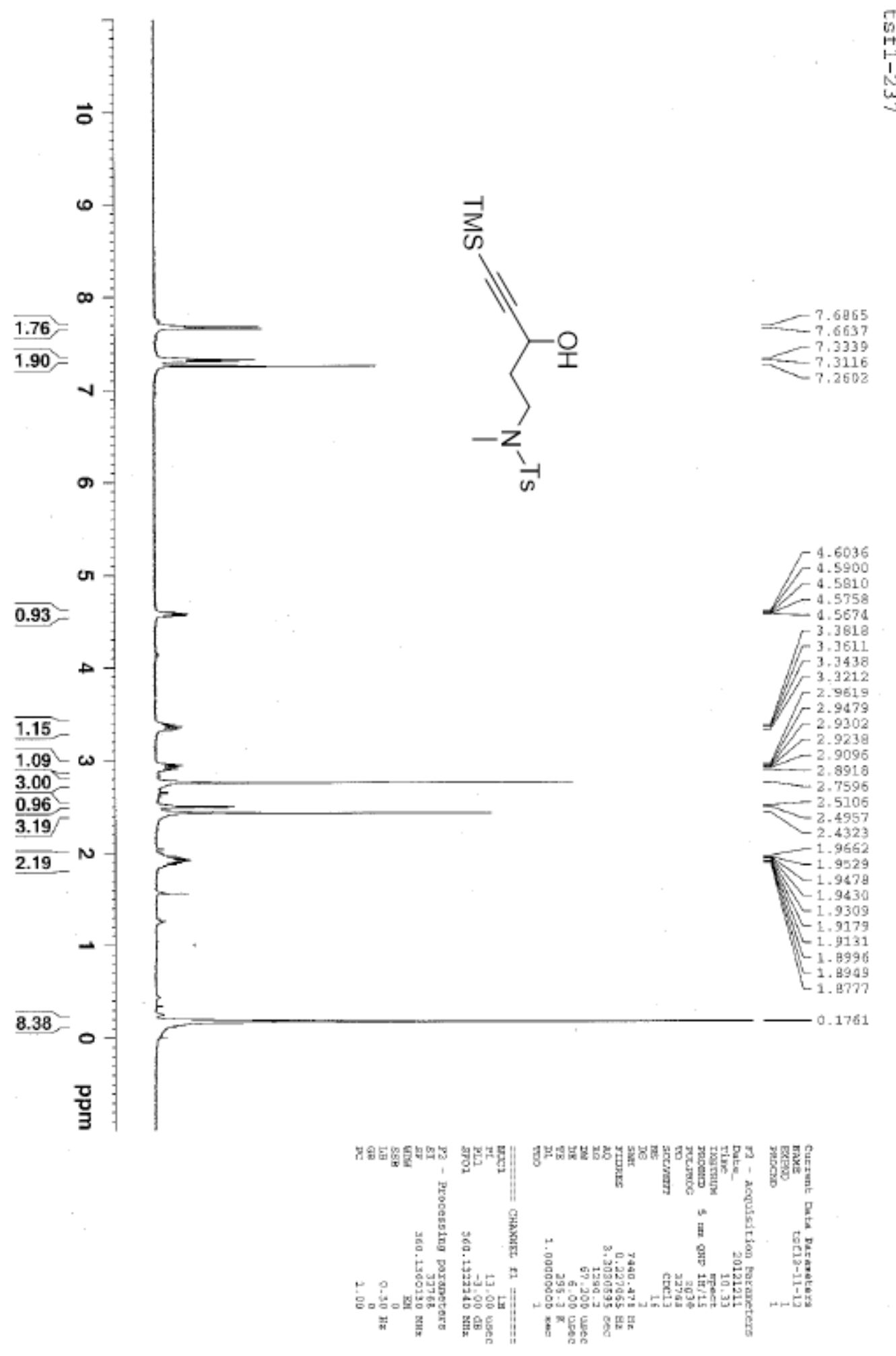


26a, ${ }^{13} \mathrm{C}$ NMR

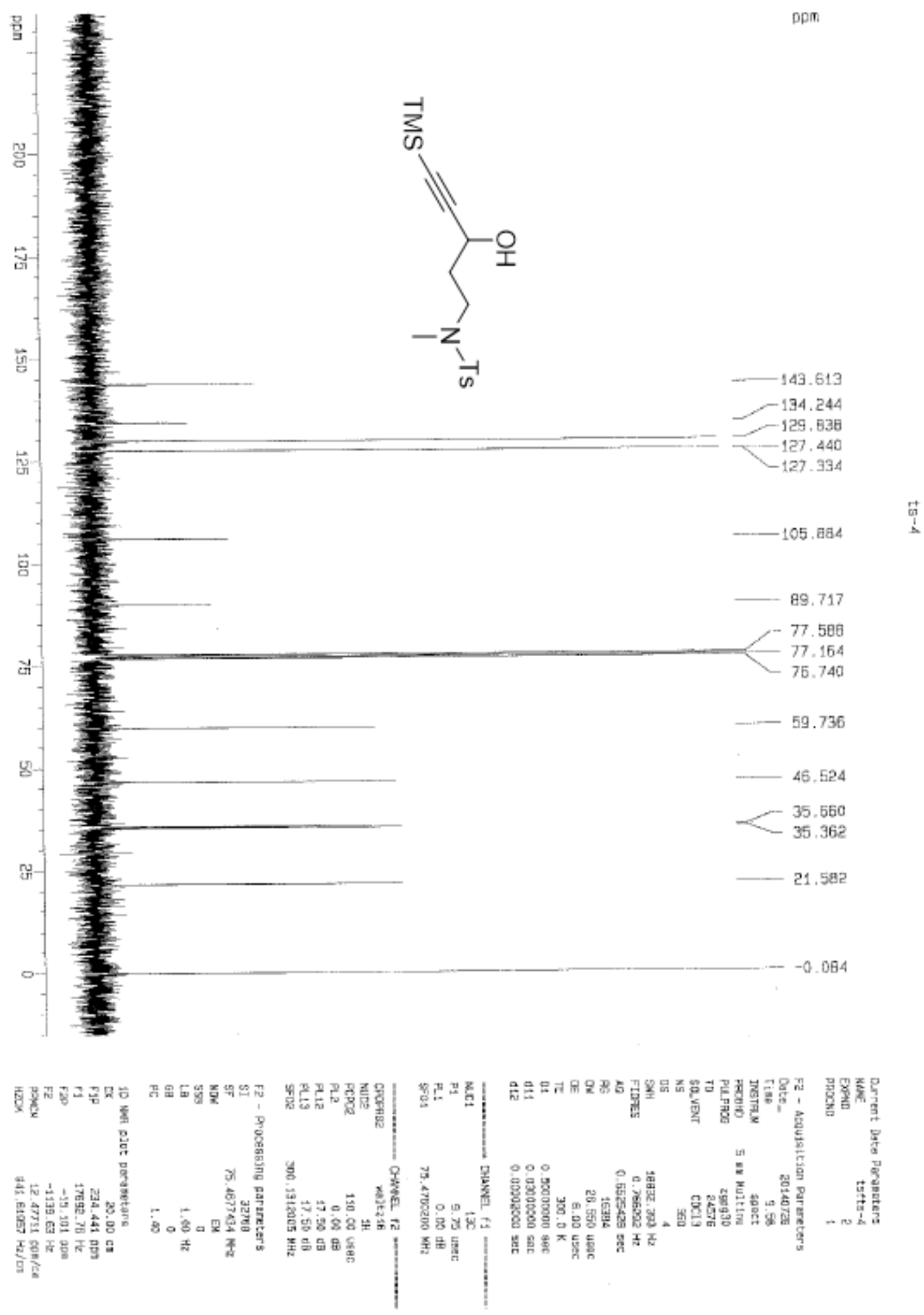


26b, ${ }^{1} \mathrm{H}$ NMR

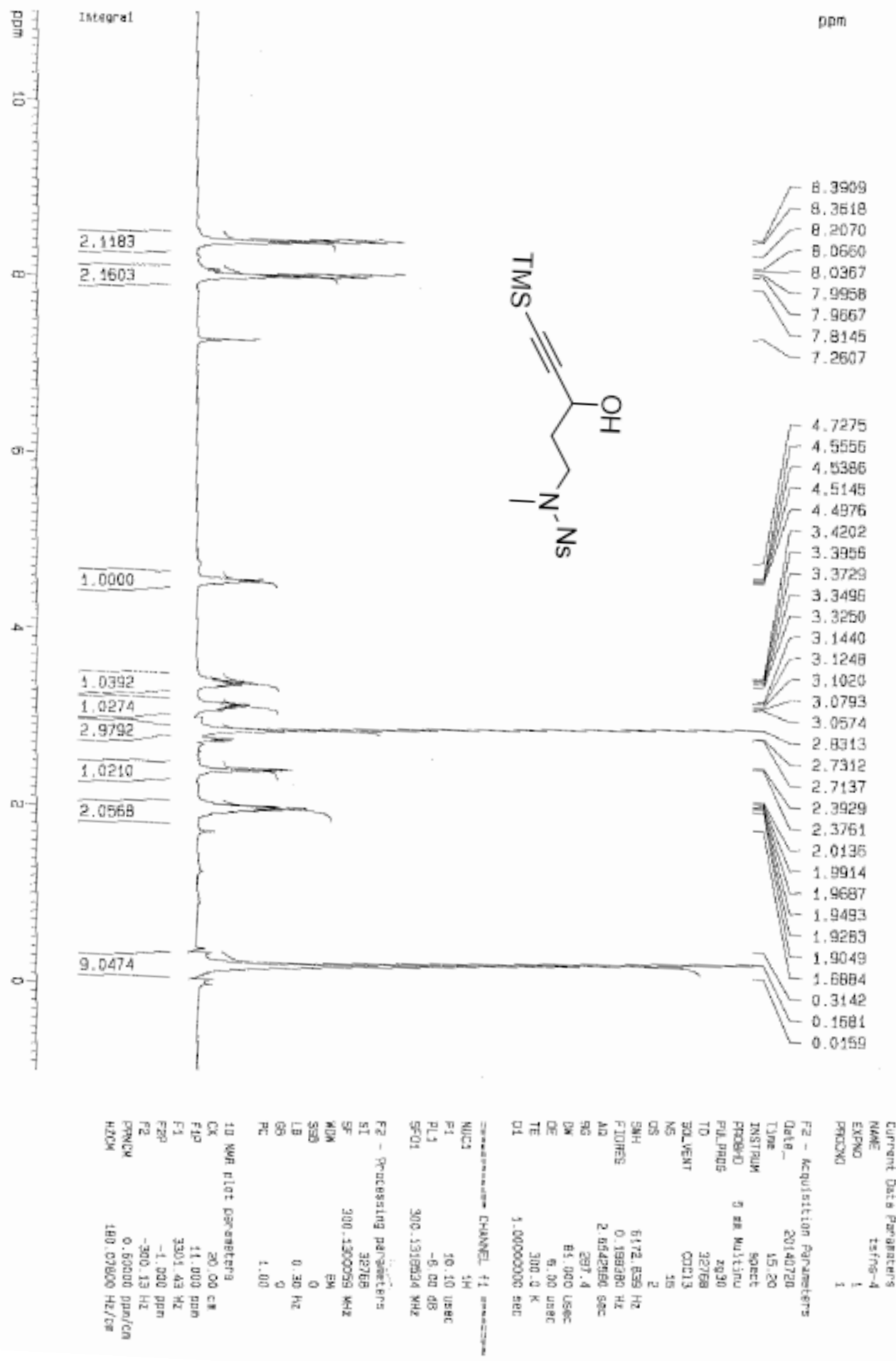


26b, ${ }^{13} \mathrm{C}$ NMR

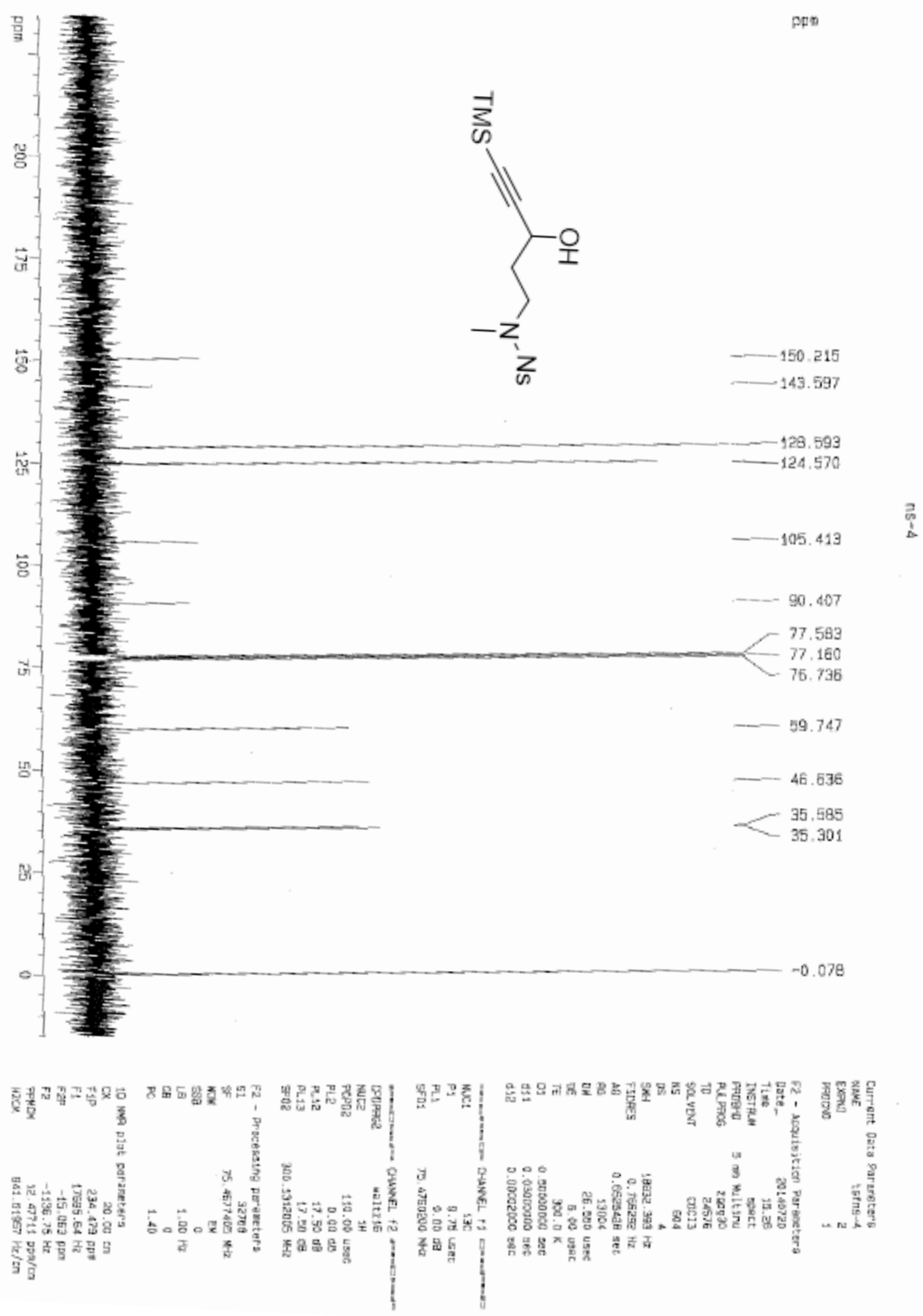




\section{7a, ${ }^{1} \mathrm{H}$ NMR}

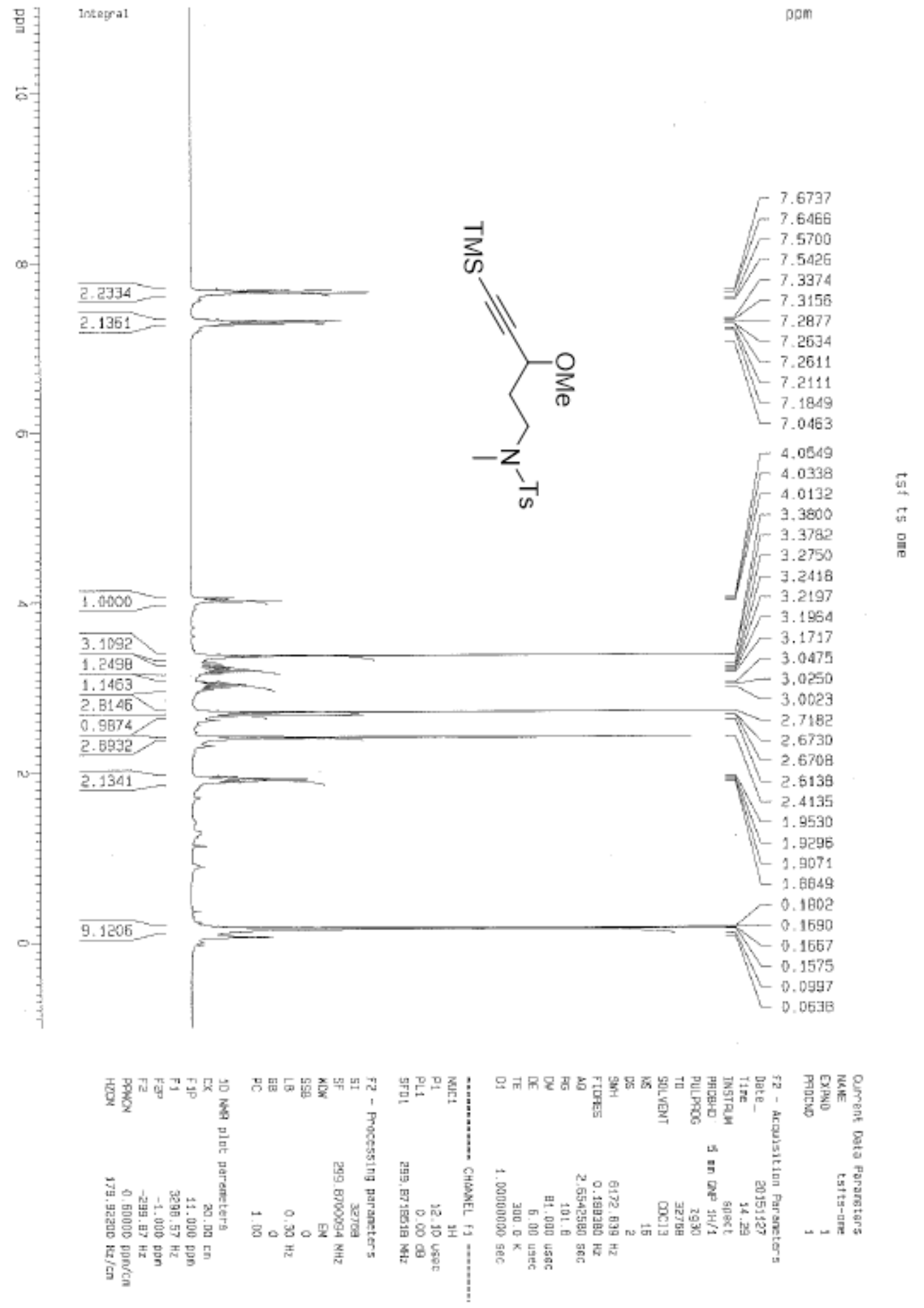


27a, ${ }^{13} \mathrm{C}$ NMR

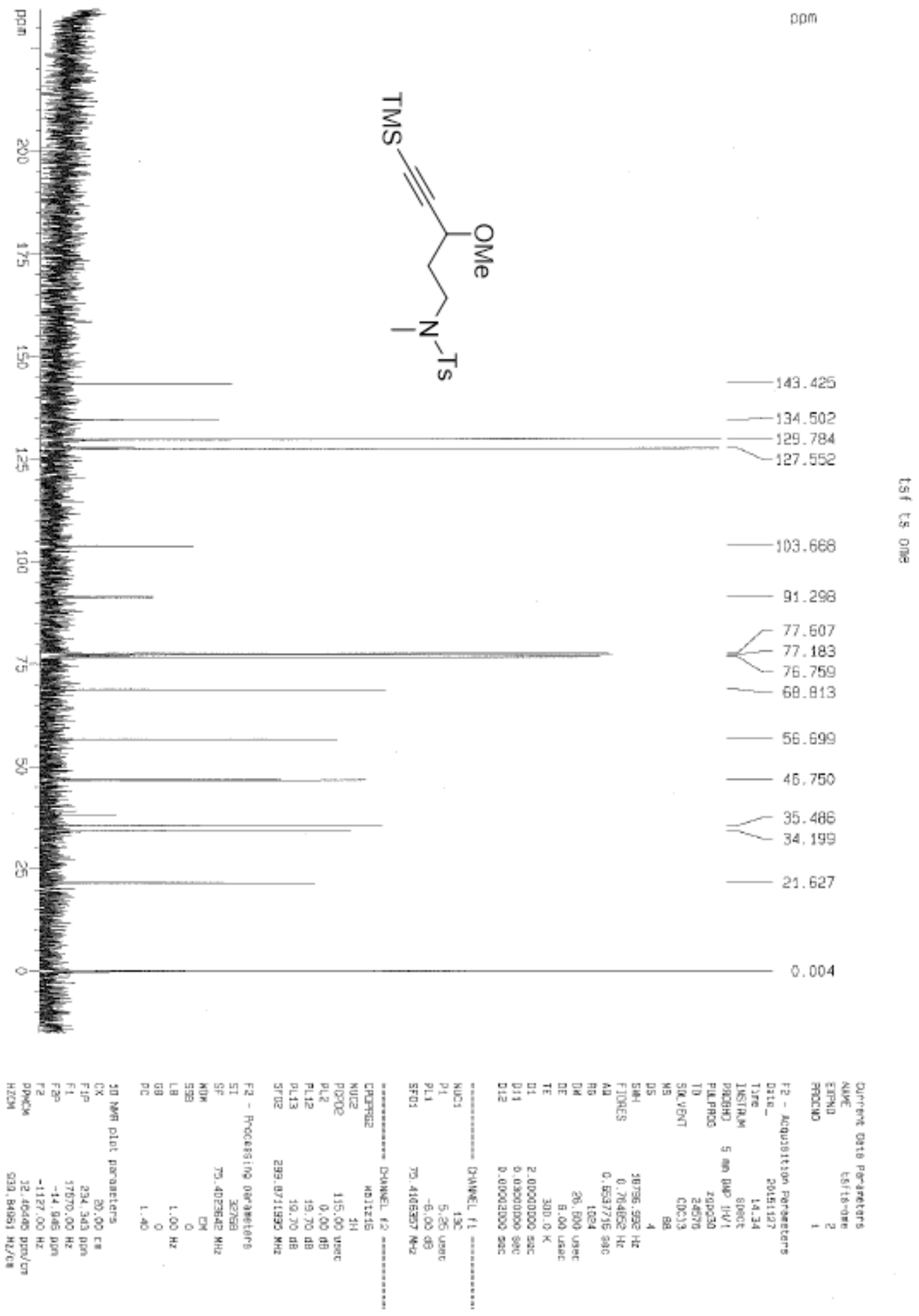


27b, ${ }^{1} \mathrm{H}$ NMR, Method A

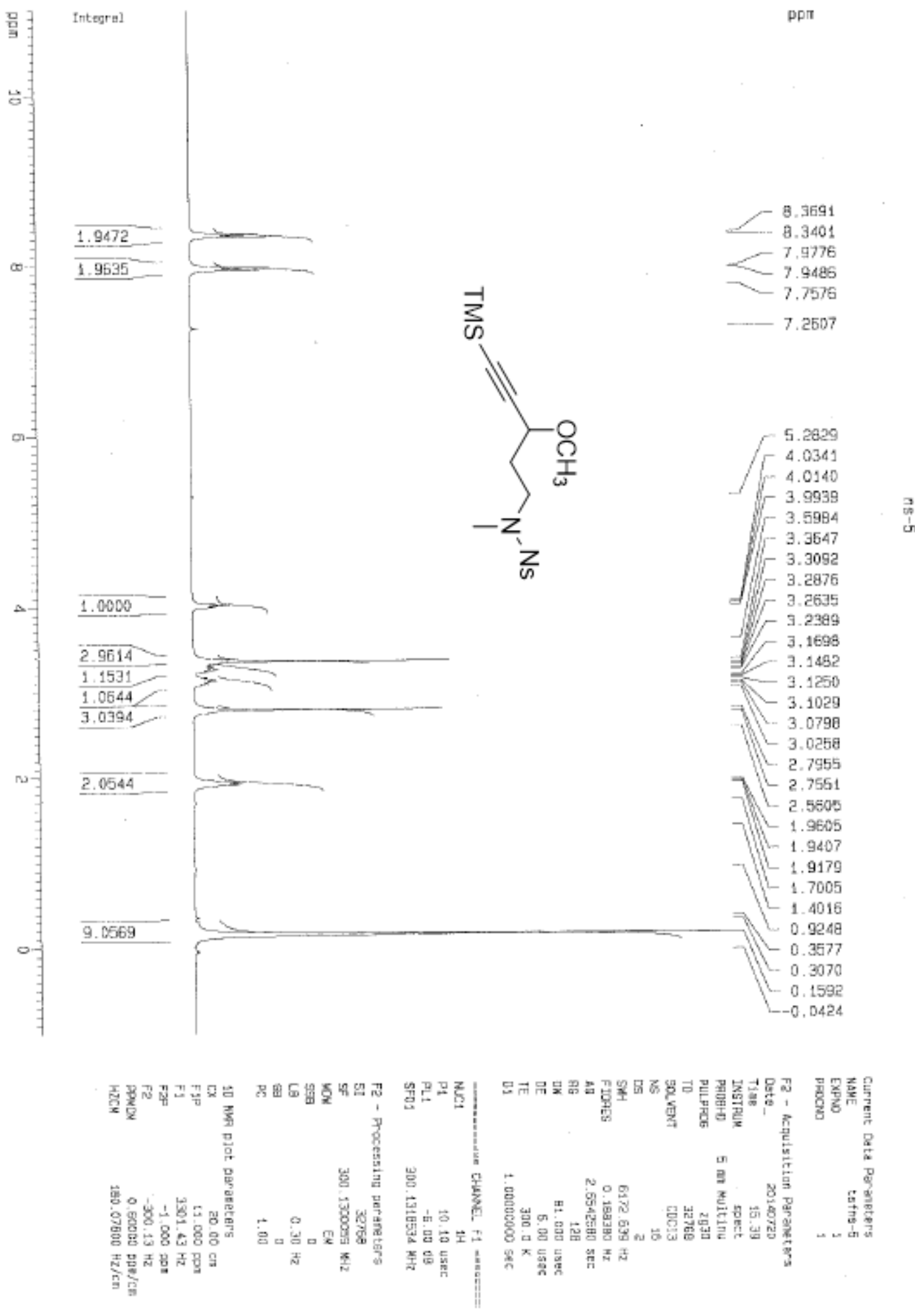


27b,${ }^{13}$ C NMR, Method A
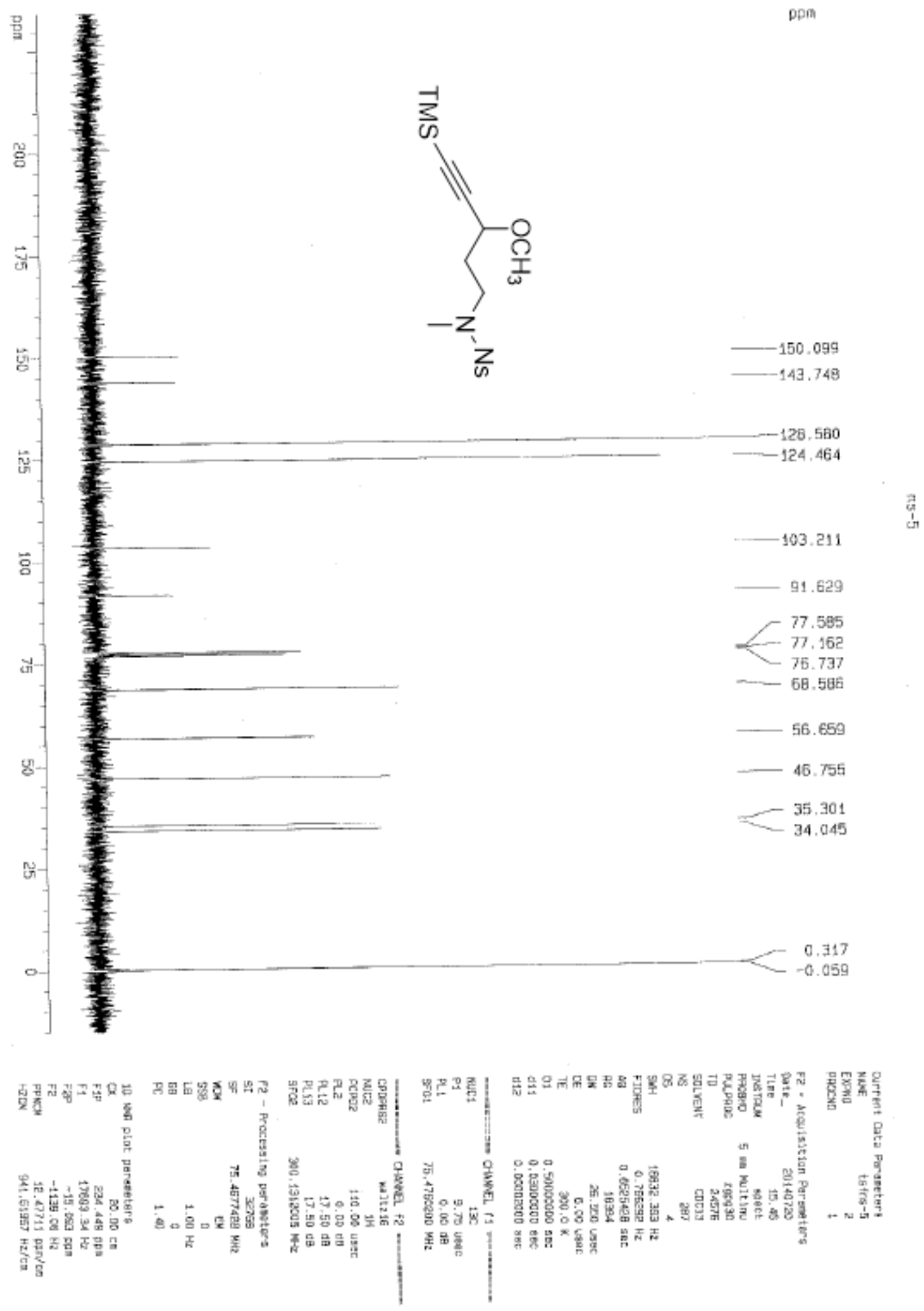
28a, ${ }^{1} \mathrm{H}$ NMR

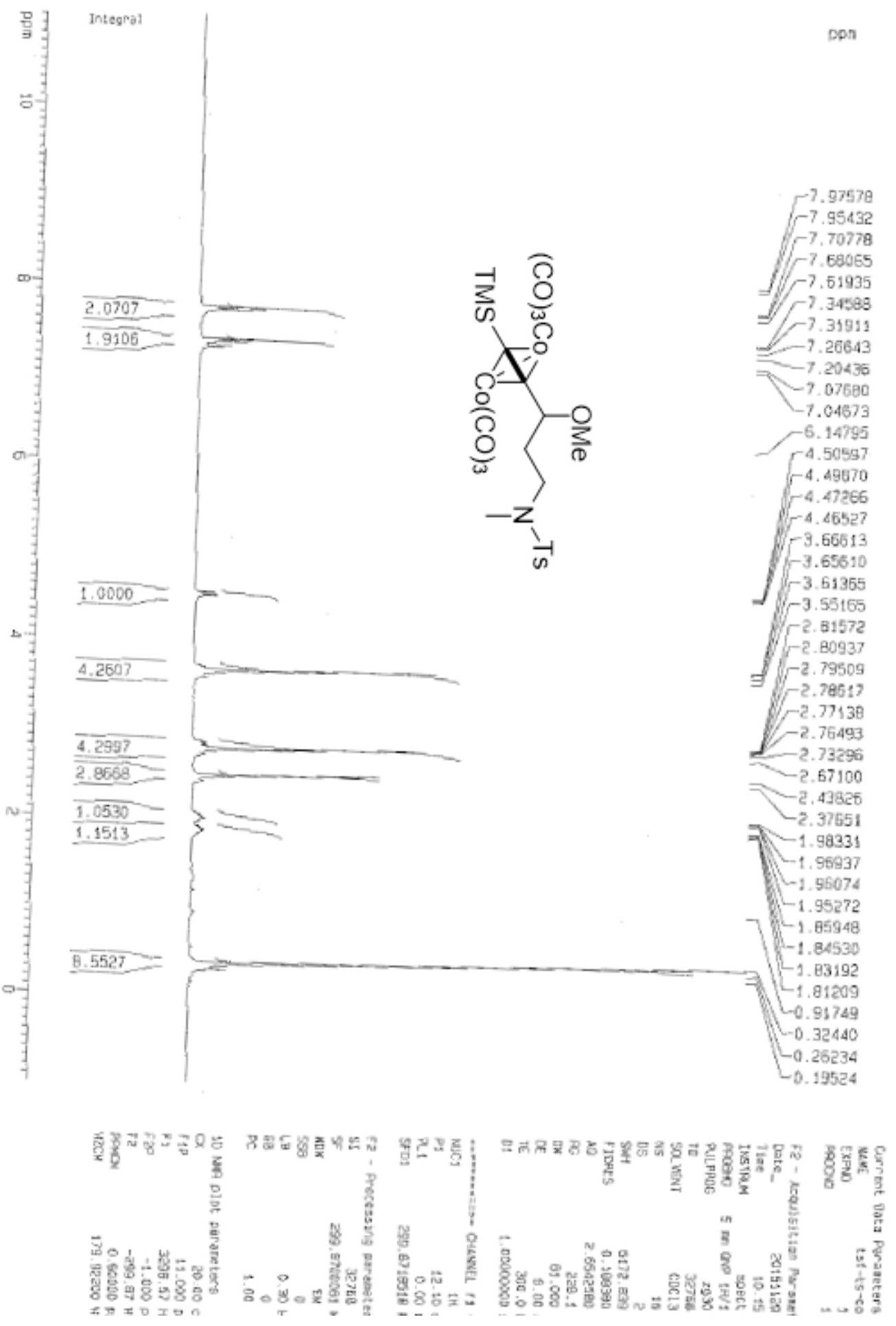


28a, ${ }^{13} \mathrm{C}$ NMR

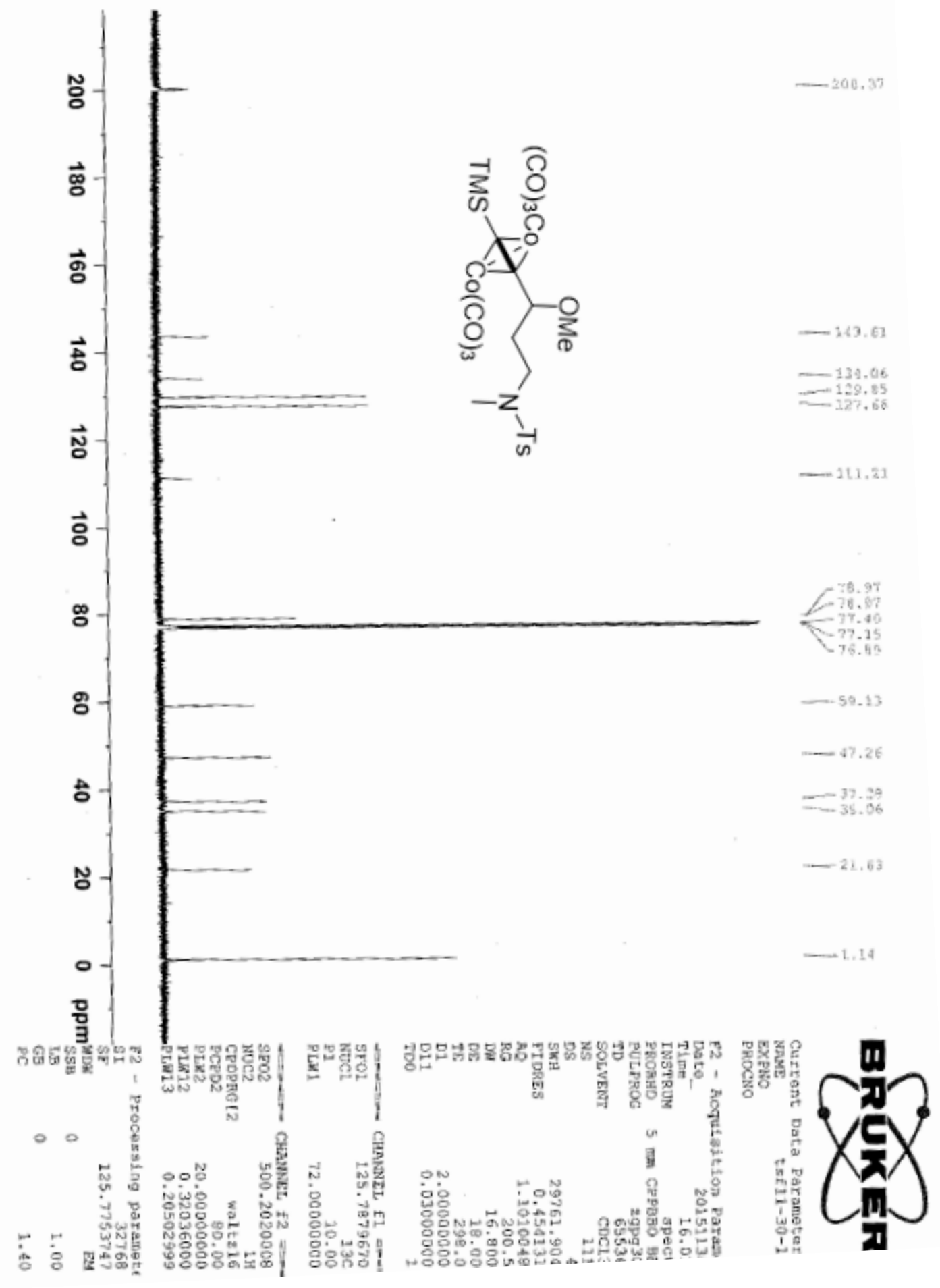




\section{8b, ${ }^{1} \mathrm{H}$ NMR}

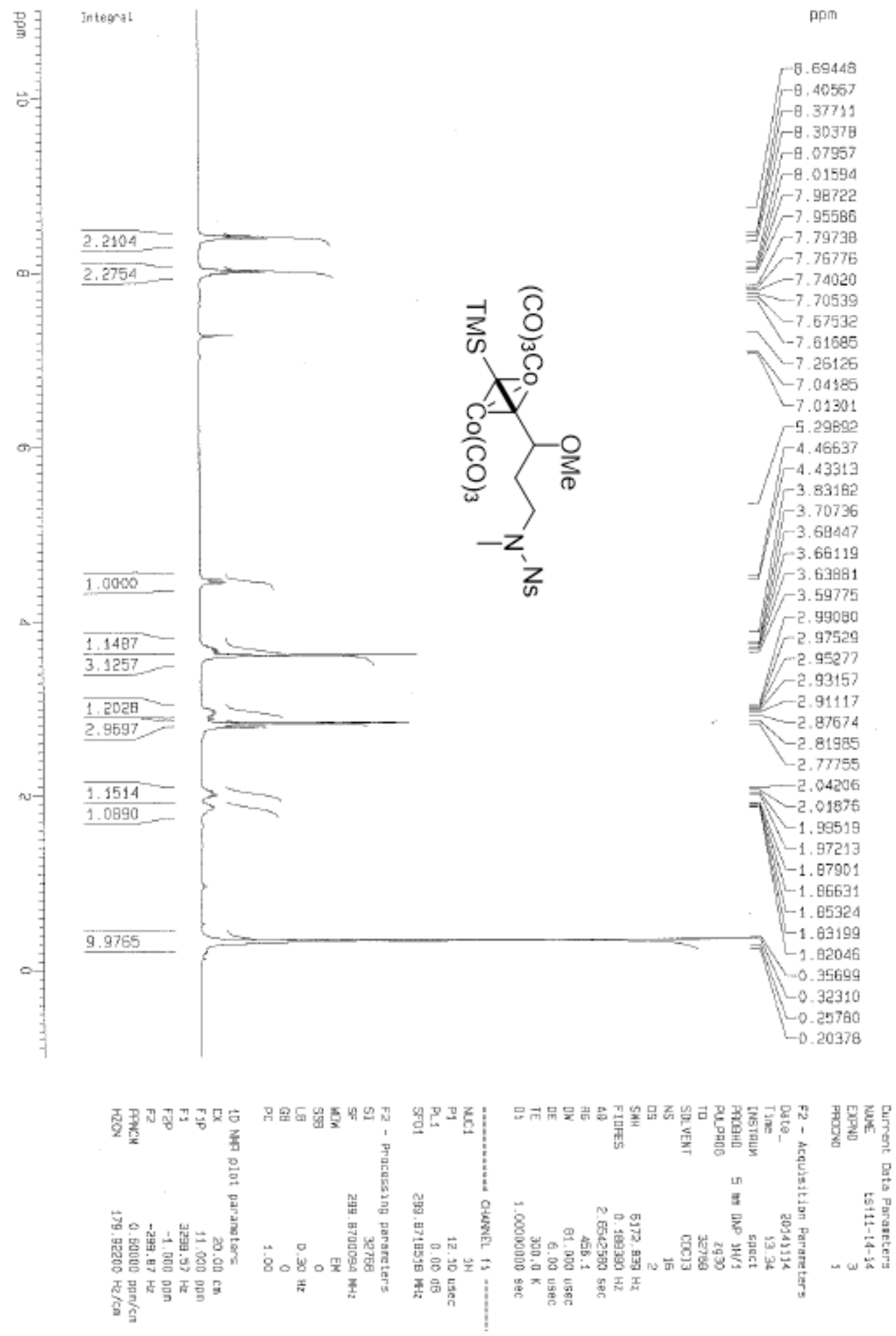


28b, ${ }^{13} \mathrm{C}$ NMR
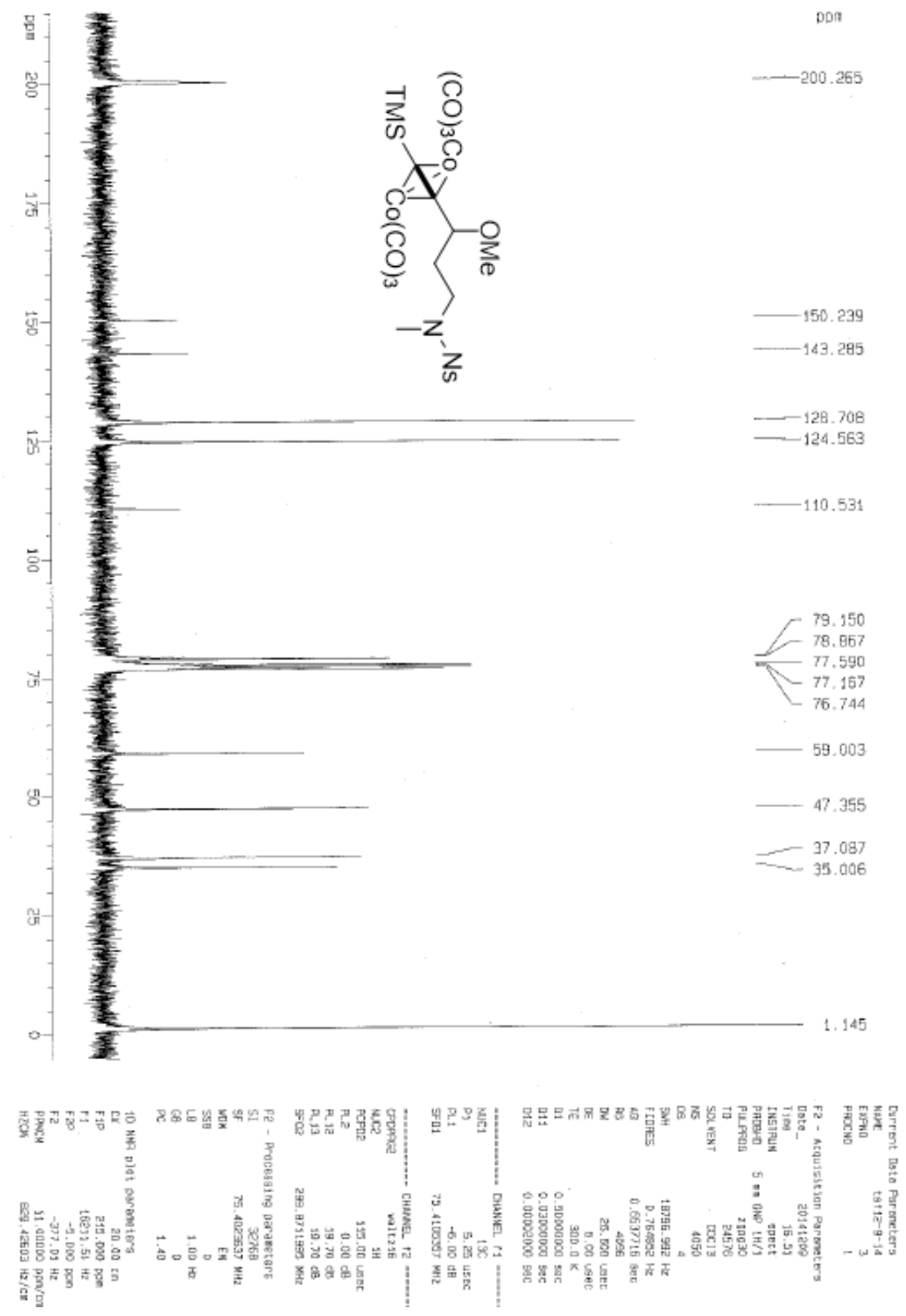
30a, ${ }^{1} \mathrm{H}$ NMR

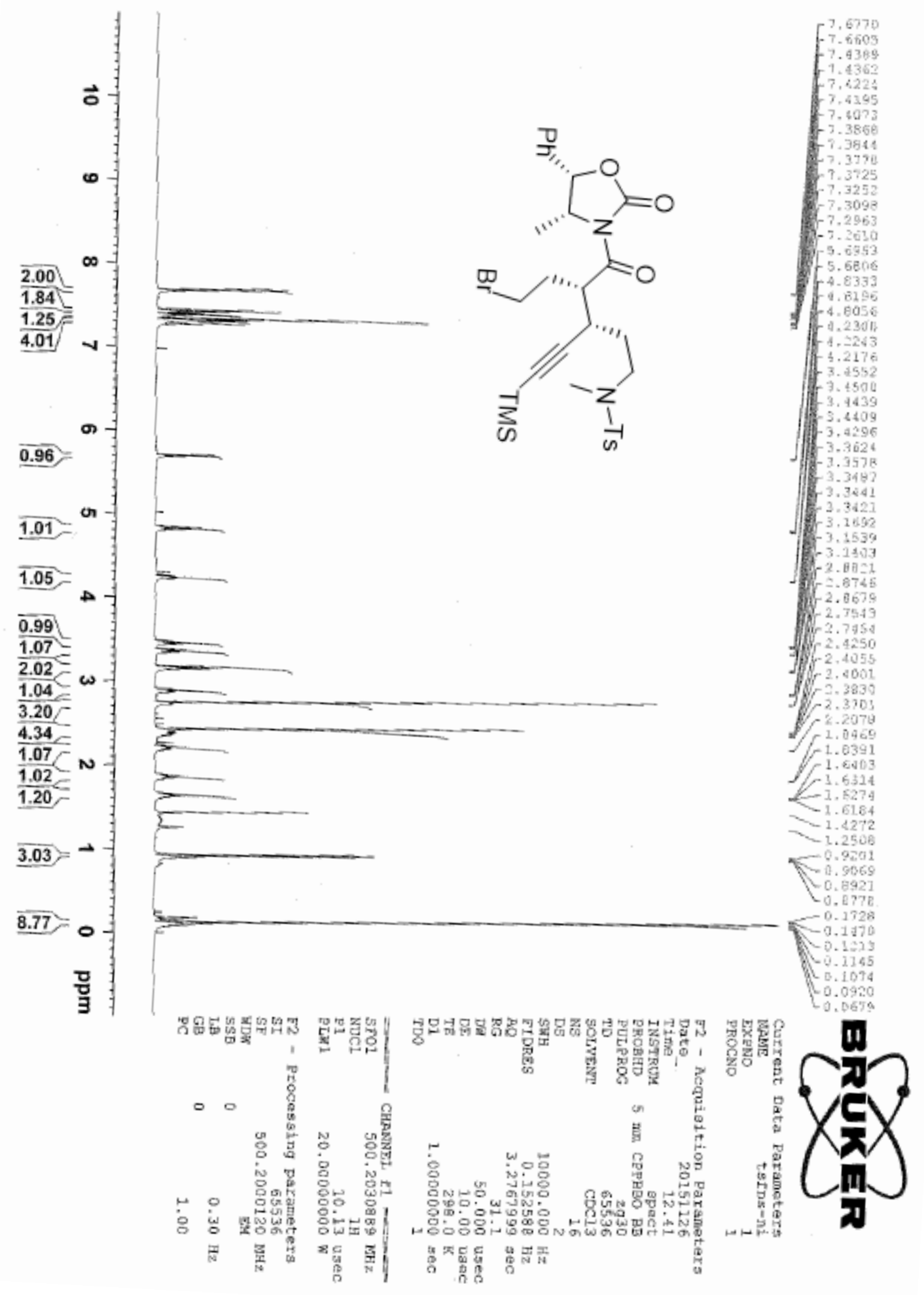


30a, ${ }^{13} \mathrm{C}$ NMR
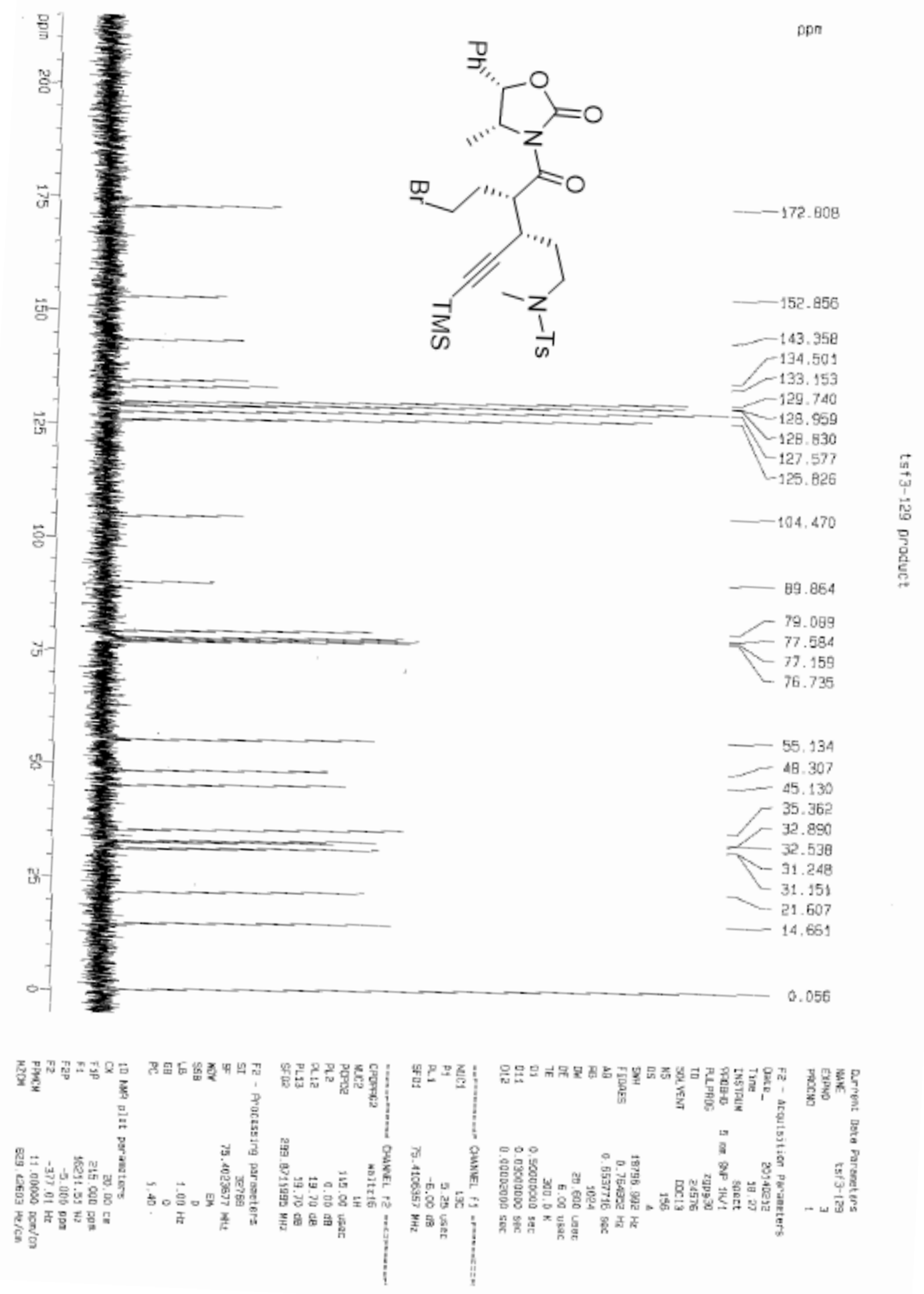
31a, ${ }^{1} \mathrm{H}$ NMR

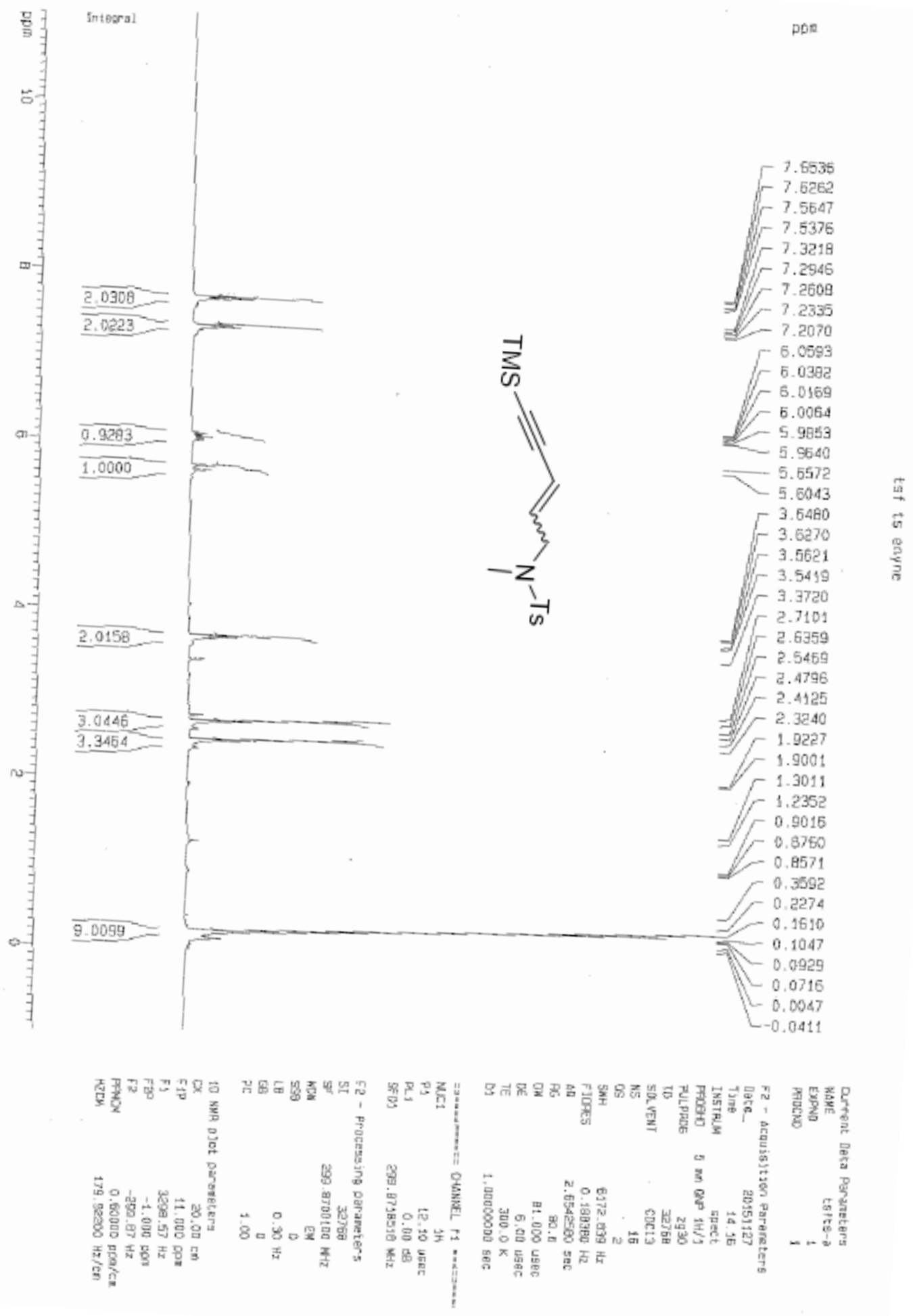


31a, ${ }^{13} \mathrm{C}$ NMR
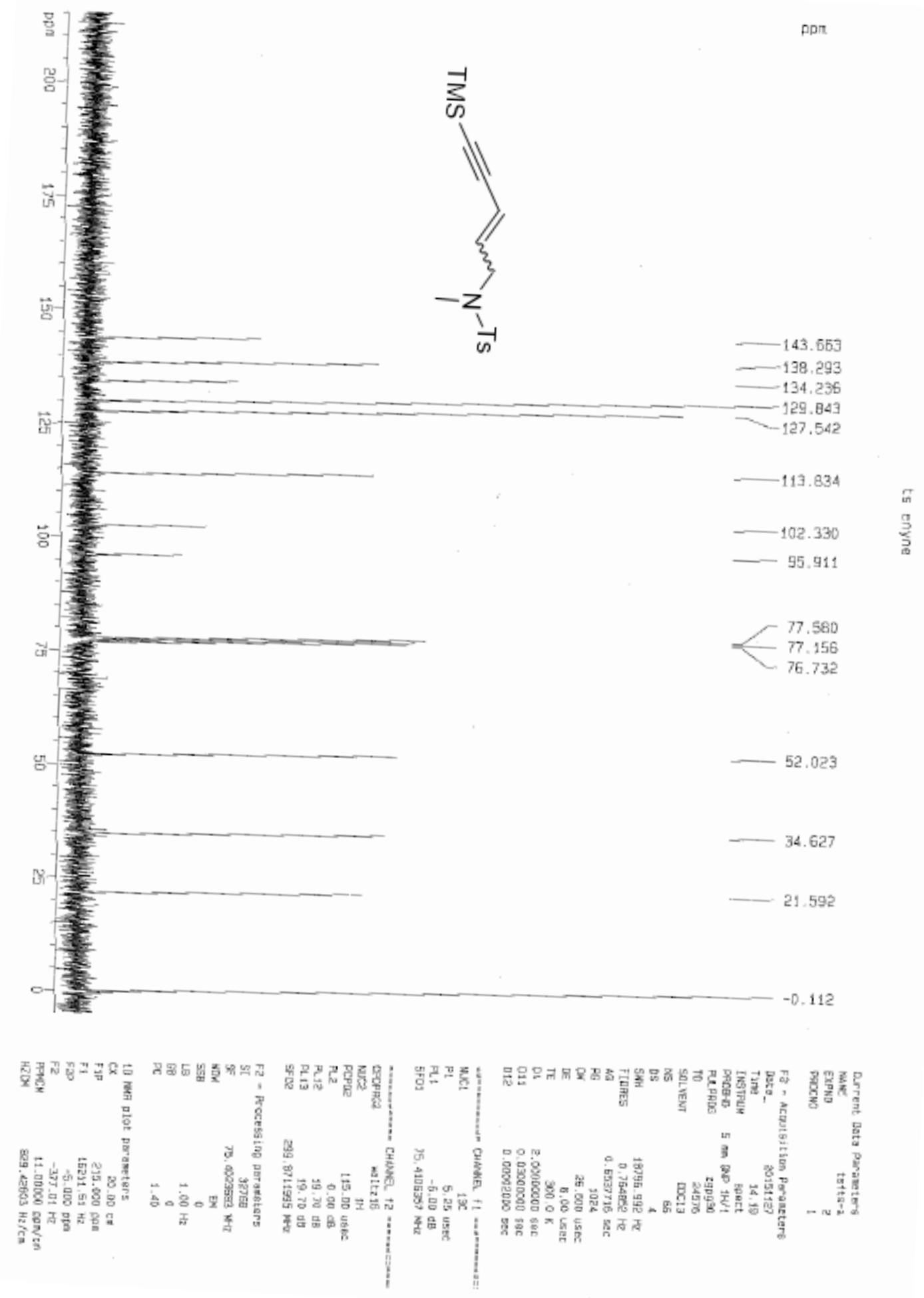
32a, ${ }^{1} \mathrm{H}$ NMR

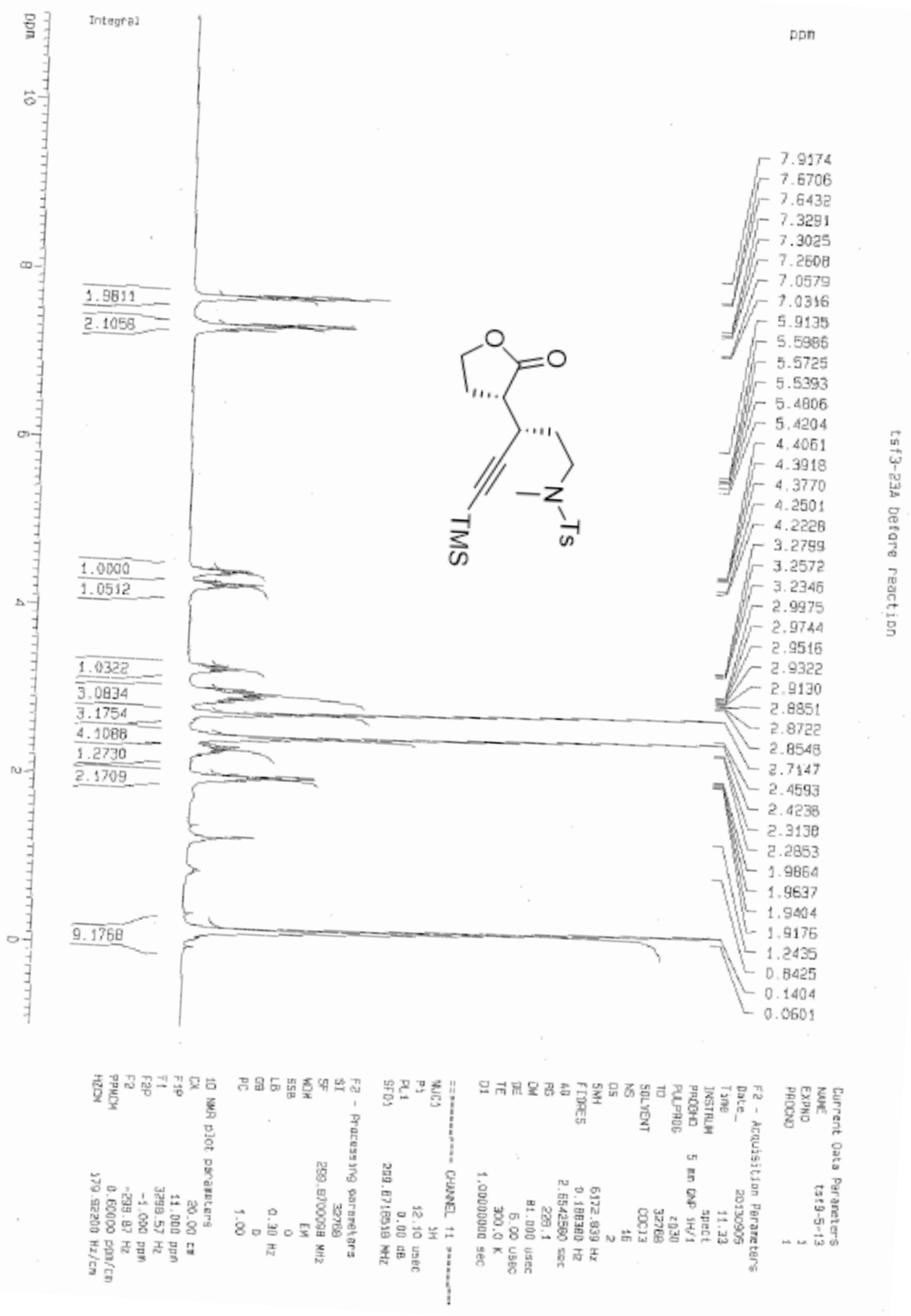


32a, ${ }^{13} \mathrm{C}$ NMR

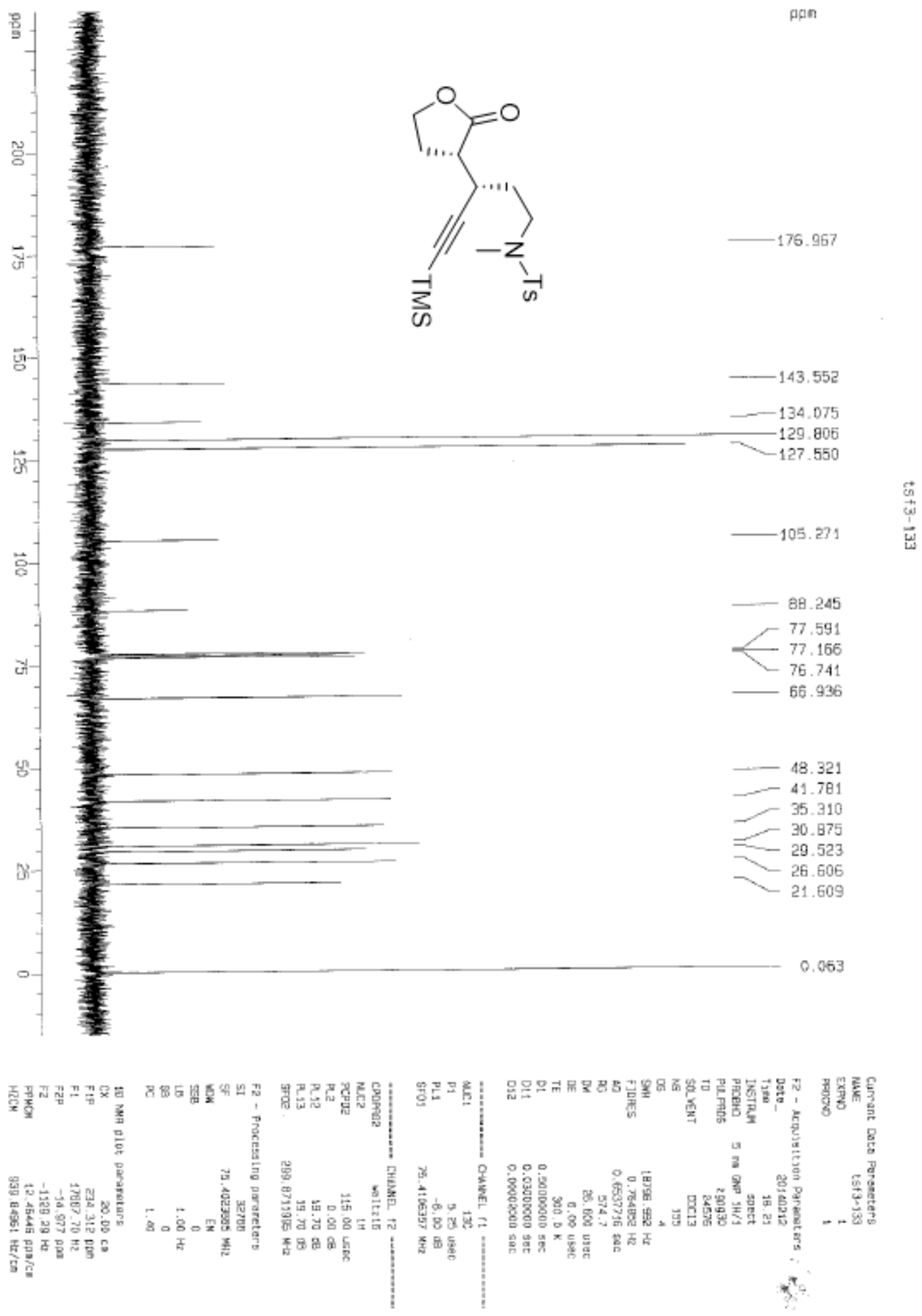


30b, ${ }^{1} \mathrm{H}$ NMR

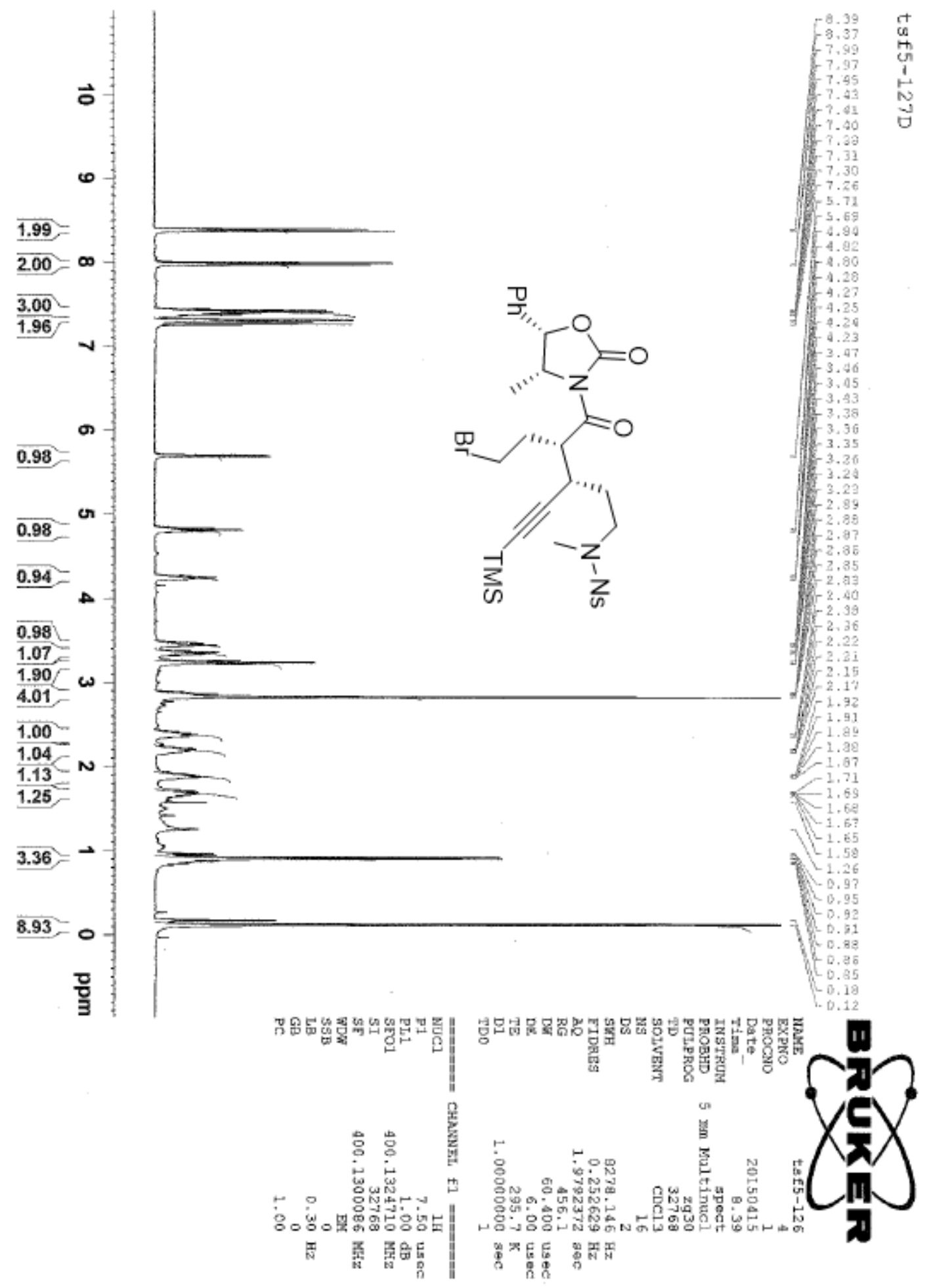


30b, ${ }^{13} \mathrm{C}$ NMR

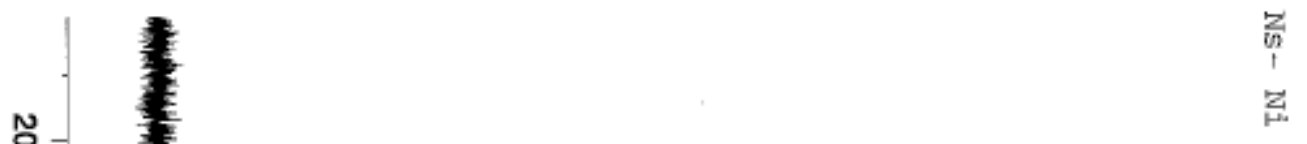

$-172,65$

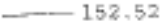

$\begin{array}{r}-152.52 \\ -\quad 150.07 \\ \hline\end{array}$

$\longrightarrow 143.49$

D

-

-

-

$\frac{0}{2}$

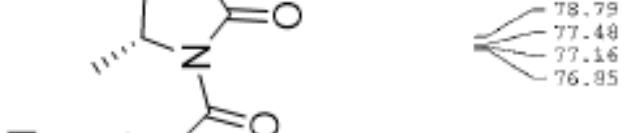

g

ㅁ. $-133.13$

-128.72
-178.49

$-125.59$

$-104.81$

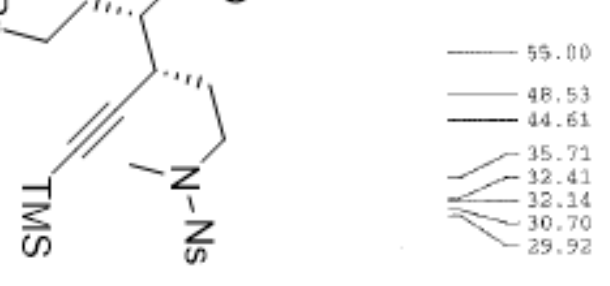

ำ

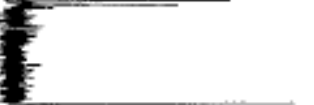

14.58
$=13.89$

○

물

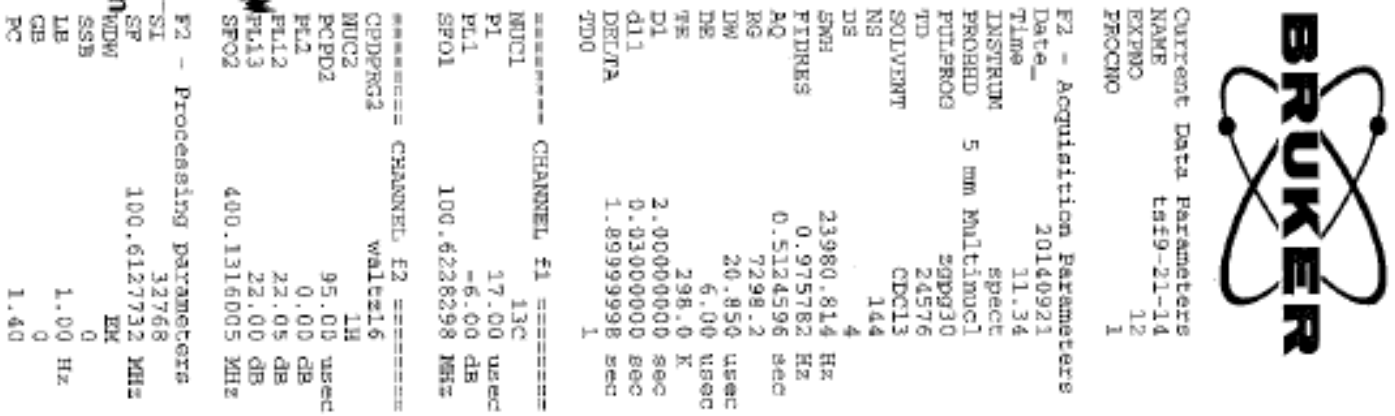


30c, ${ }^{1} \mathrm{H}$ NMR

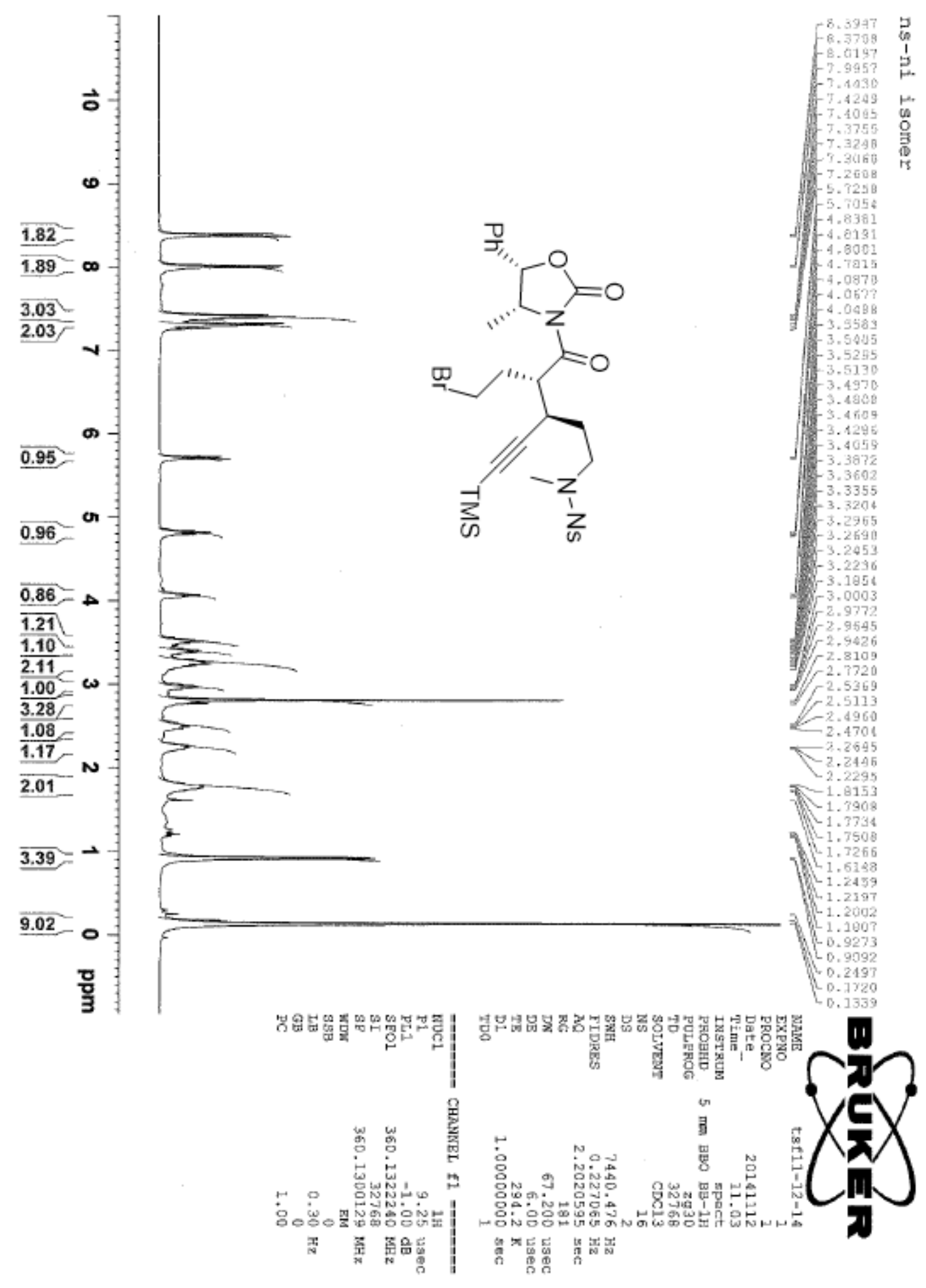


30c, ${ }^{13} \mathrm{C}$ NMR
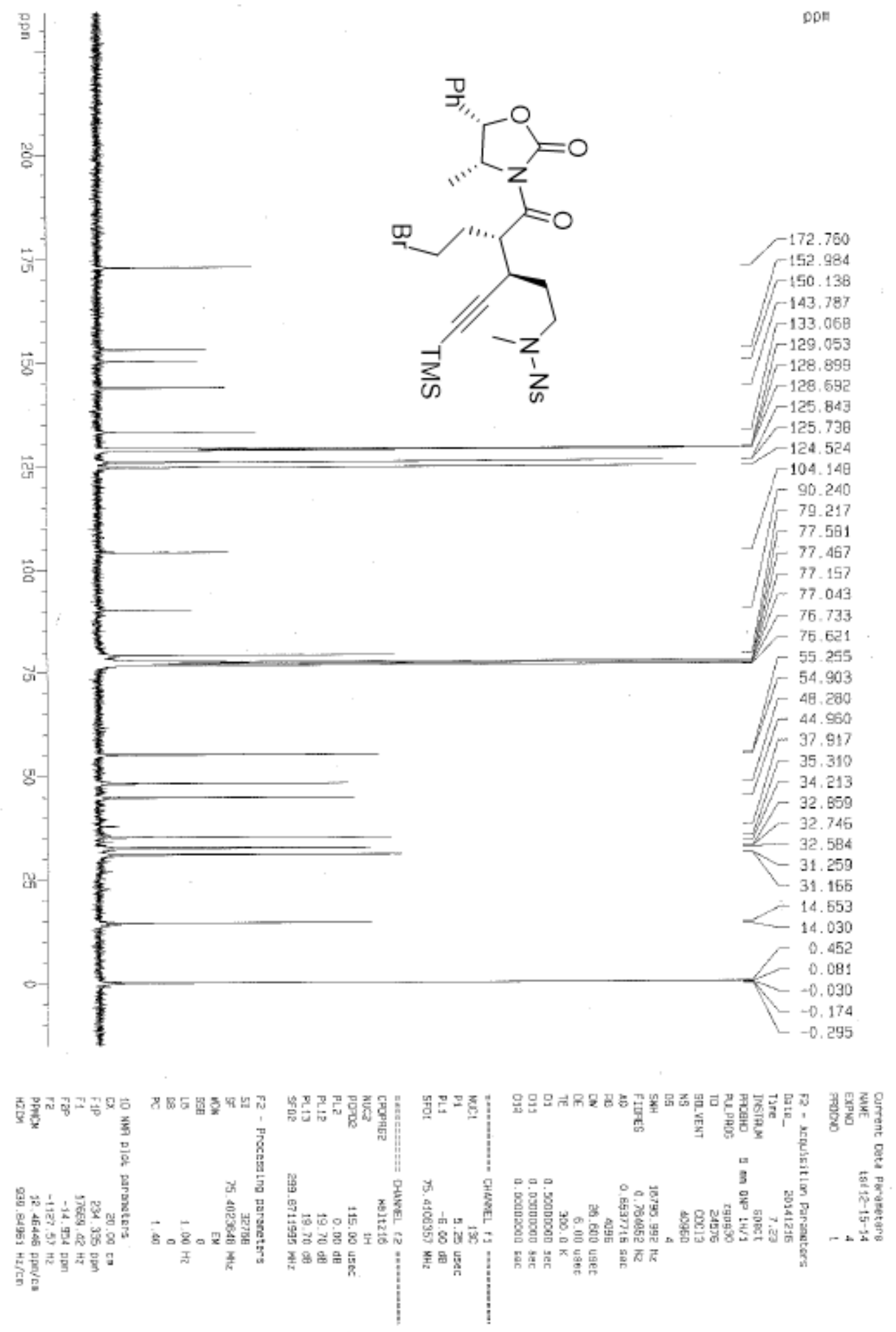
32b, ${ }^{1} \mathrm{H}$ NMR

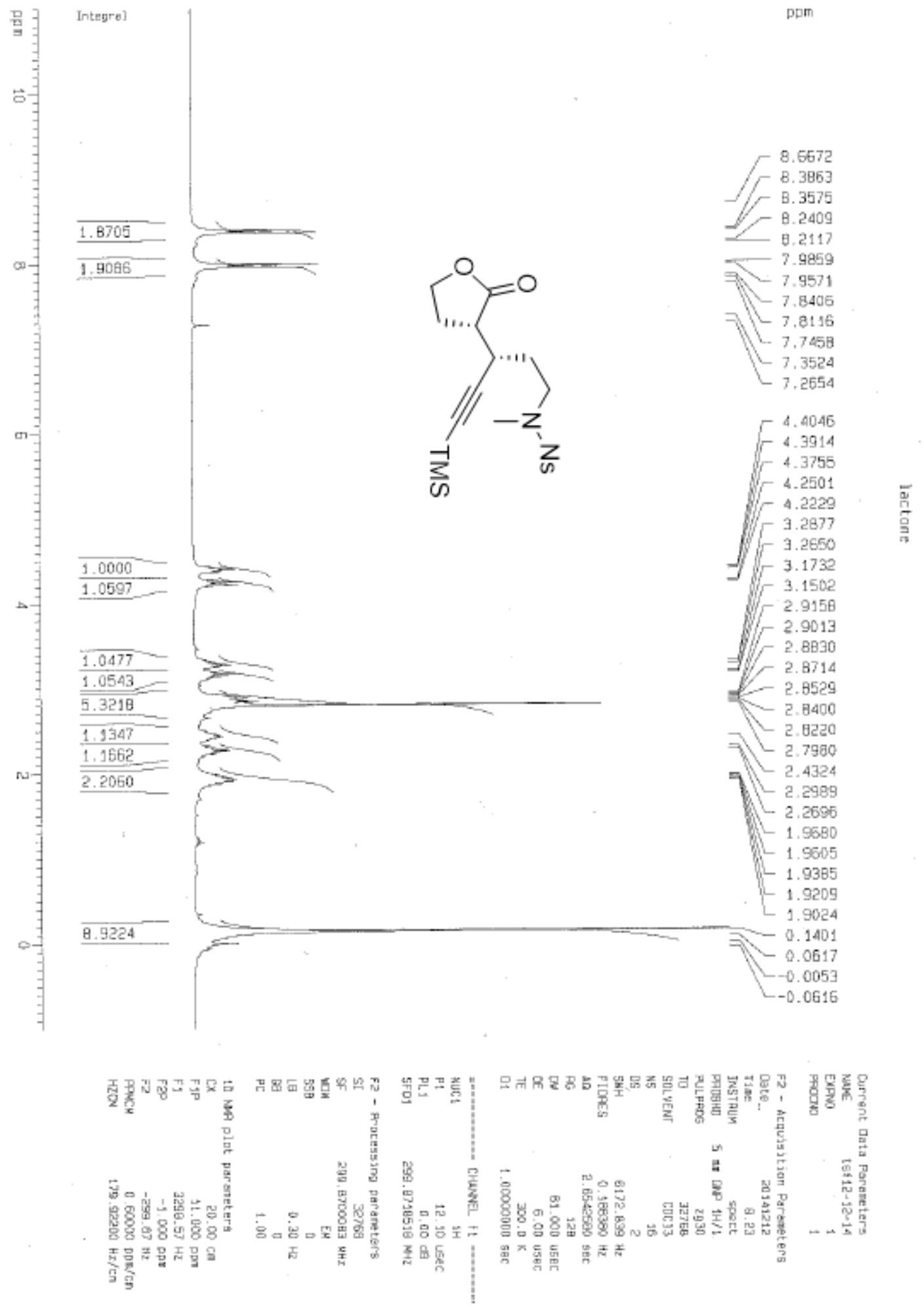


32b, ${ }^{13} \mathrm{C}$ NMR
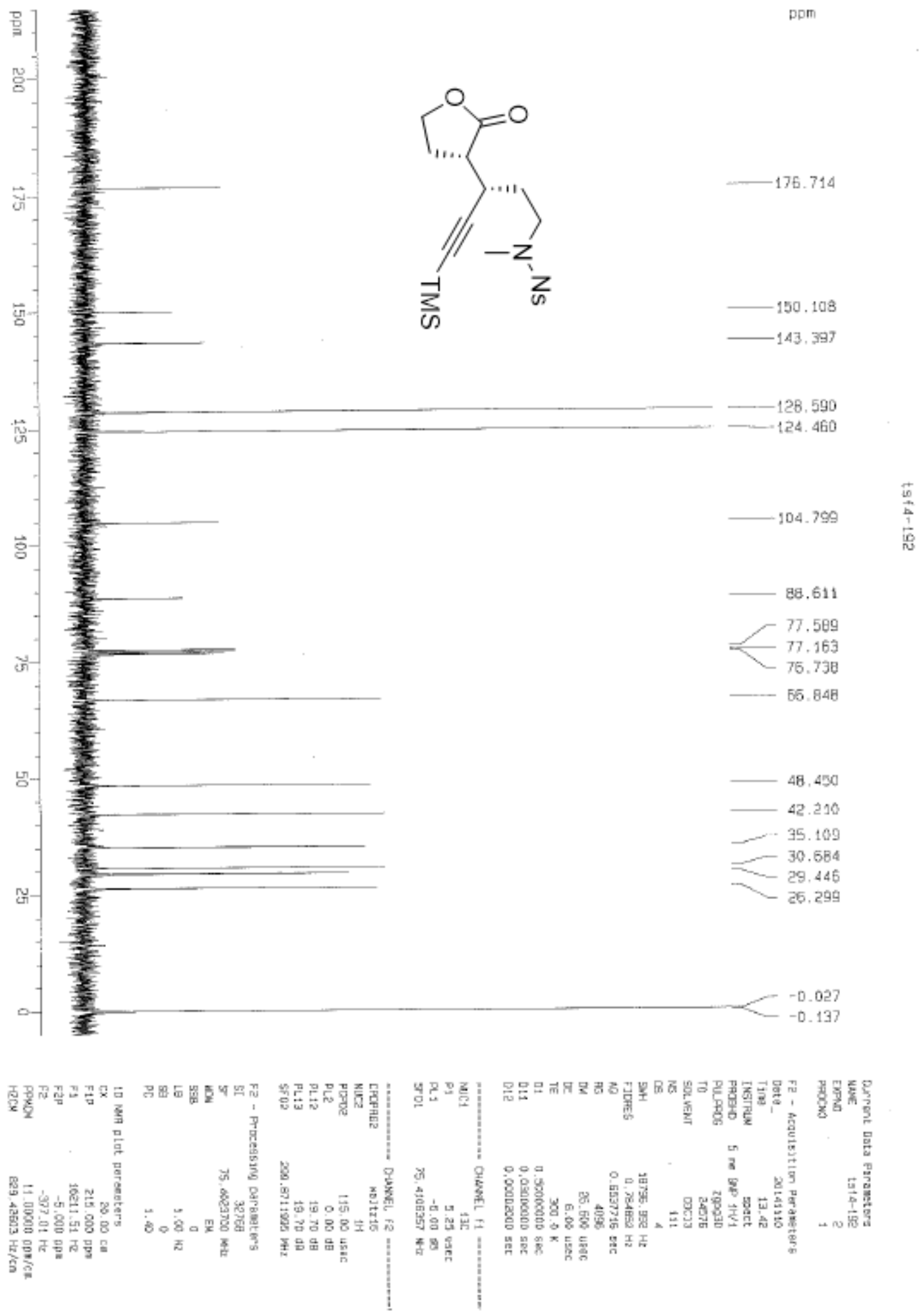


\section{4, ${ }^{1} \mathrm{H}$ NMR}

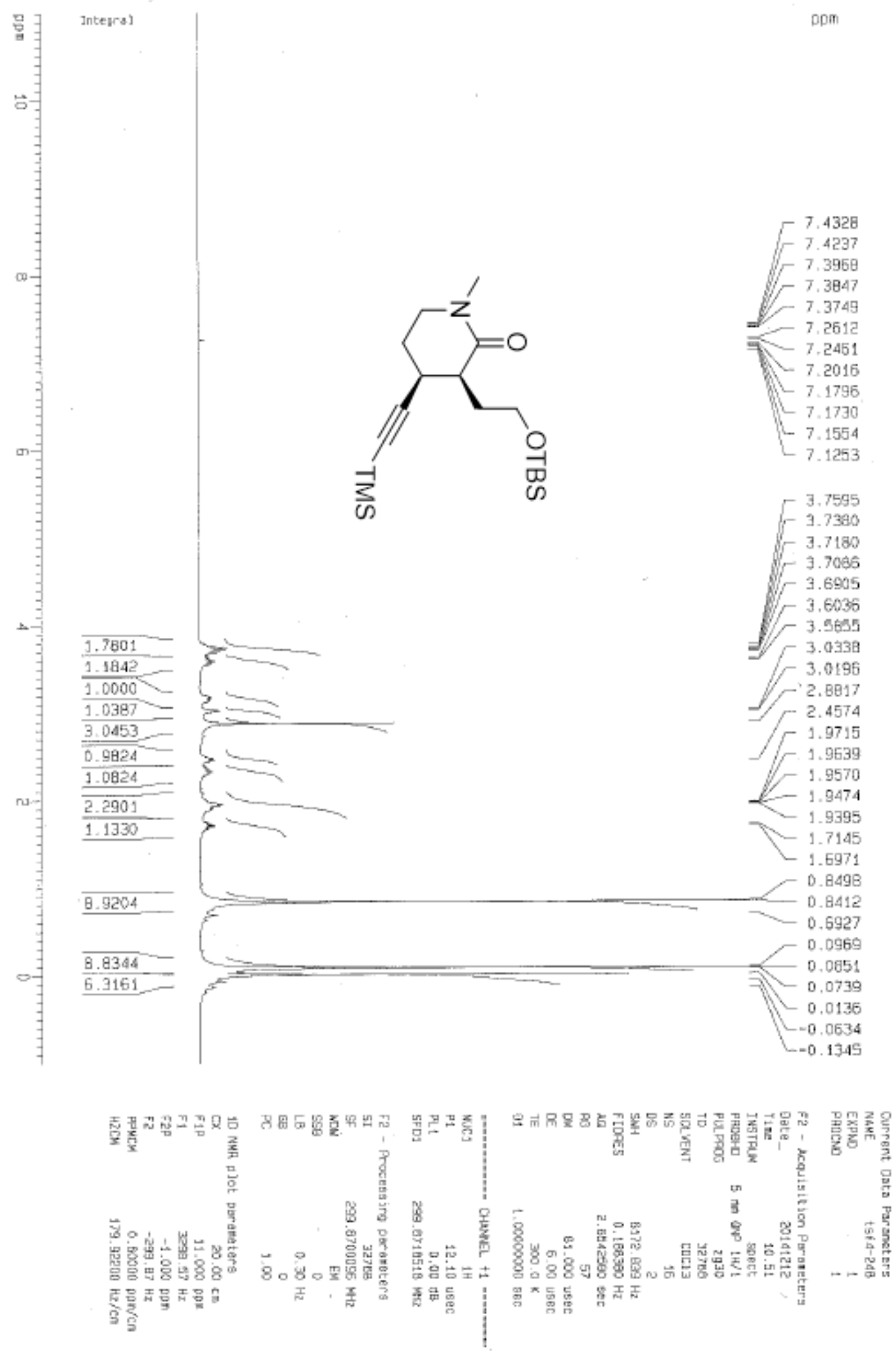


34, ${ }^{13} \mathrm{C}$ NMR

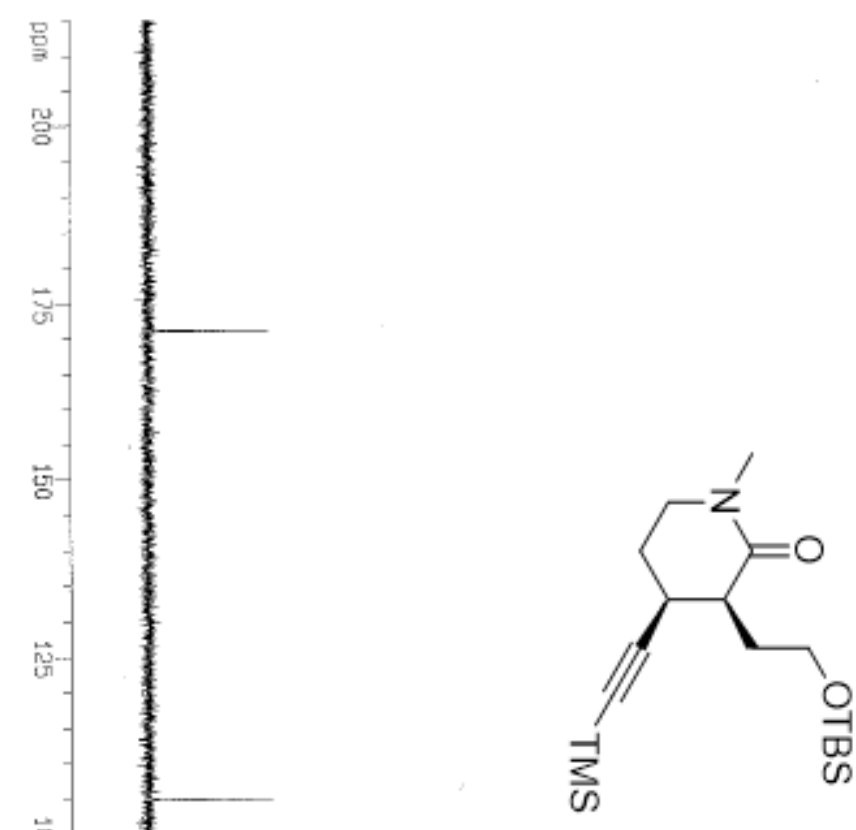

ppm

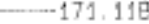

iे

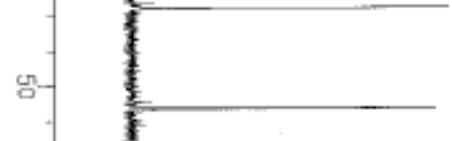

䍐

心

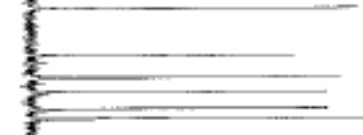

$-104.823$

- 88.520

- 77.579

$-77.153$

$-76.729$

$-76.586$

ᄃ 51.684

$=-51.042$

$\int_{-45.790} 47.720$

$\int / 41.478$

r 34.816

$\int r^{31.674}$

$/ /-29.538$

29. 491

- 25.993

-24.846
-18.295

- 0.509

0.135
-0.012
-0.236
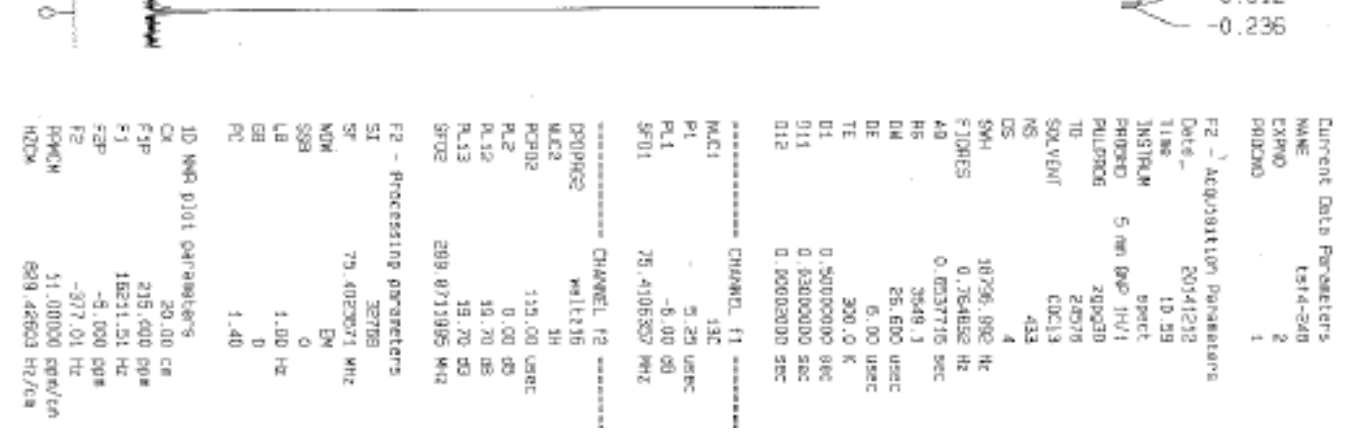
12, ${ }^{1} \mathrm{H}$ NMR

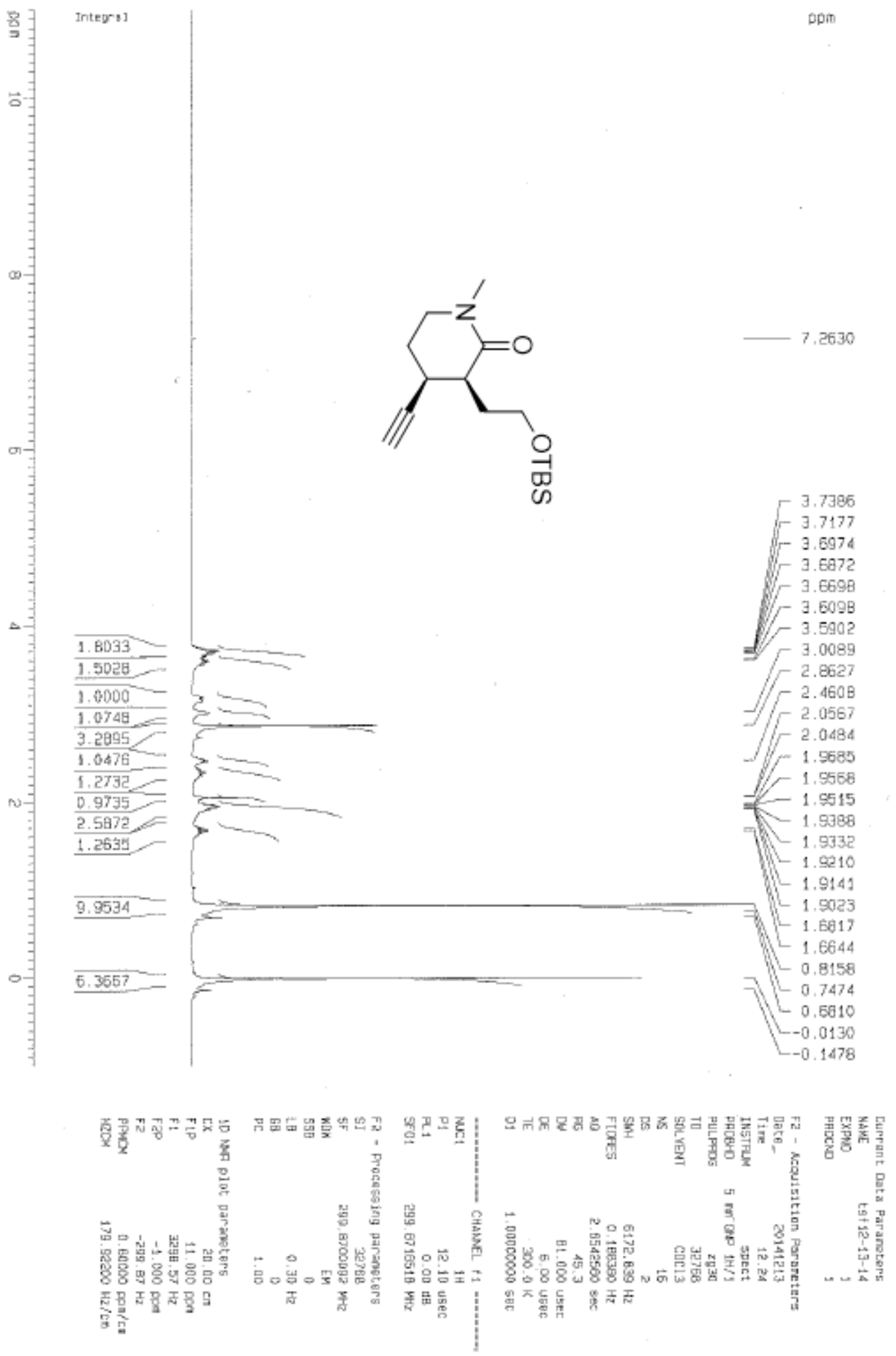




\section{2, ${ }^{13} \mathrm{C}$ NMR}

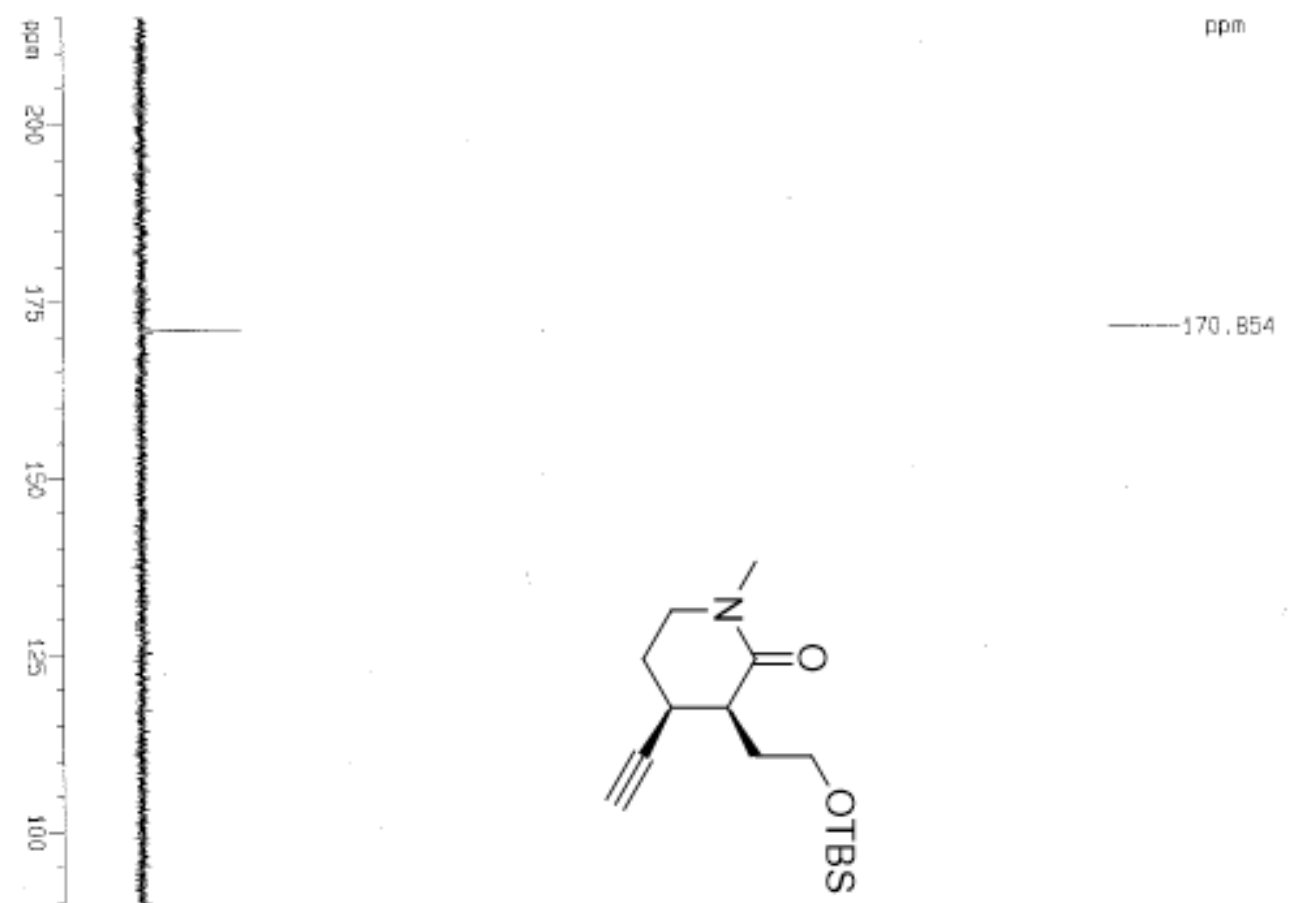

$-82.247$

$-77.5 \mathrm{B2}$

$=77.157$

$-76.732$

$-71.980$

- 60. 852

$\tau^{46.575}$

-41.121

- 40.989

r 34.769

- 31.482

- 31.354

-

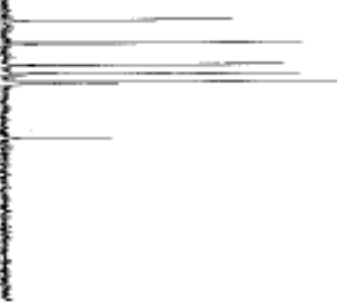

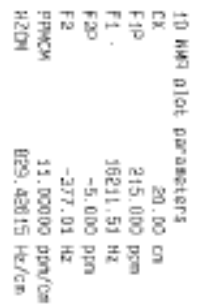

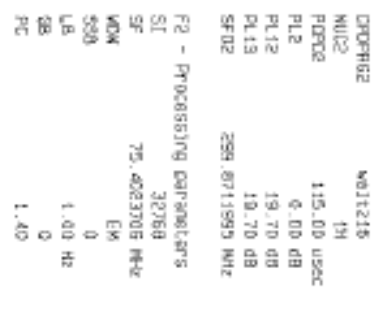

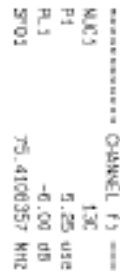

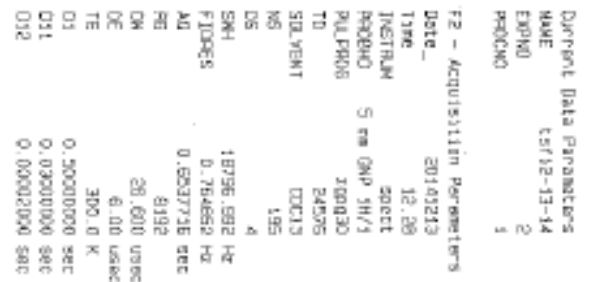




\section{5, ${ }^{1} \mathrm{H}$ NMR}

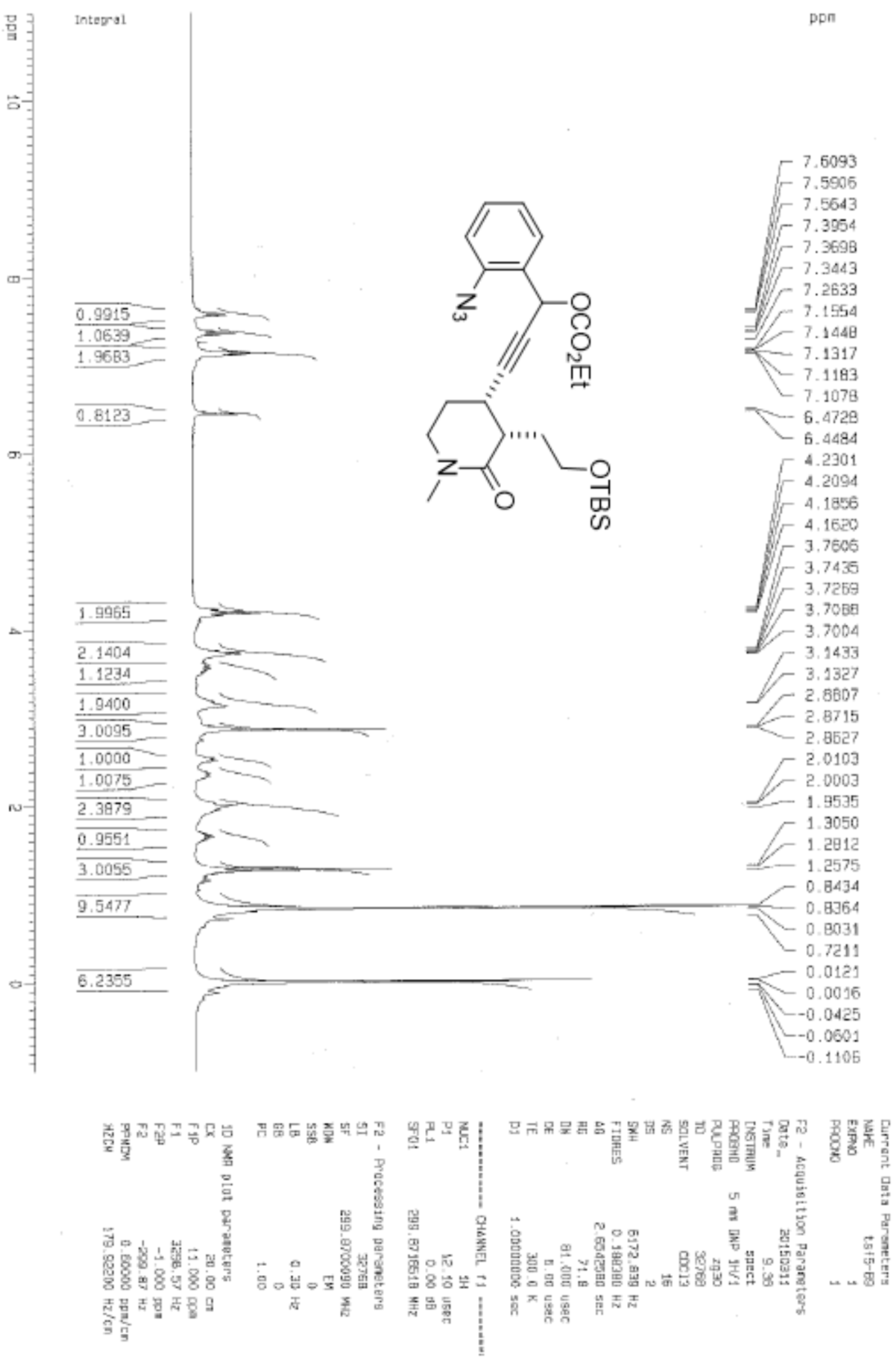




\section{5, ${ }^{13} \mathrm{C}$ NMR}

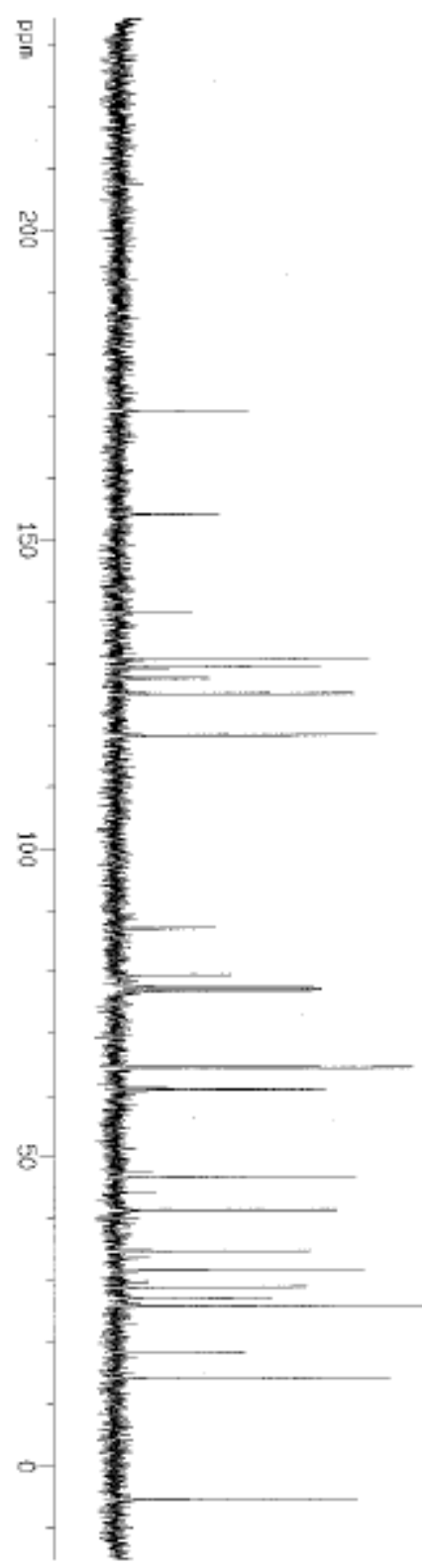

apm

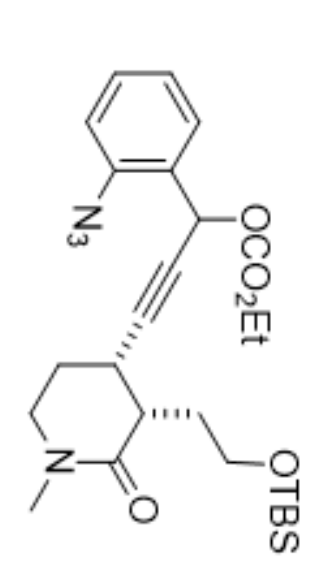

$-170.786$

$-154,019$

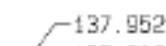

$-137.900$

$-130.606$

-129.387
-129.338

$-127.50$

$-125,05 \mathrm{E}$

$-118,302$

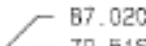

- 79.518

$-77.587$

$-77.166$

76.736 $-54.566$

$-64.482$

$-61.526$

$-60.912$

- 41.434

$-34.786$

- 31.720

$-27.228$

$-25.953$

$-18.255$

$-25.258$

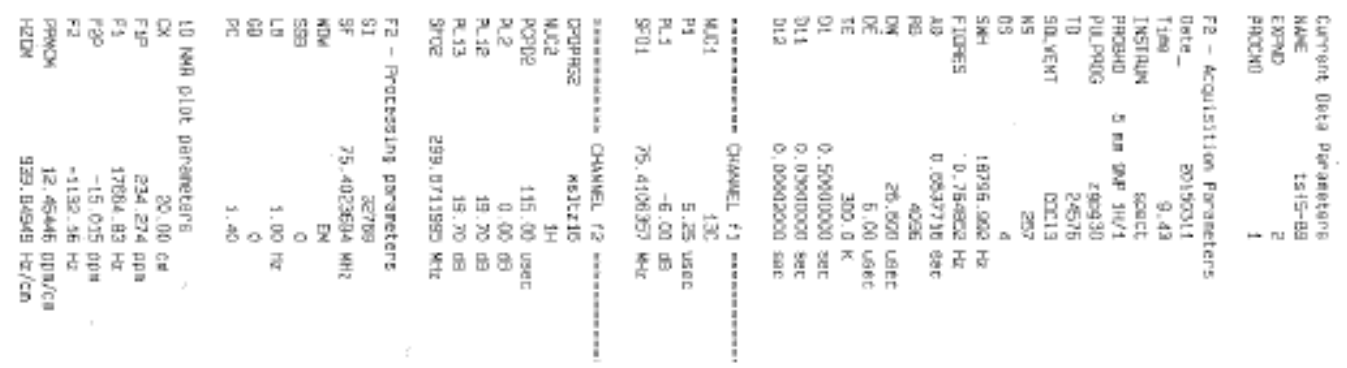


43, ${ }^{1} \mathrm{H}$ NMR

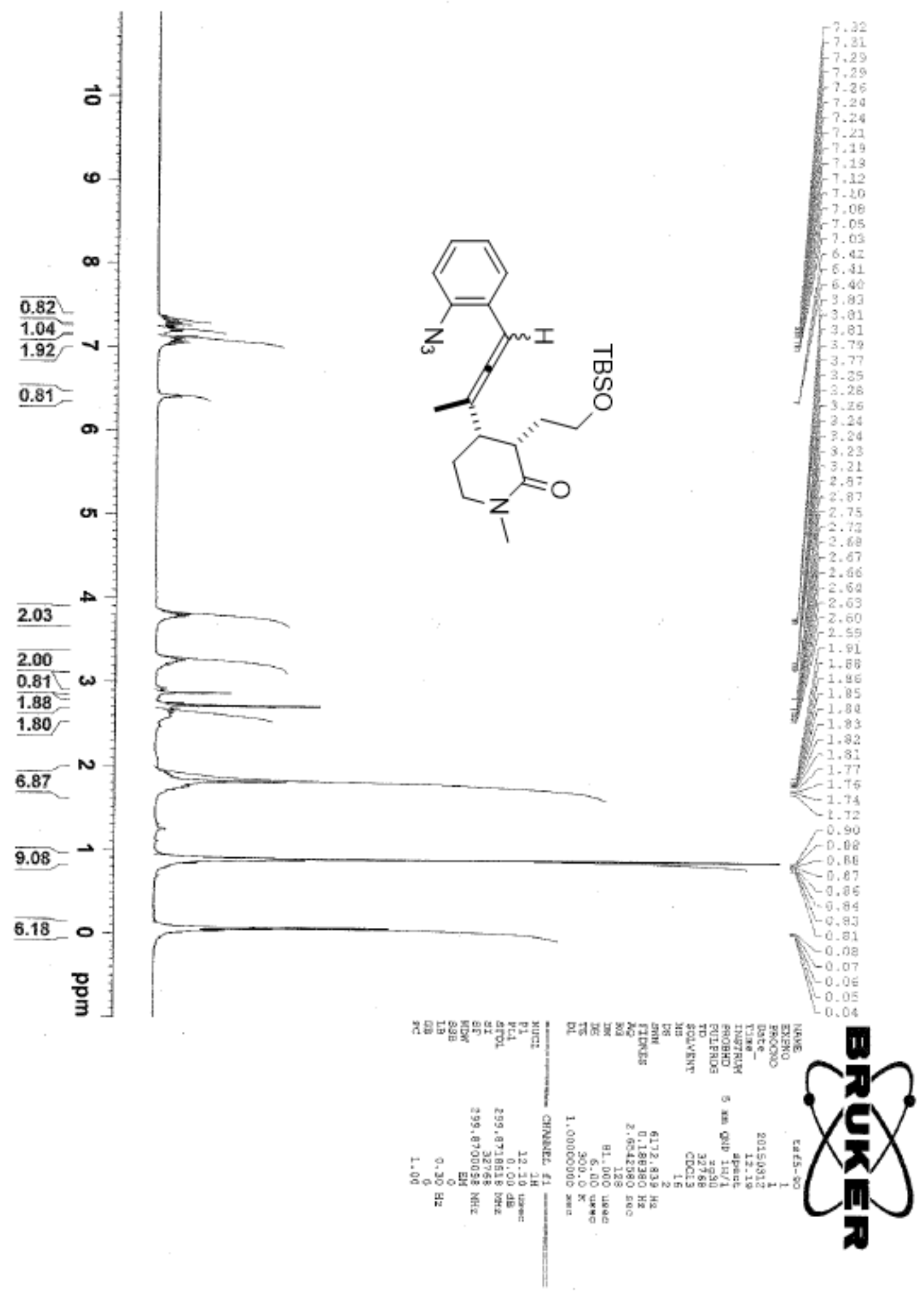


43, ${ }^{13} \mathrm{C}$ NMR

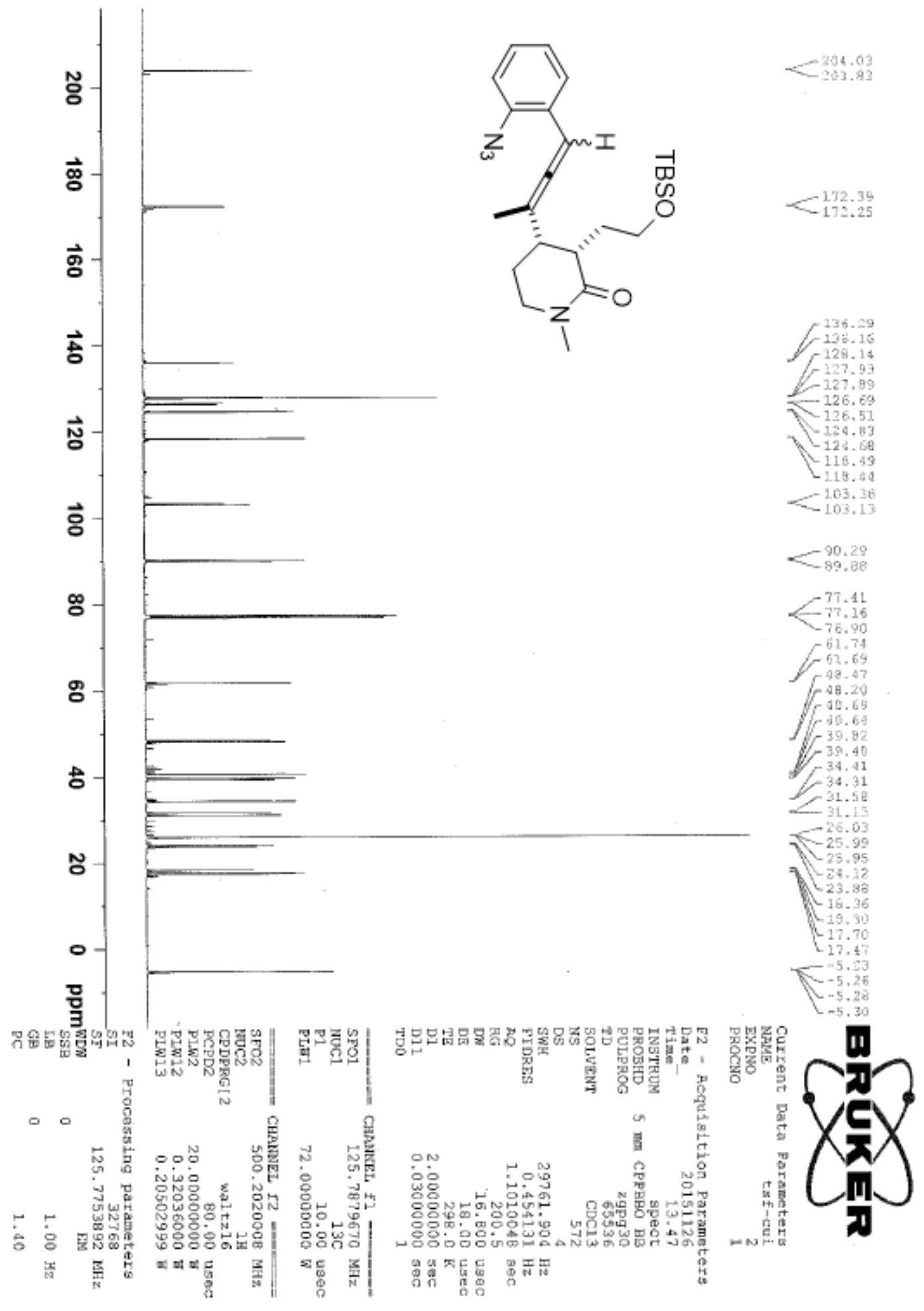


11, ${ }^{1} \mathrm{H}$ NMR

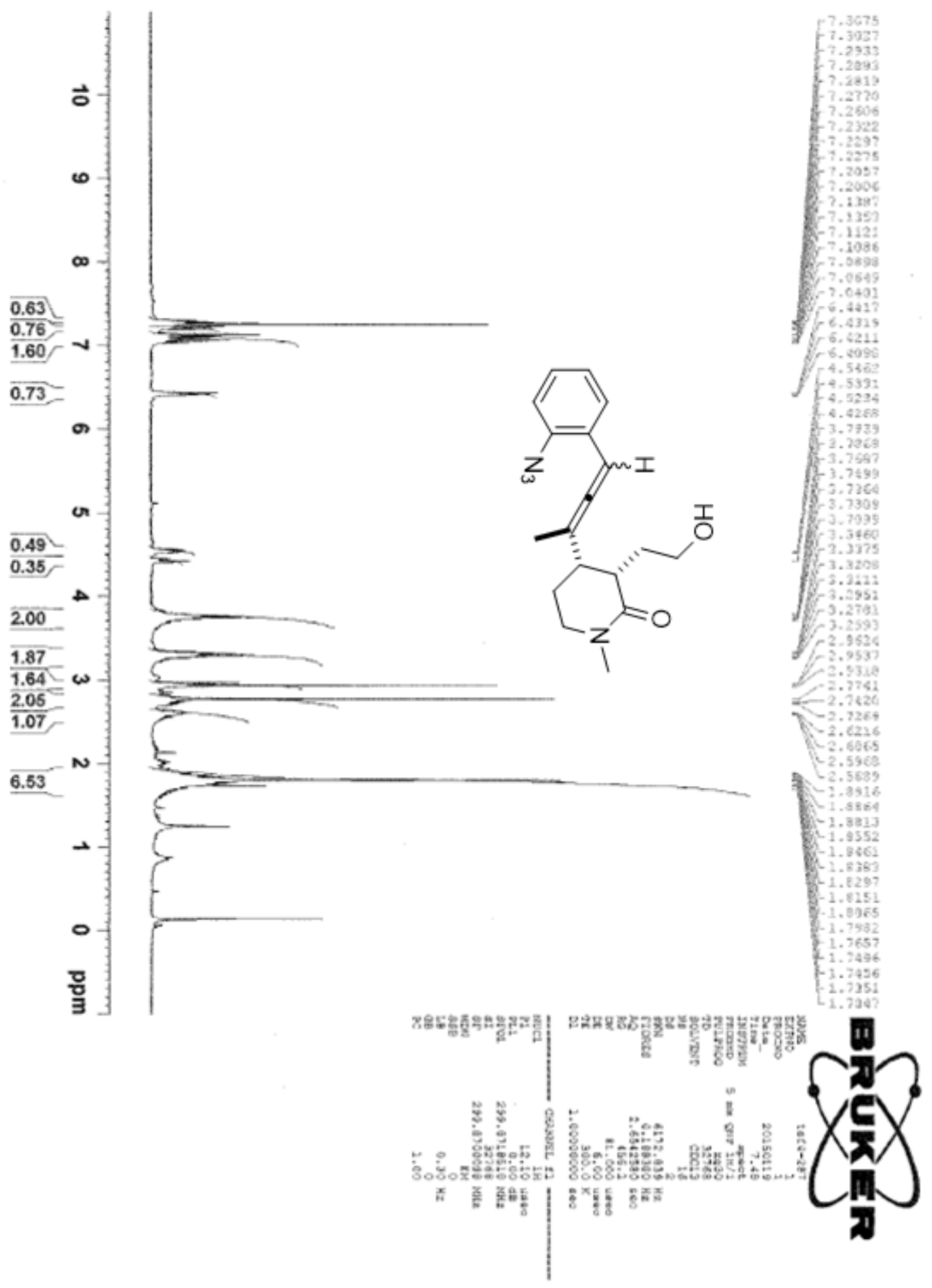


11, ${ }^{13} \mathrm{C}$ NMR

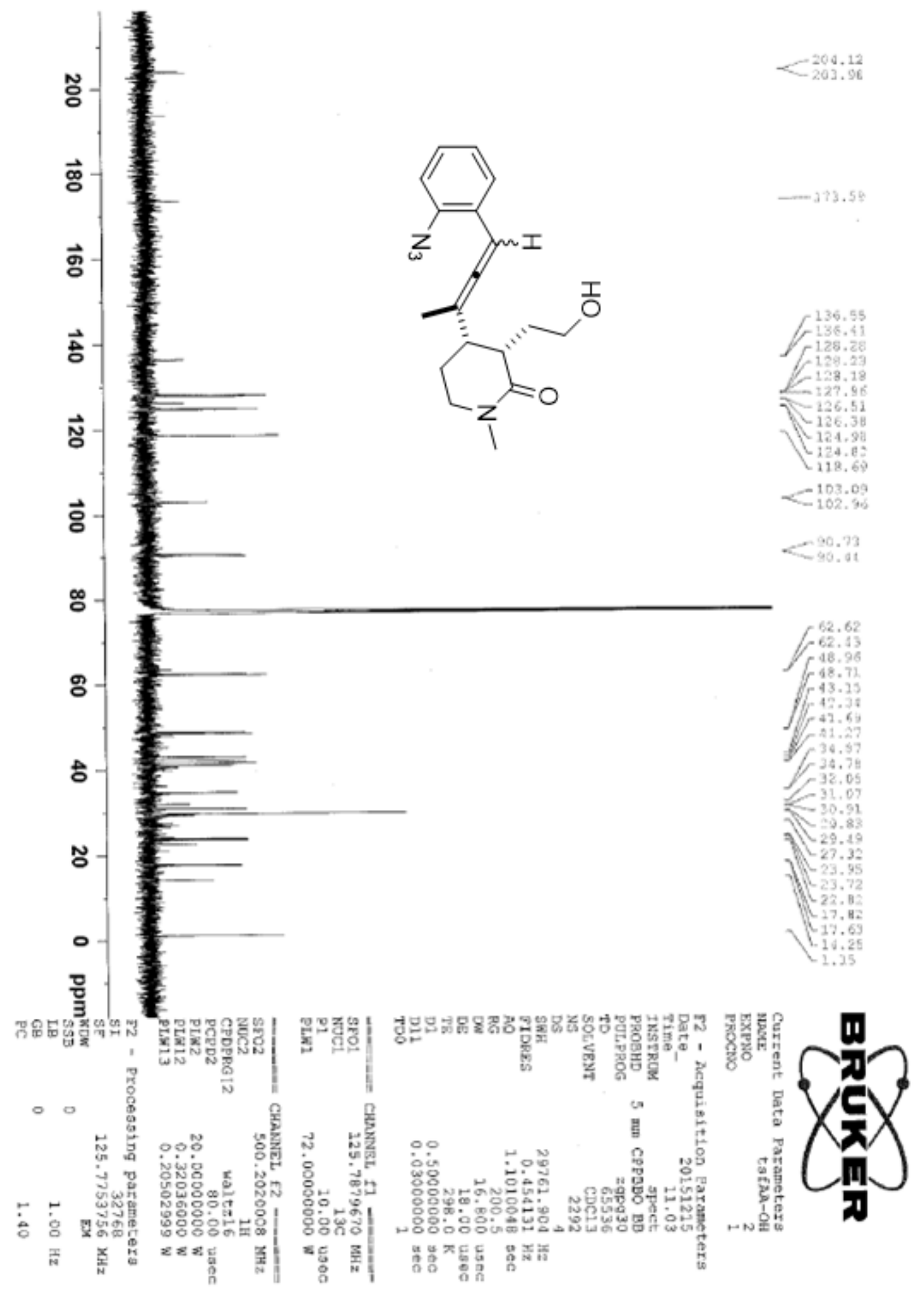


9, ${ }^{1}$ H NMR. Method B

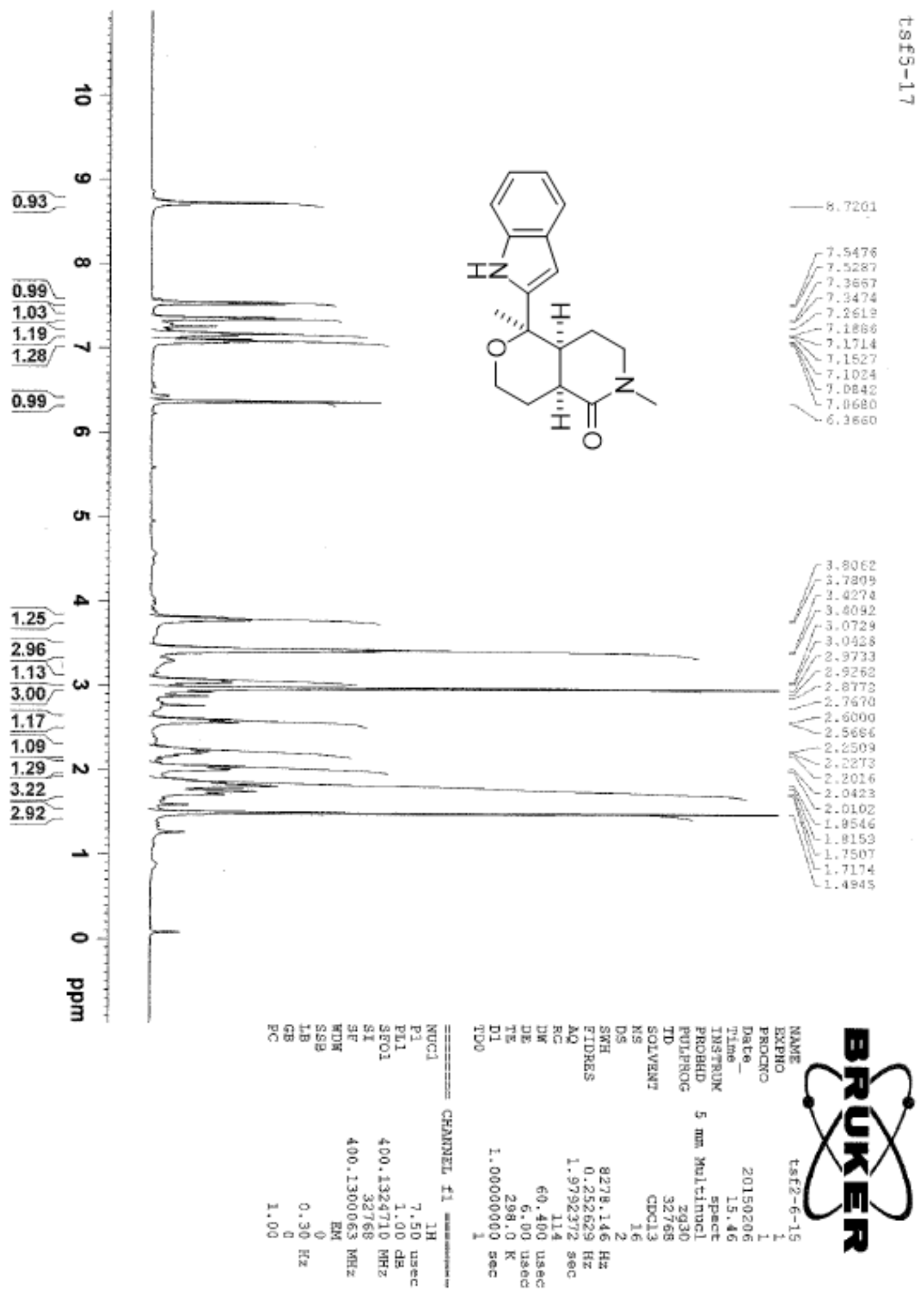


9, ${ }^{13}$ C NMR, Method B

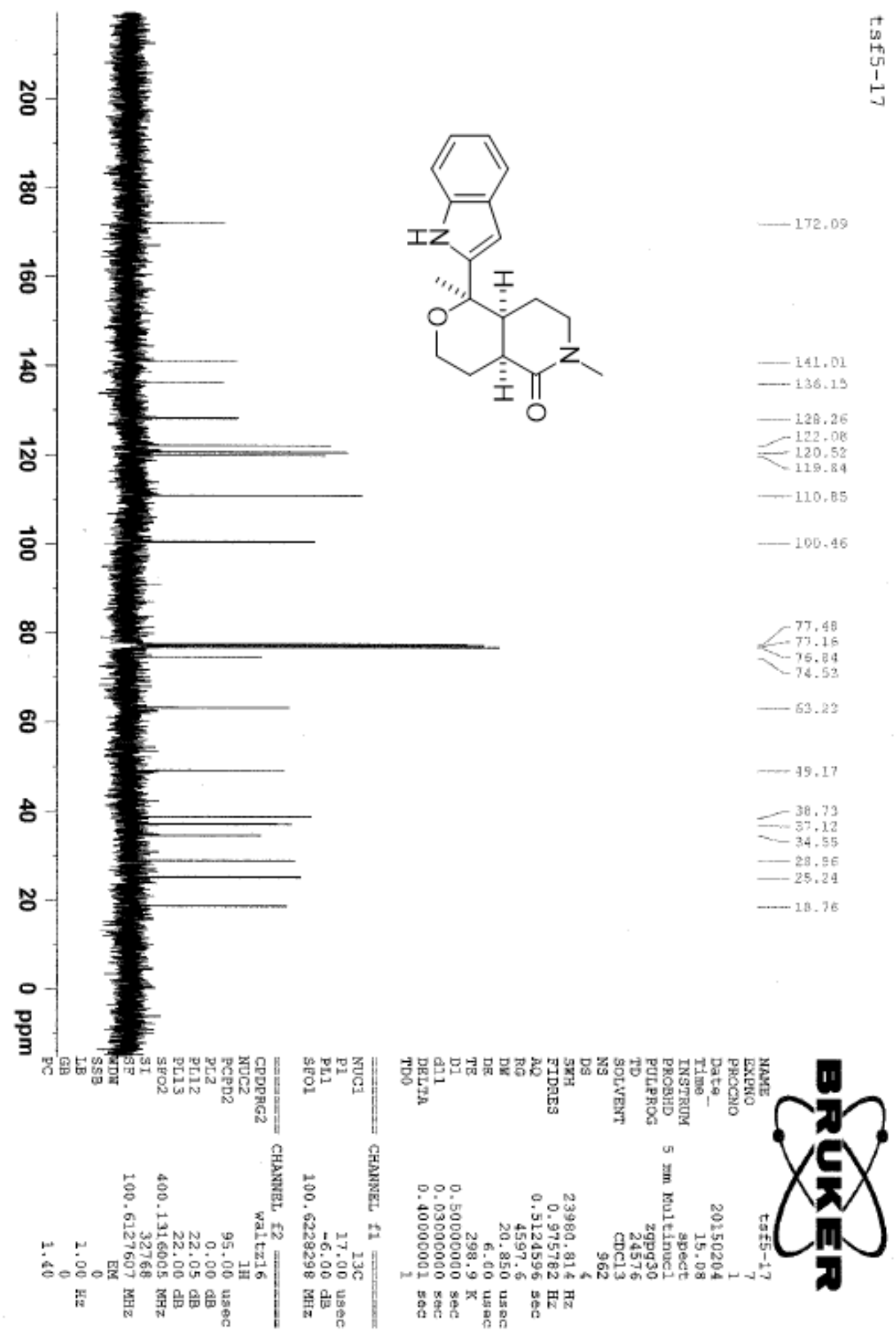


42, ${ }^{1} \mathrm{H}$ NMR

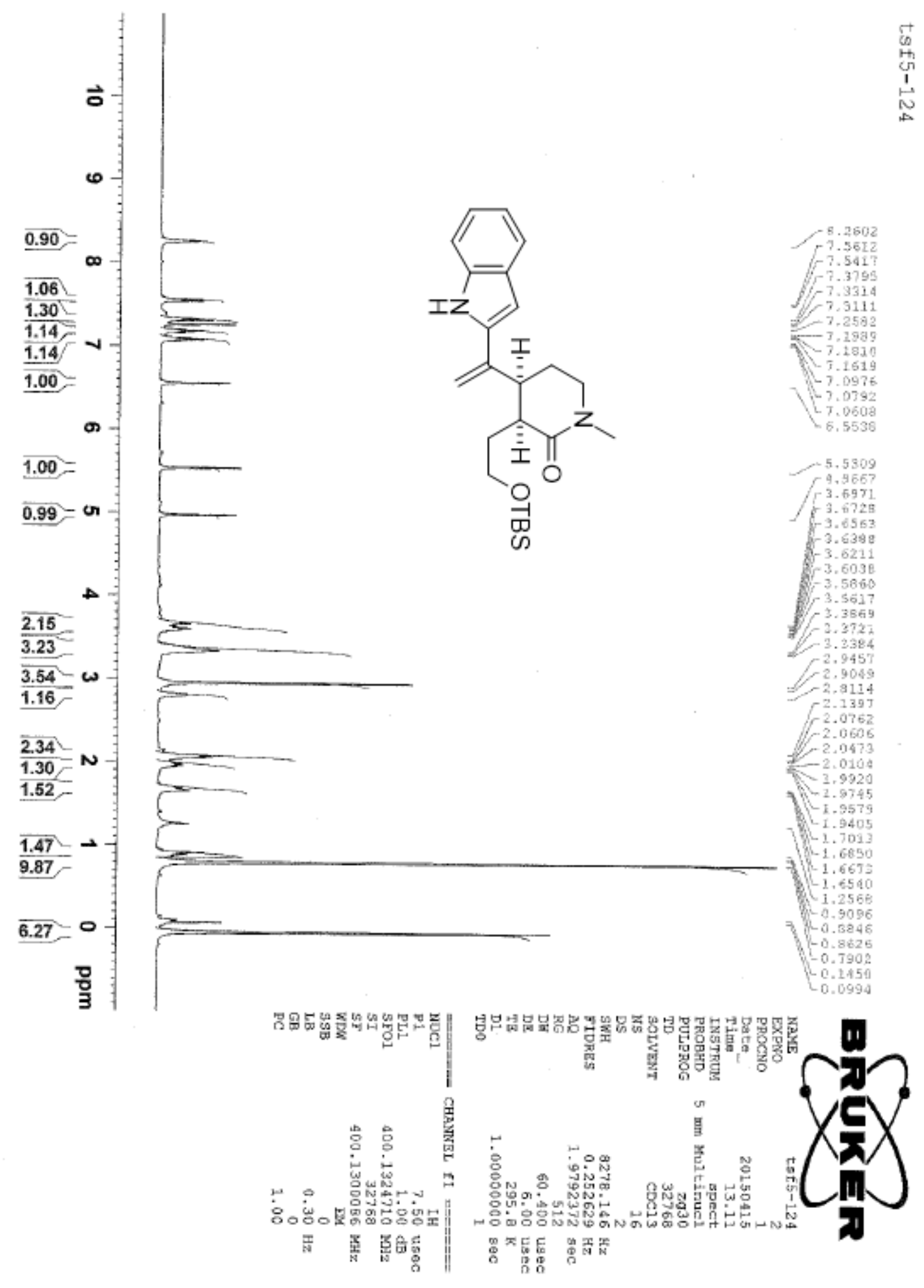


42, ${ }^{13} \mathrm{C}$ NMR

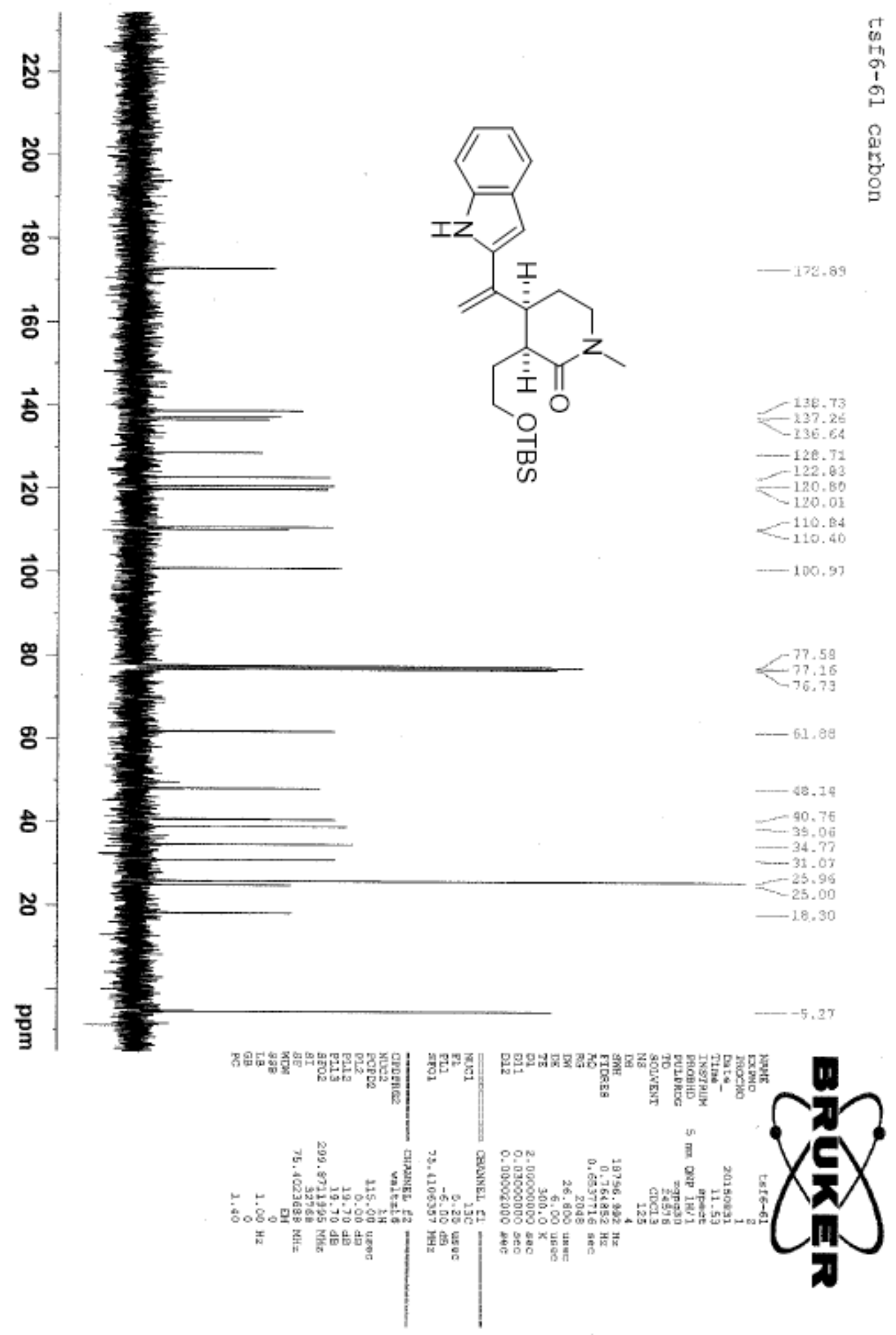


40, ${ }^{1} \mathrm{H}$ NMR

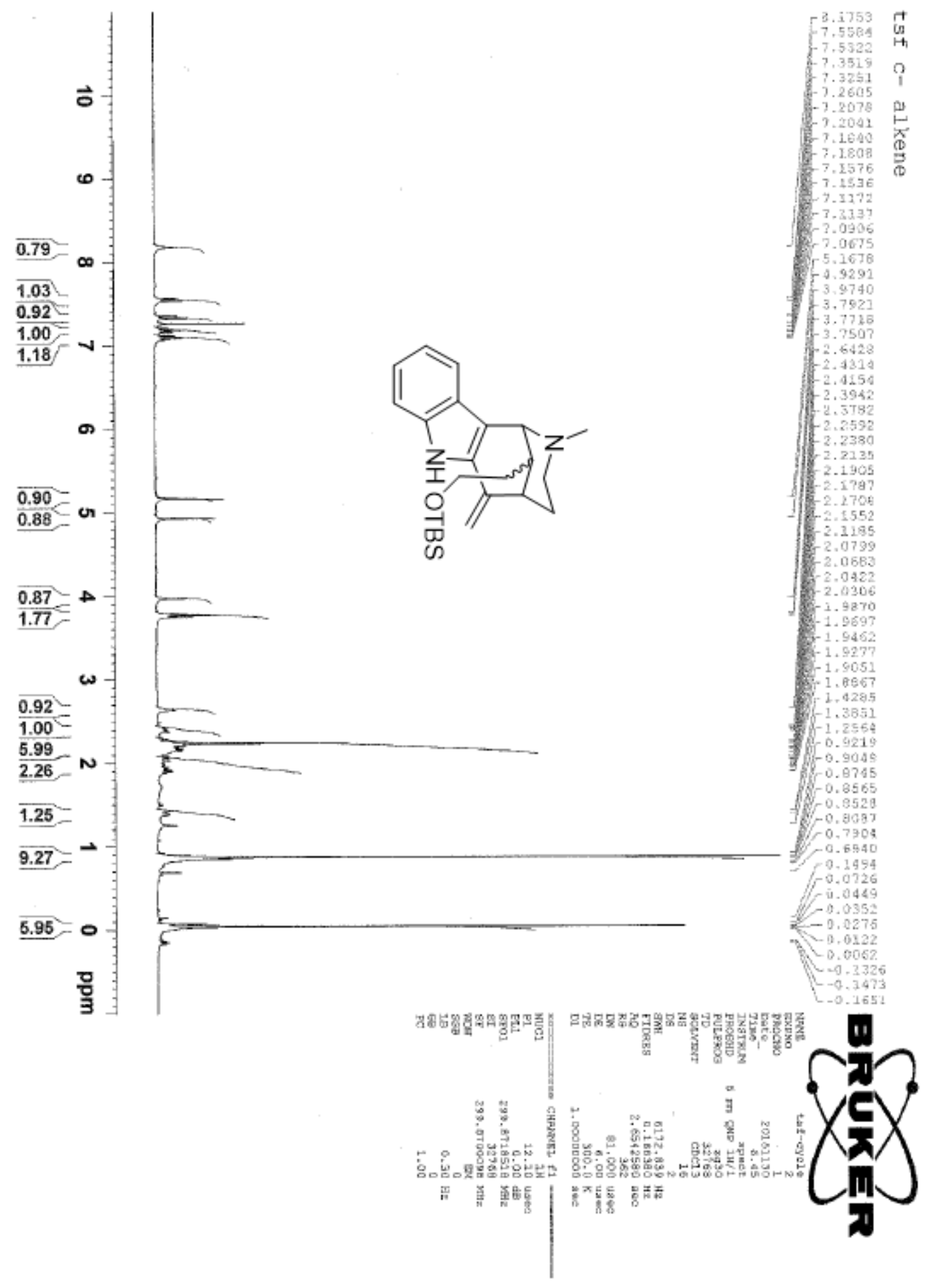


40, ${ }^{13} \mathrm{C}$ NMR

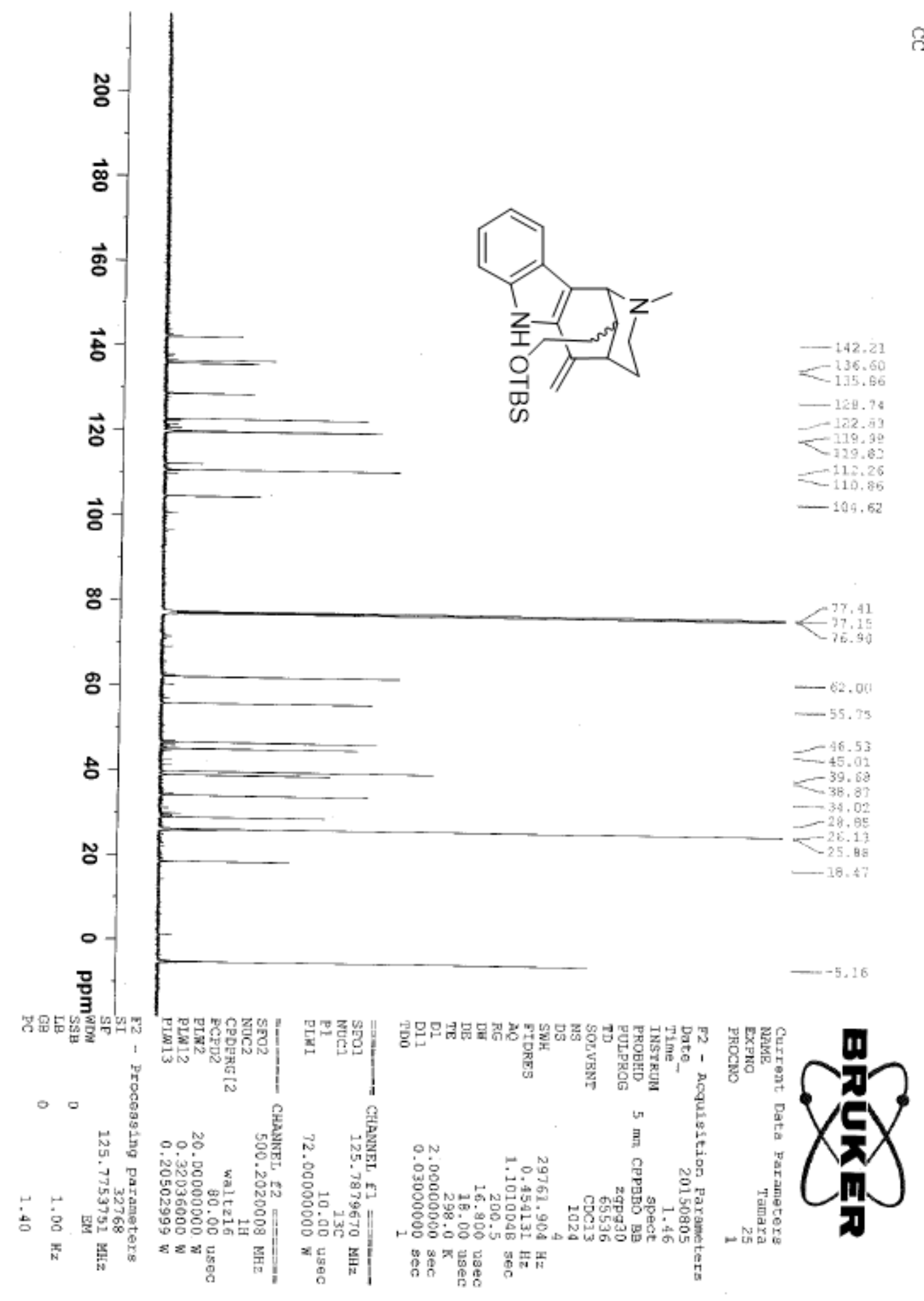


44, ${ }^{1} \mathrm{H}$ NMR

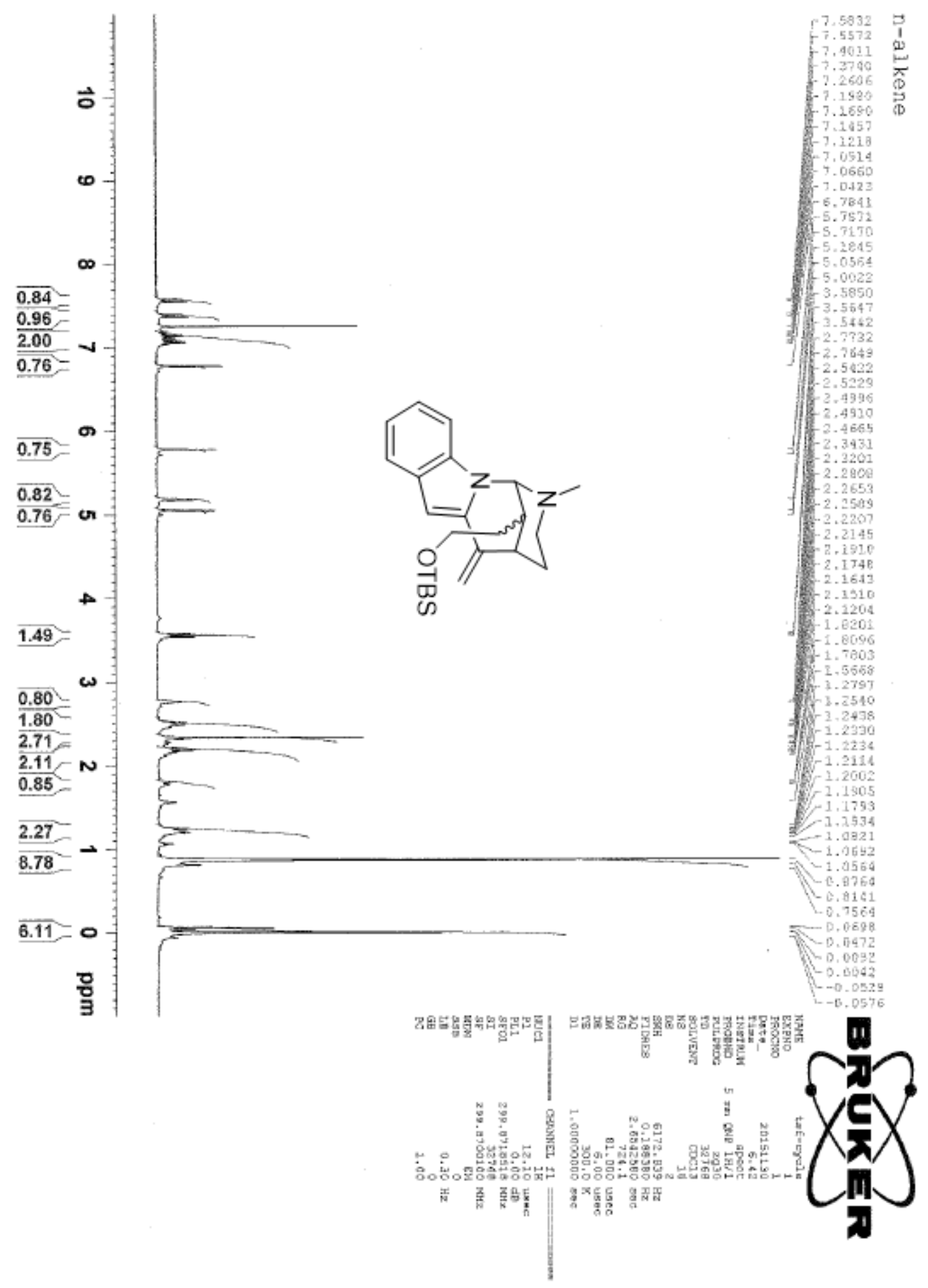


44, ${ }^{13} \mathrm{C}$ NMR

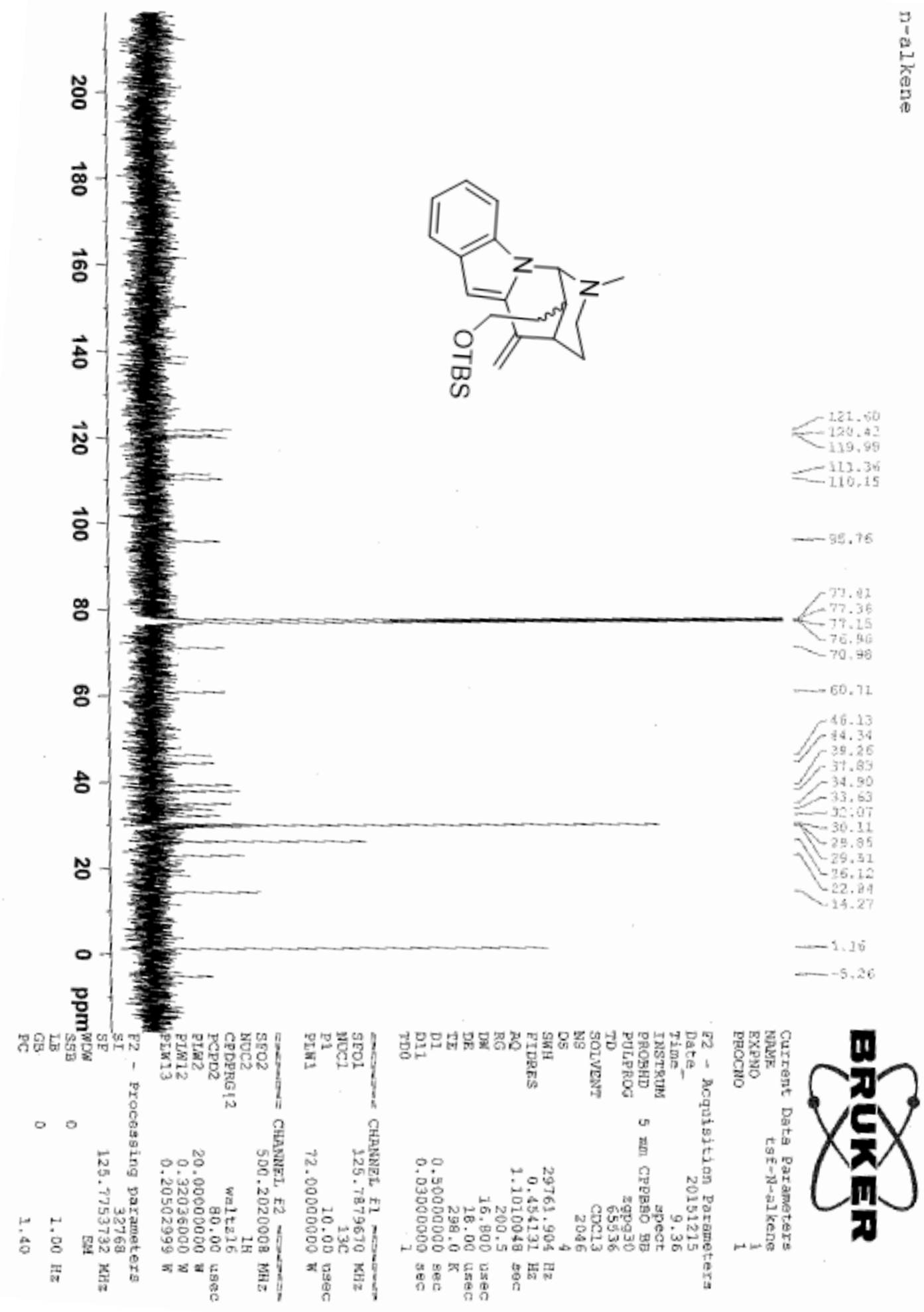


12, HMBC

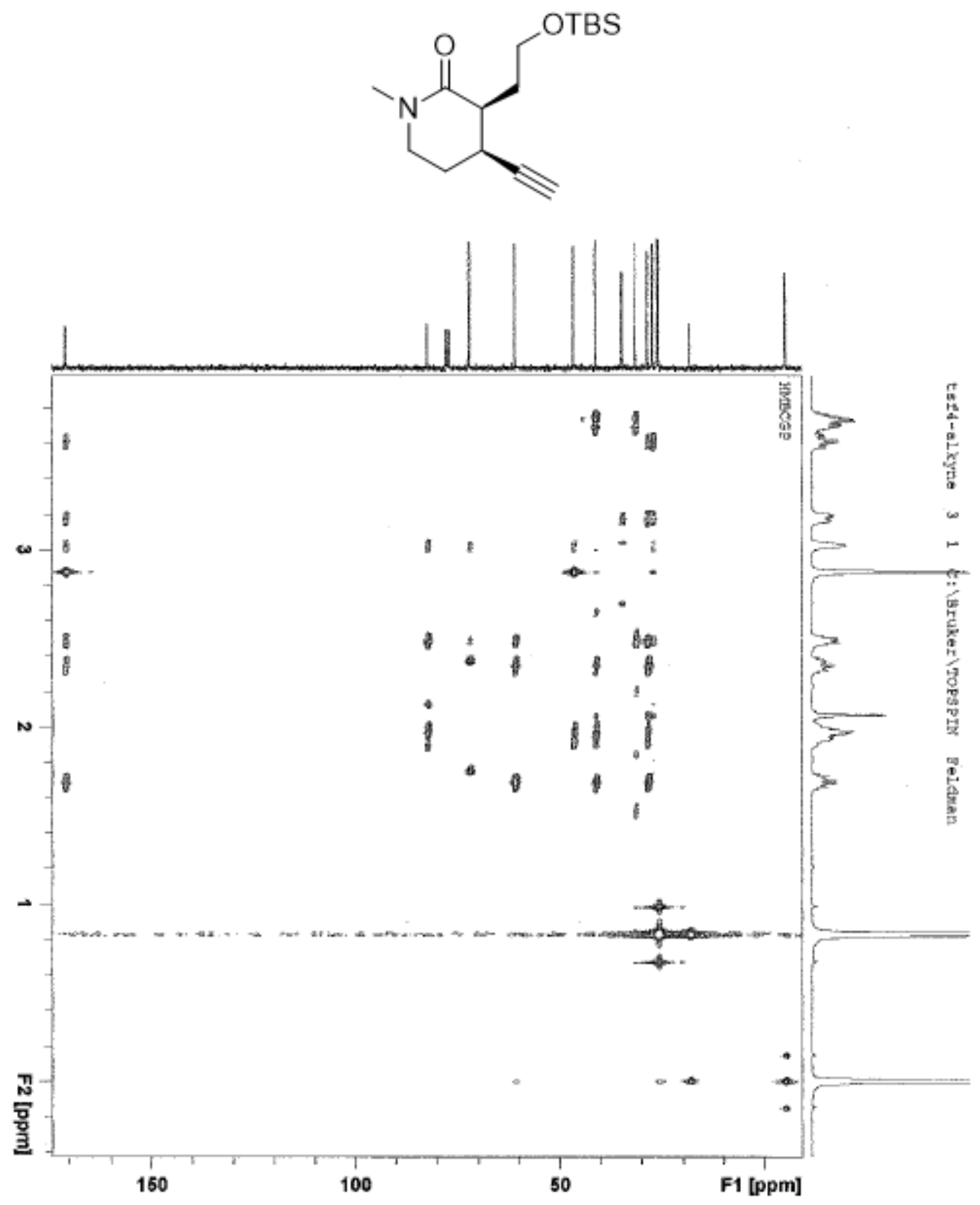


12, HSQC
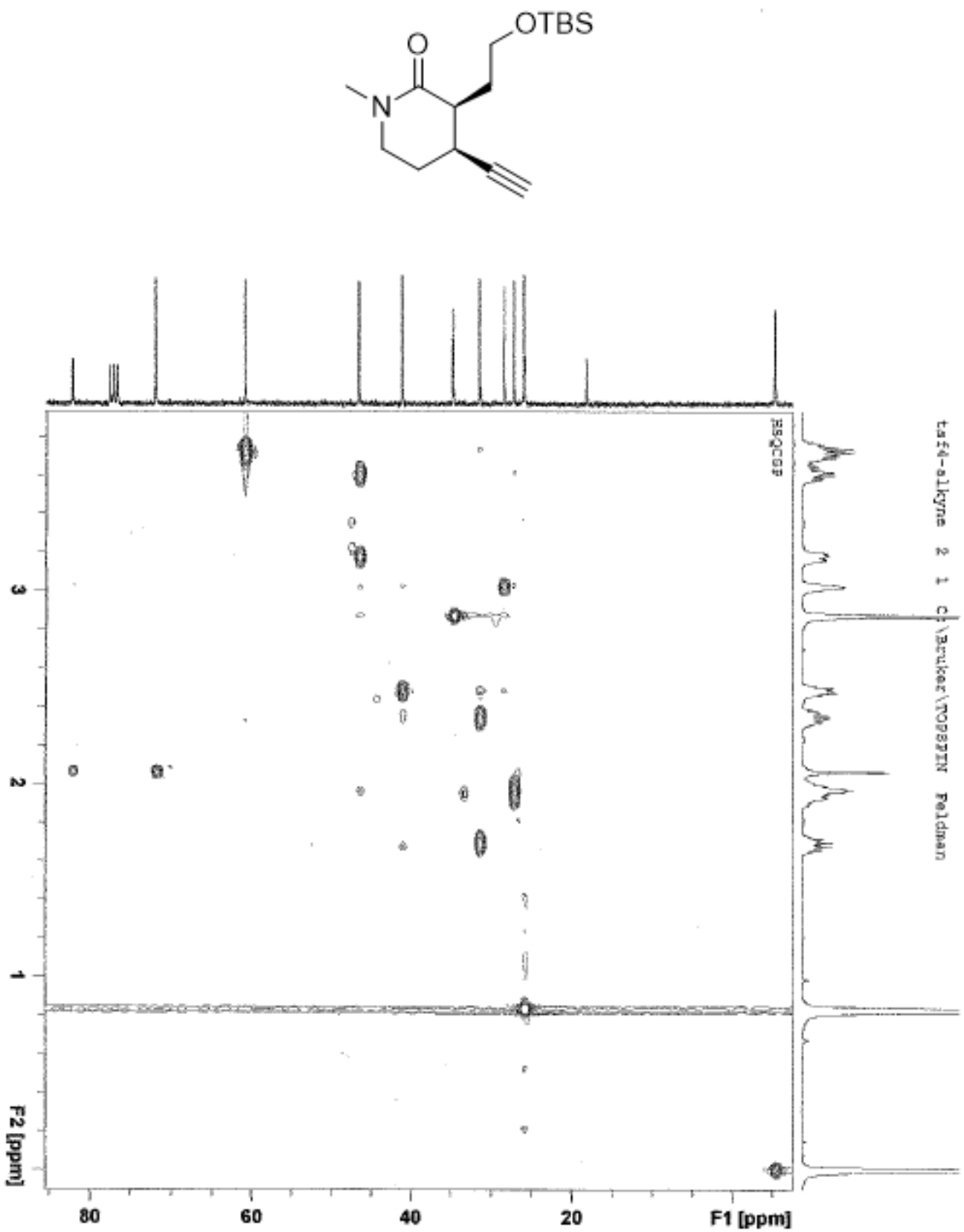
12, COSY
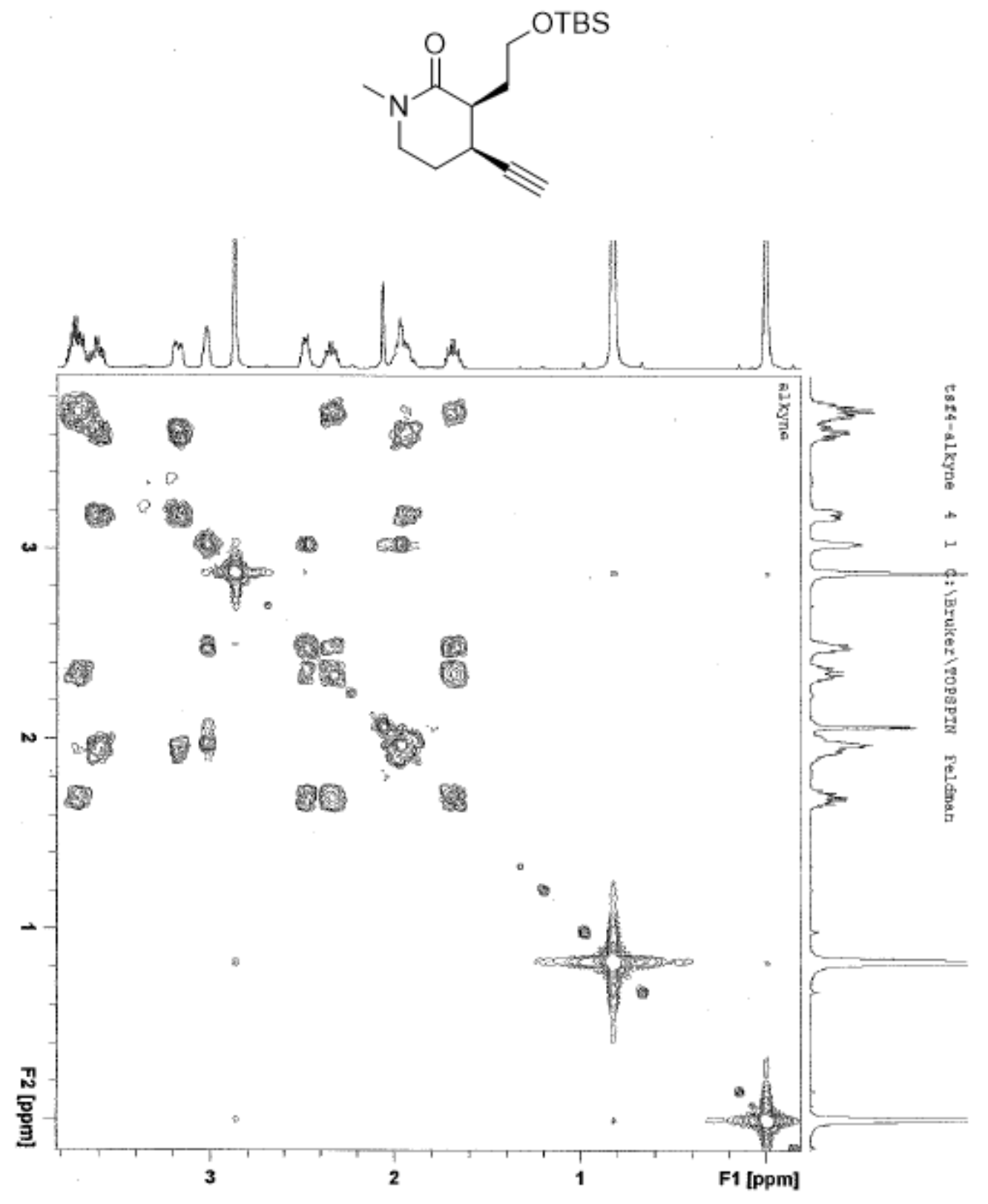
12, NOSEY
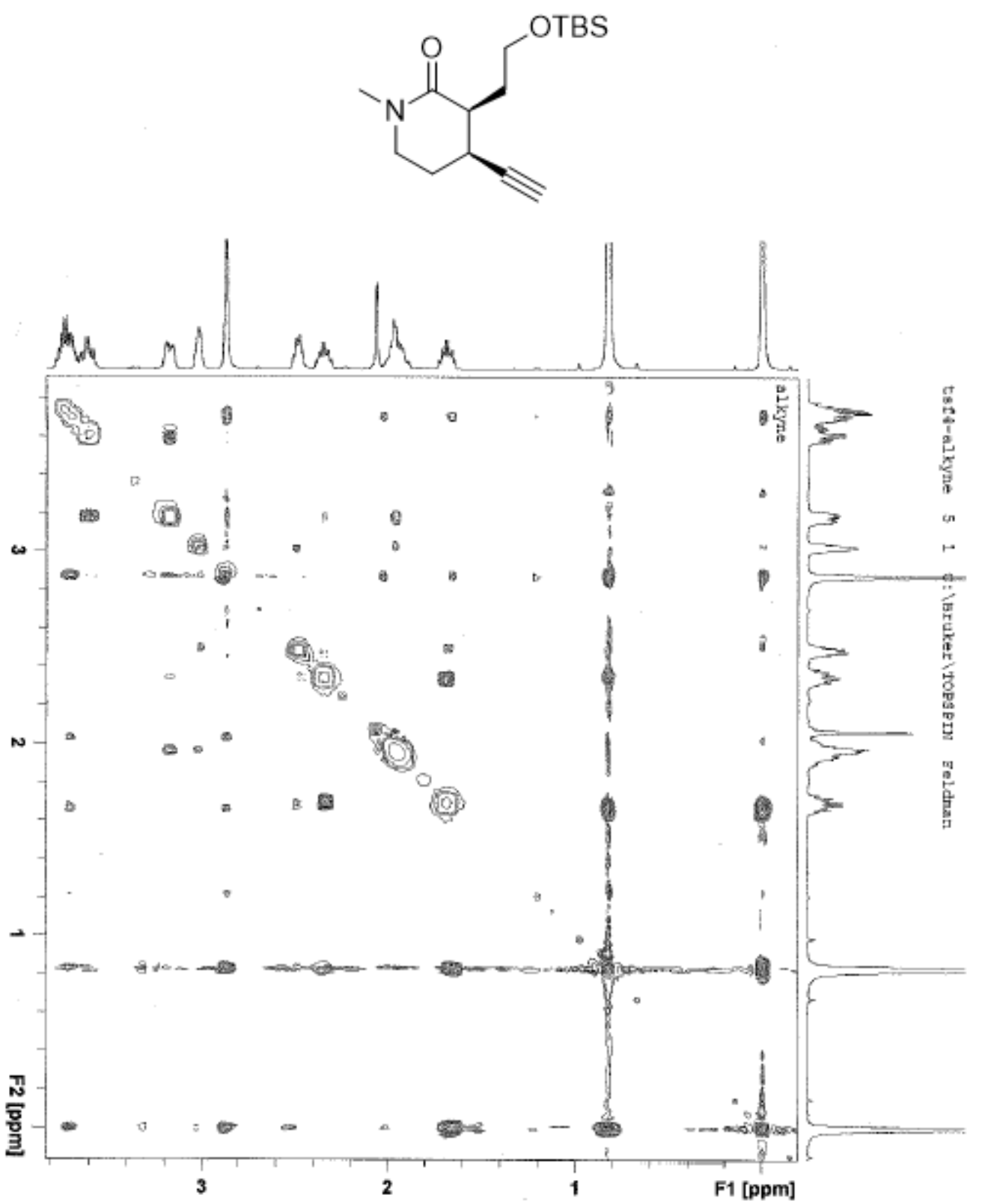
9, HMBC, Method B
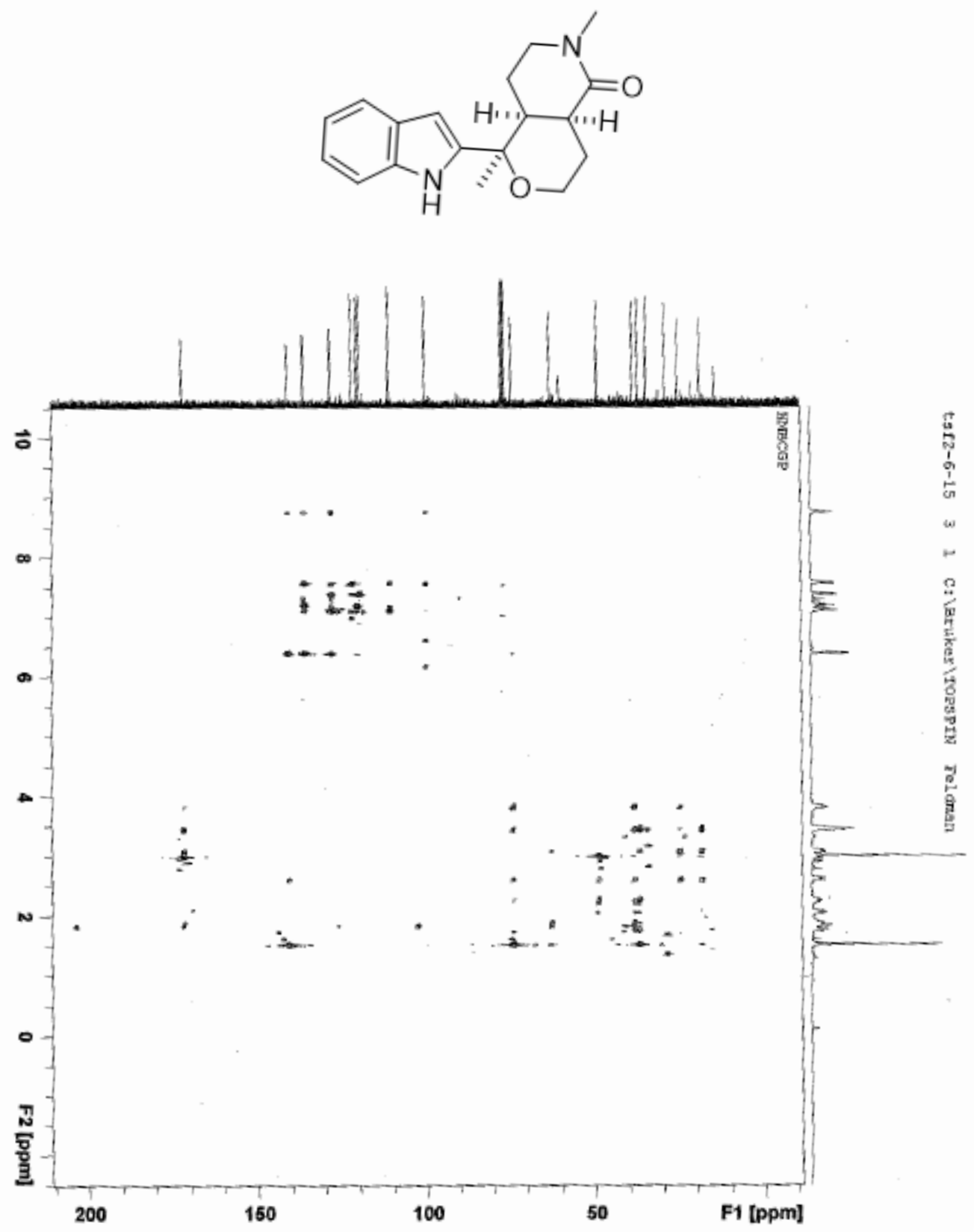
9, HSQC, Method B
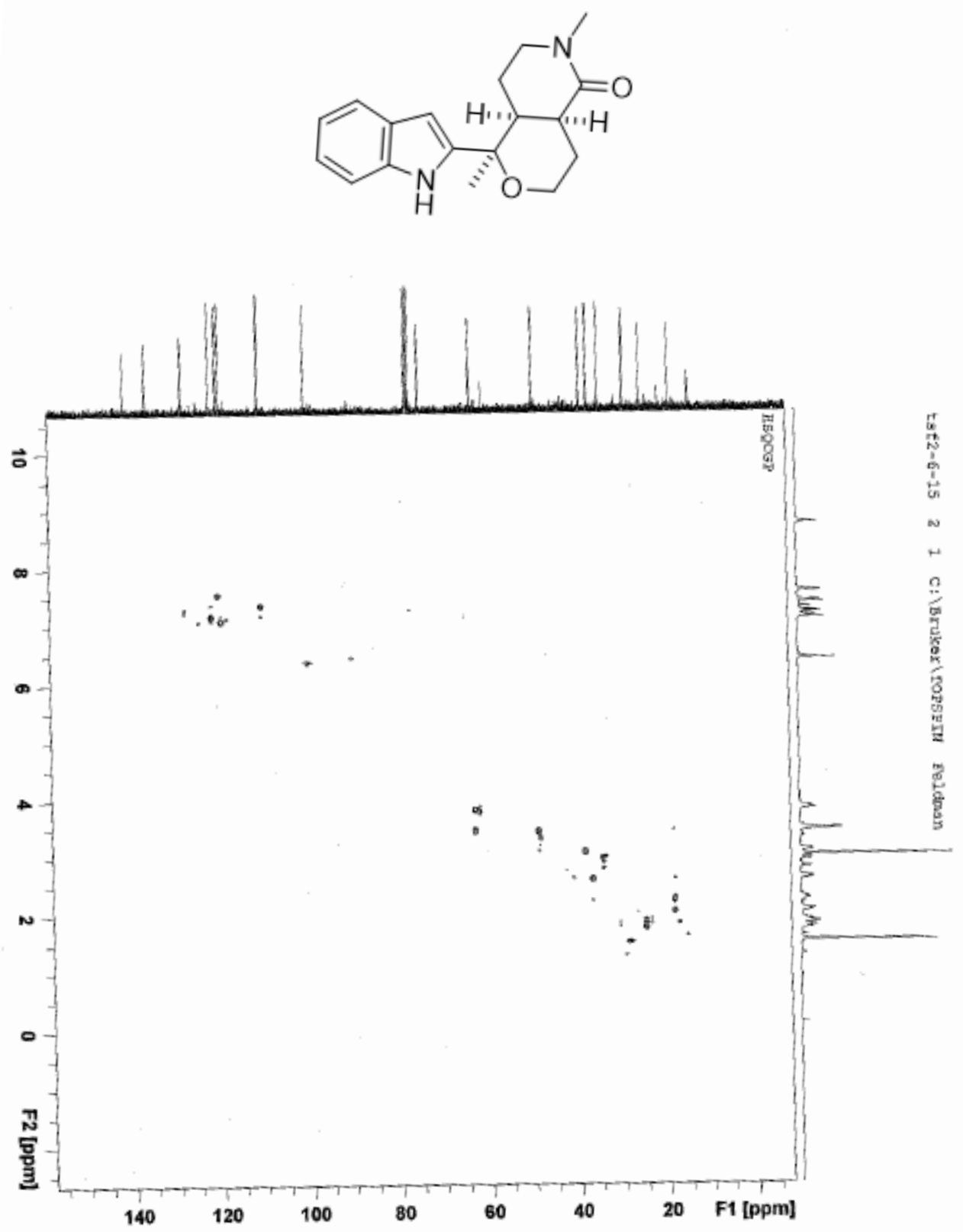
9, COSY, Method B
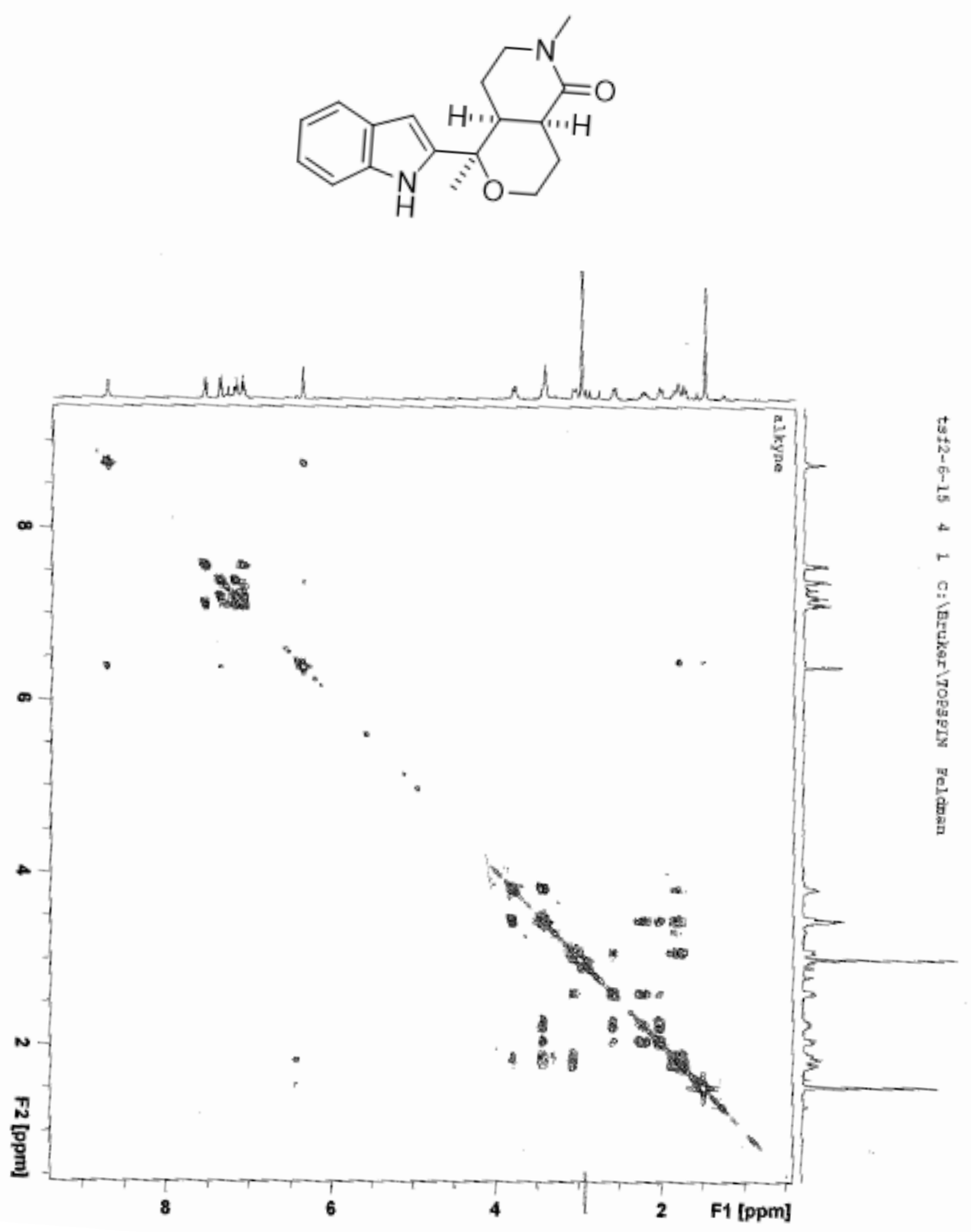
9, NOSEY, Method B

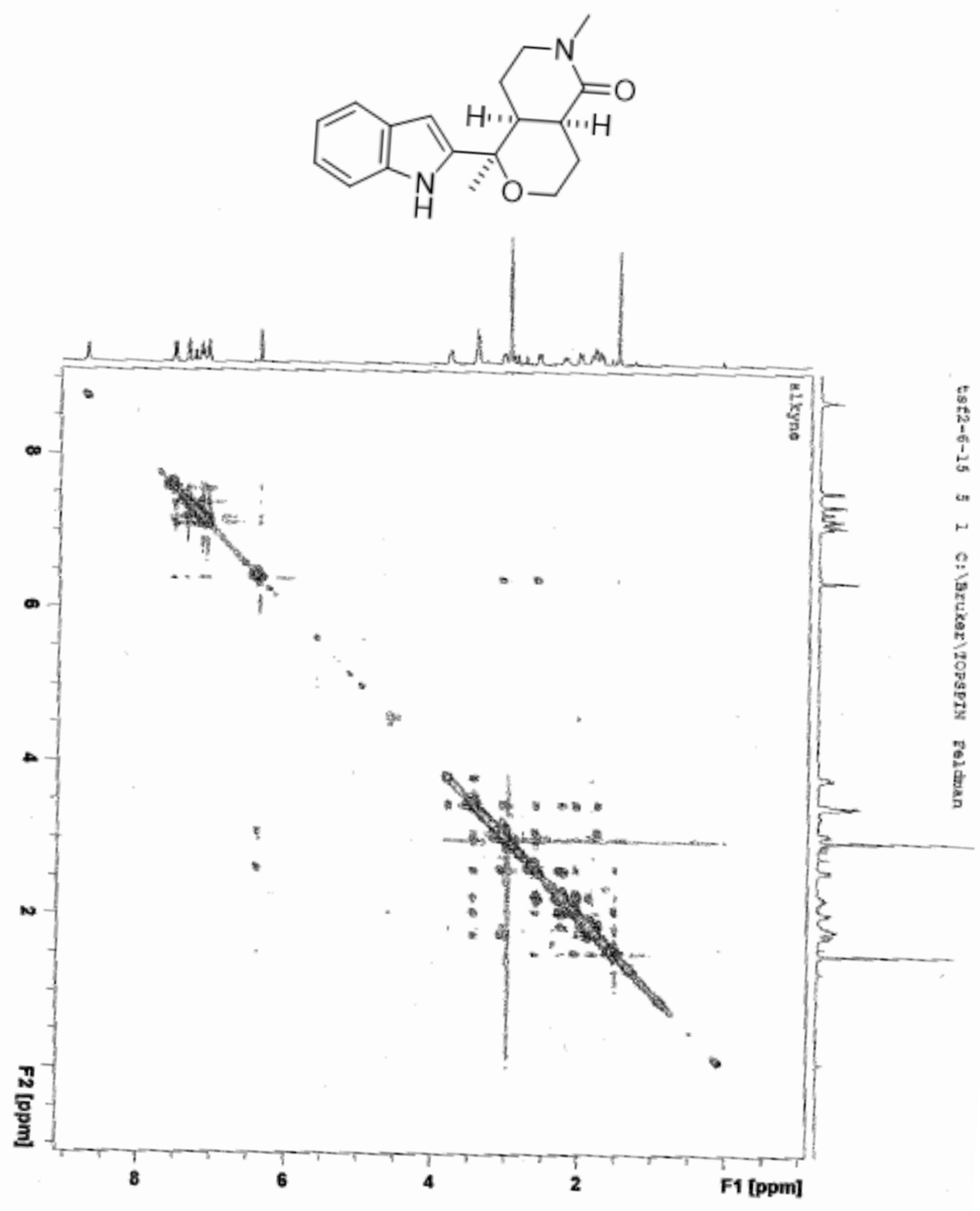

